University of Rhode Island

DigitalCommons@URI

Open Access Dissertations

2002

\title{
An Examination of Collaborative Practice in Anesthesia Care Team Settings and Occupational Sress in Nurse Anesthetists
}

Steve Louis Alves

University of Rhode Island

Follow this and additional works at: https://digitalcommons.uri.edu/oa_diss

\section{Recommended Citation}

Alves, Steve Louis, "An Examination of Collaborative Practice in Anesthesia Care Team Settings and Occupational Sress in Nurse Anesthetists" (2002). Open Access Dissertations. Paper 670. https://digitalcommons.uri.edu/oa_diss/670

This Dissertation is brought to you for free and open access by DigitalCommons@URI. It has been accepted for inclusion in Open Access Dissertations by an authorized administrator of DigitalCommons@URI. For more information, please contact digitalcommons-group@uri.edu. 


\author{
AN EXAMININATION OF COLLABORATIVE PRACTICE \\ IN ANESTHESIA CARE TEAM SETTINGS AND \\ OCCUPATIONAL STRESS IN NURSE ANESTHETISTS \\ BY \\ STEVE LOUIS ALVES
}

A DISSERTATION SUBMITTED IN PARTIAL FULFILLMENT OF THE REQUIREMENTS FOR THE DEGREE OF DOCTOR OF PHILOSOPHY IN NURSING 
DOCTOR OF PHILOSOPHY DISSERTATION

$\mathrm{OF}$

STEVE LOUIS ALVES

APPROVED:

Dissertation Committee

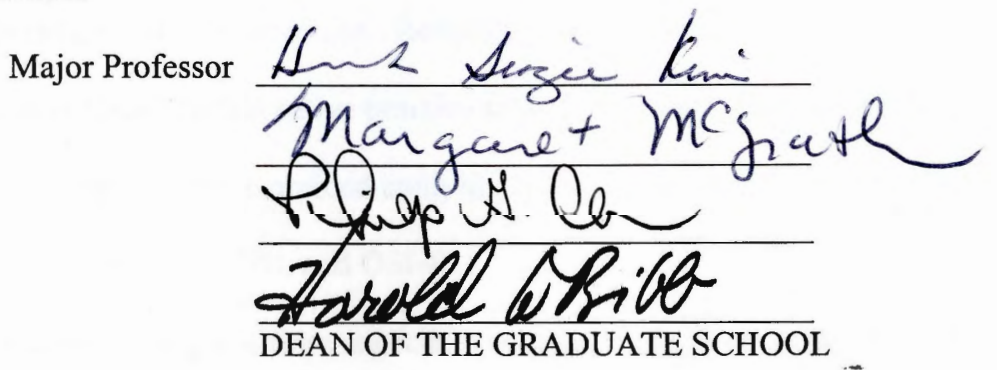

UNIVERSITY OF RHODE ISLAND

2002 


\begin{abstract}
The purpose of this study was to provide a comprehensive understanding of the nature of certified registered nurse anesthetist (CRNA) scope of practice (SOP), collaboration with anesthesiologists in anesthesia care team (ACT) settings, and occupational stress. A critical philosophy viewpoint serves as a broad perspective in understanding the depiction of domination and conflict between CRNAs and anesthesiologists in ACT environments. The theoretical basis for this study was derived from the quality of nursing practice framework, with an elaboration of the process component to examine CRNA's scope of practice, collaboration between CRNAs and anesthesiologists, and rolerelated occupational stress. A mailed survey questionnaire was mailed to all CRNAs from the six (6) New England states, with a return rate of $31 \%(n=347)$. Data analyses were conducted in terms of sample practice characteristics and demographics. Reliability testing were performed using Cronbach's alpha for the three measures (SOP, collaborative practice scale [CPS], and occupational stress inventory [OSI-R]). The research questions were examined applying correlational analysis, t-test, and ANOVA addressing relationships among SOP, CPS, and OSI-R.

Restrictions to scope of practice were especially evident with CRNAs employed by anesthesiology groups, compared to hospital employed. There were relationships between SOP and CPS; higher scores on SOP were associated with higher scores on CPS, while lower SOP scores were associated with lower scores on CPS. Most respondents indicated utilizing "compromise" as a conflict resolution mode, instead of "collaboration." This suggested that CRNAs tended to avoid the escalation of conflict by neutralizing interpersonal differences, which may result in reducing the ability of the CRNA to satisfy their own concerns regarding the patient's care. Finally, respondents with higher levels of SOP reported higher stress in role overload and responsibility. However, respondents with lower SOP reported higher stress in role insufficiency and role ambiguity. These findings suggested that a broader SOP was related to increased responsibilities, independence, and active engagement in complex patient care. CRNAs in this context may be viewed as emotionally and professionally more self-assured, allowing more intrinsic power to practice autonomously. Implications for further research include exploring "best practice" ACT models, understanding productivity and anesthesia provider mix structures, and improving overall anesthesia care team services.
\end{abstract}




\section{ACKNOWLEDGEMENTS}

The support and encouragement of many people contributed to the completion of this research endeavor. With deep appreciation I acknowledge the support and mentoring of my doctoral committee chair and dissertation advisor, Dr. Hesook (Suzie) Kim, for providing the fundamental knowledge and skills to effectively execute this dissertation project. Dr. Kim's theoretical perspective was the overriding schema for this study. The opportunity to collaborate with such an outstanding nursing scholar has shaped and will influence my theoretical thinking as I approach the future expansion of a program of research. In addition, I acknowledge the confidence of the other members of my dissertation committee-Dr. McGrath, Dr. Clark, Dr. Burbank, and Dr. Beauvais. I thank all of you for your individual support and guidance throughout the past few years.

I would also like to extend my appreciation to the CRNAs who participated in the study.

These CRNAs took their valuable time to promptly complete and return the rather lengthy instruments, individually making a contribution to understanding nurse anesthesia practice. A special thanks to the American Association of Nurse Anesthetists Foundation (AANA-F), for their financial support which was crucial in completing the study. In receiving the AANA-F 2001 "Research Scholar" award for my dissertation work, I learned first hand the Foundation's continued support for the expansion of nurse anesthesia research and knowledge development.

I owe a special recognition to my closest friend and colleague, Stephen Yermal from Chicago. Soon to be Dr. Yermal and I have spent the last six years devoted to completing our doctoral course work and ultimately, the dissertation. Along this journey Steve was always there to either listen to my ideas on the telephone, and/or have a healthy discourse in terms of "making sense" of philosophy of science arguments and linking theory to the research questions, and of course the notion of "epistemic chaos." Although we surely have racked-up some mighty long-distance telephone bills, it truly was worth the investment! I also owe a special tribute to the faculty and students at Northeastern University School of Nursing for their enthusiasm and mentoring during my first year there as the nurse anesthesia program coordinator, and throughout the writing of this document. 
Words cannot express the appreciation I feel for the special people in my life that have continued to support and assist me throughout this process. My friends Debbie and Susan, Kathy, Everton and Pete, and Claire and Workia were always there to lift me up when I was feeling indifferent about my progress and wanted to throw in the towel. My brother Tony and his family shared and suffered with me in the great loss of our dearly beloved parents, Tony and Adeline, for whom I dedicate this dissertation. Finally, but certainly not last, was the never ending support and continual encouragement of my partner Gerry, for without your unconditional assurances throughout this process, it would have been more difficult for me to succeed. 
TABLE OF CONTENTS

ACKNOWLEDGEMENTS

LIST OF TABLES

viii

LIST OF FIGURES

xi

CHAPTER

Page

I. INTRODUCTION

Statement of Problem

Research Questions 3

II. BACKGROUND AND THEORETICAL FRAMEWORK 5

Role of the Certified Registered Nurse Anesthetist (CRNA) 5

$\begin{array}{ll}\text { Philosophical and Theoretical Basis for Nursing Practice } & 7\end{array}$

$\begin{array}{ll}\text { Critical Philosophy Perspective for Nurse Anesthesia Practice } & 7\end{array}$

$\begin{array}{ll}\text { Framework for Quality Nursing Practice } & 12\end{array}$

Quality Framework for Anesthesia Care Team (ACT) Practice 19

Collaboration and Occupational Stress in ACT Practice 19

$\begin{array}{ll}\text { Collaborative Practice } & 24\end{array}$

$\begin{array}{ll}\text { Occupational Stress } & 27\end{array}$

Influence of Organizational Behavior $\quad 27$

$\begin{array}{ll}\text { Stress in Nurse Anesthesia Practice } & 28\end{array}$

$\begin{array}{ll}\text { Summary } & 32\end{array}$

$\begin{array}{ll}\text { III. METHODOLOGY } & 34\end{array}$

$\begin{array}{ll}\text { Research Design } & 34\end{array}$

Sample and Sampling $\quad 35$

$\begin{array}{ll}\text { Instrumentation } & 37\end{array}$

Individual CRNA Scope of Practice (SOP) 37

$\begin{array}{ll}\text { Collaborative Practice Scale (CPS) } & 38\end{array}$ 
Protection of Human Subjects

Data Collection

Method of Data Analysis

IV. RESULTS

Sample Characteristics

Findings Related to the Measures in the Study

Scope of Practice (SOP)

Overview of Results

Reliability of SOP Instrument

Collaborative Practice Scale (CPS)

Overview of Results

Reliability of CPS

Occupational Stress Inventory-Revised (OSI-R)

Overview of Results

Reliability of the OSI-R

Findings Related to the Research Questions

Research Question \#1: Characteristics of ACT and Scope of Practice

Research Question \#2: CRNAs Perceptions of Collaboration

Research Question \#3: Relationship Between Scope of Practice and Collaboration

Research Question \#4: Relationship Among Scope of Practice, Collaboration, and Occupational Stress

Relationship Between Collaboration and Occupational Stress

Relationship Among Collaboration and Occupational Stress

According to Different Levels of Scope of Practice 
V. CONCLUSIONS, IMPLICATIONS, AND RECOMMENDATIONS $\begin{array}{ll}\text { Introduction } & 106\end{array}$

$\begin{array}{ll}\text { Summary of Findings and Conclusions } & 107\end{array}$

$\begin{array}{ll}\text { Limitations } & 111\end{array}$

$\begin{array}{ll}\text { Implications and Recommendations } & 111\end{array}$

$\begin{array}{lll}\text { APPENDIX A CRNA Demographics Tool } & 116\end{array}$

$\begin{array}{llr}\text { APPENDIX B } & \text { CRNA Scope of Practice Tool (SOP) } & 118\end{array}$

$\begin{array}{lll}\text { APPENDIX C CRNA Collaborative Practice Scale (CPS) } & 120\end{array}$

$\begin{array}{lll}\text { APPENDIX D } & \text { Permission to Modify CPS } & 122\end{array}$

APPENDIX E Occupational Stress Inventory-Revised (OSI-R) Sample Questions $\quad 123$

$\begin{array}{lll}\text { APPENDIX F } & \text { IRB Approval from University of Rhode Island } & 124\end{array}$

$\begin{array}{lll}\text { APPENDIX G Explanatory Letter/Consent } & 125\end{array}$

$\begin{array}{lll}\text { APPENDIX H } & \text { Reminder Post Card } & 126\end{array}$

$\begin{array}{lll}\text { APPENDIX I } \quad \text { SOP Item Intercorrelational Matrix } & -\end{array}$

$\begin{array}{lll}\text { APPENDIX J } & \text { CPS Item Intercorrelational Matrix } & 131\end{array}$

BIBLIOGRAPHY 132 


\section{LIST OF TABLES}

TABLE

$\underline{\text { Page }}$

1.

Respondents' New England State of Primary Practice

2.

Employment Status, Arrangement, Setting and Bed Size

50

3.

Availability of Anesthesia Specialty Services in Primary

Practice Setting

4.

Respondents Age, Gender, and Highest Academic Credential.

5.

Number of Years as an RN and as a CRNA

6.

Anesthesia Care Team as Primary Practice

7. Number of CRNAs and Anesthesiologists in Primary

Practice Setting

8.

Medical Direction in Primary Practice Setting

9.

Means and Standard Deviations for Scope of Practice

(Questions 1-24)

10. Means and Standard Deviations for Scope of Practice

(Questions 25-41)

11. Scope of Practice Total Scale Range, Means, and

Standard Deviations

12. Collaborative Practice Scale (CPS) Item Means and Standard

Deviations (Assertiveness: Questions 1-9)

13. Collaborative Practice Scale (CPS) Item Means and Standard

Deviations (Cooperativeness: Questions 10-19)

14.

CPS Frequency Distribution (Assertiveness: Questions 1-9)

15.

CPS Frequency Distribution (Cooperativeness: Questions 10-19

16.

Alpha Coefficients for CPS, Compared to Reported Reliability

18.

Distribution of Sample for OSI

19. Means, Standard Deviations, T-test Comparing OSI with ACT and Non-ACT

20.

OSI Scale Inter-correlations 
23. Means, Standard Deviations, and T-test Comparing Specialty Services and Scope of Practice (SOP)

Tukey HSD Multiple Comparison for SOP and Specialty Services

Tukey HSD Multiple Comparison for

SOP and Sub-scales of OSI-ORQ

(Role Overload and Responsibility) 
Means, Standard Deviations, and T-test Comparing Employment Arrangement with CPS-Total, OSI-Total

45.

Means, Standard Deviations, and T-test Comparing

Gender with CPS-Total, OSI-Total

46.

Means, Standard Deviations, and T-test Comparing Age with CPS-Total, OSI-Total

47.

Means, Standard Deviations, and T-test Comparing Educational Levels with CPS-Total, OSI-Total 


\section{LIST OF FIGURES}

\section{FIGURE}

$\underline{\text { Page }}$

1.

Philosophies of Therapy and Care

2. Quality of Nursing Practice Framework

3. Collaborative Practice in Anesthesia Care Teams

4. Collaborative Practice in Anesthesia Care Teams: An Elaboration of the Process Component

5.

Initial Model for the Conceptualization of the Research Questions

6.

A Revised Model of the Relationships Among

Scope of Practice, Collaboration, and Occupational Stress 


\section{CHAPTER I}

\section{INTRODUCTION}

Anesthesia services in the United States is provided by physicians or nurses with advanced education in the specialty of anesthesiology. Anesthesia care is provided in three distinct manners: fee for services by physicians, fee for services by Certified Registered Nurse Anesthetists (CRNAs), and anesthesia care team (ACT), which is currently the dominant mode of practice in most acute care hospitals. The ACT involves both CRNAs and anesthesiologists providing services together. In ACT settings,. CRNAs are in constant attendance with the patient and perform the majority of anesthetic procedures, while anesthesiologists concurrently supervise the progress of two to four cases and are personally involved at key stages, such as anesthesia induction and emergence from anesthesia.

Seventy-three percent of CRNAs practice in ACT settings. Despite the prevalence of ACTs, there are wide variations in the division of labor, the roles and responsibilities of anesthesiologists and CRNAs, and CRNAs permitted scope of practice. There are no consistent standards or models that best utilizes both CRNAs and anesthesiologists, some CRNAs are accorded a broader scope of practice, while others practice within a more restricted scope. The imposed restrictions to individual CRNA scope of practice influences the quality of the CRNA/anesthesiologist relationship and, supports the notion that role conflict, ambiguity, lack of control and autonomy in one's job contribute to occupational stress and burnout. The CRNA/anesthesiologist relationship is an essential part of ensuring quality for both patients and providers. A better understanding of these relationships will help support efforts to improve both the quality and efficiency of anesthesia services in a changing health care environment, and overall well-being of anesthesia care providers.

The Tax Equity and Fiscal Responsibility Act of 1982 (TEFRA) established the following criteria that anesthesiologists must meet in order to be paid by Medicare Part B for medically directing CRNAs in concurrent cases (two to four cases at a given time):

- Performs a pre-anesthetic examination and evaluation.

- Prescribes the anesthesia plan.

- Personally participates in the most demanding procedures of the anesthesia plan, including induction and emergence. 
- Ensures that any procedures in the anesthesia plan that $\mathrm{s} /$ he does not perform, are performed by a qualified anesthetist.

- Monitors the course of anesthesia administration at intervals.

- Remains physically present and available for immediate diagnosis and treatment of emergencies.

- Provides indicated post-anesthesia care.

The TEFRA payment conditions came about because of abuses to the system by some anesthesiologists who were making enormous profits by billing for supervising CRNAs, when the anesthesiologists were not even in the hospital. Prior to TEFRA, there had been no effective limit on the number of concurrent cases for which anesthesiologists could bill for providing medical direction to CRNAs. The purpose of these payment conditions therefore, was to place anesthesiologists in positions of accountability for the services they were claiming to provide as they worked with and/or employed CRNAs. The TEFRA conditions were not intended to define the clinically appropriate or most costeffective roles for the members of an ACT, nor have any studies been conducted to support such an interpretation (Klein, 1997).

Unfortunately, over the past few years, the TEFRA conditions have been inappropriately interpreted as quality of care standards, instead of merely conditions for reimbursement of physicians. The TEFRA conditions have led to restrictions to CRNA practice in performing all the components of anesthesia care services that CRNAs are legally authorized to perform. Because of the restrictions imposed, disruptions in the flow of cases through a surgical schedule have been affected. An example of this would be; when the whole surgical team must wait for the availability of an anesthesiologist to begin or end a case, even though the CRNA is quite capable of conducting the procedure alone.

The widespread variations in the structure of individual ACTs, has created an urgency to better understand what constitutes an effective, exemplar team, in which quality of care is the focus. From region to region, and from hospital to hospital within specific communities, there are wide variations in ACT provider mix and division of labor. Klein (1997) points out, in one hospital, for instance, the overall ratio of anesthesiologists to CRNA may be 1:4, with CRNAs involved in all cases and accorded a broad scope of practice including administration of regional anesthetics, insertion of invasive lines, and other complex procedures. In another hospital, within the same city, and with similar patient 
populations may have a 1:2 ratio, with anesthesiologists handling many cases on their own and CRNAs highly restricted in the types of procedures they may perform. In this environment, tensions between anesthesiologists and CRNAs are quite common. This atmosphere may lead to a stressful, ineffective practice relationship, reducing the overall quality of patient care, and affecting the well-being of both CRNAs and anesthesiologists.

\section{Statement of Problem}

How does individual scope of practice and collaboration with anesthesiologists in anesthesia care team settings relate to occupational stress in CRNAs?

\section{$\underline{\text { Research Questions }}$}

1. What are the characteristics of the anesthesia care team environment based on aspects of individual CRNA scope of practice?

2. What are individual CRNA's reported perceptions of collaboration between CRNAs and anesthesiologists, based on the Weiss and Davis (1985), Collaborative Practice Scale (CPS)?

3. Is there a relationship between CRNAs reported individual scope of practice in ACT settings and collaboration?

More specifically,

a. Do CRNAs who report restrictions to individual scope of practice perceive lower collaboration?

b. Do CRNAs who report a broader individual scope of practice perceive higher collaboration?

4. Is there a relationship among CRNAs reported scope of practice, perception of collaboration, and occupational stress based on the Osipow (1998) Occupational Stress Inventory (OSI)?

a. When CRNAs report restrictions to individual scope of practice, what is the relationship between their perception of collaboration and occupational stress? 
b. When CRNAs report a broader individual scope of practice, what is the relationship between their perception of collaboration and occupational stress?

A descriptive, correlational survey design was used to address the research questions. A questionnaire was mailed to all practicing CRNAs $(n=1124)$ from the six (6) New England states. The questionnaire packets included a demographic instrument, an instrument to measure CRNA scope of practice, the collaborative practice scale (CPS), and the occupational stress inventory-revised (OSI-R). 


\section{CHAPTER II}

\section{BACKGROUND AND THERORETICAL FRAMEWORK}

\section{Role of Certified Registered Nurse Anesthetists (CRNAs)}

Up until recently, there has been little research in how to improve anesthesia care and efficiency within the ACT model (Klein, 1997). Kelly (1991), Thompson (1992), and Loeffler (1993) conducted studies addressing the functional and human elements that are associated with anesthesia care delivery and practice. Kelly (1991) developed a model of anesthesia care provided by a team of anesthesiologists and nurse anesthetists that conceptualized the characteristics and components of the anesthesia care team, based on a qualitative, inductive approach. Thompson (1992) and Loeffler (1993) examined relationships of job satisfaction to indicators of burnout among CRNAs and job turnover, stipulating that there are relationships between specific factors of the work environment that influences job satisfaction and turnover. In addition, the American Association of Nurse Anesthetists (AANA, 1990) identified human factors that influenced anesthesia care, in a major national practice study.

Although these studies made several points about the human elements and concepts that directly relate to ACT structure and division of labor, there is little empirical evidence focusing on the hyper-vigilant nature of the medical community placing boundaries and restricting many CRNAs' scope of practice responsibilities. This strategy has been fueled by monetary issues, leading to higher anesthesia service costs, thereby pointing to the need to revise the current medical direction guidelines. Fassett and Calmes (1995), in one of the only research attempts at examining the quantitative need for medical direction, determined that anesthesiologists and CRNAs agreed in the perception that $70 \%$ of the cases did not need medical direction. Even though this study, according to Fassett and Calmes (1995), was from one unique practice setting, it suggests that excessive medical direction contributes to higher costs. Revisions to medical direction guidelines are recommended to preserve the ACT as a practice option.

Fassett and Calmes (1995) also point out that trends in medical manpower have shifted toward training of fewer physician specialists and more physician generalists. This has led to increased utilization of non-physician providers, and has generated heated debate in the healthcare community regarding appropriate scopes of practice, levels of education, quality of care, and professional autonomy 
(Fasset \& Calmes, 1995, p. 118). Anesthesia, which has had two competing providers in the United States since the 1890 s, is an example of a specialty which has actively debated and failed to resolve these differences. Managed care and federal reimbursement policies have the ability to mandate change and call for compromise and constructive resolution to these issues.

Managed care organizations have begun to closely evaluate practice pattern variations in areas such as elective surgery, diagnostic procedures, and the treatment of specific conditions. The goal of managed care organizations with respect to anesthesia services is to provide high quality care as efficiently as possible. Unique features of the market for anesthesia labor have prevented managed care from reshaping anesthesia practice (Klein, 1997).

In a more recent study, Posner and Freund (1999) investigated trends in quality of anesthesia care associated with changing staffing patterns in a university hospital in the north west. In the study, anesthesia care team productivity and supervisory ratios (concurrency) were measured, and compared with quality of anesthesia care measures. Anesthesia team productivity was measured as mean monthly surgical anesthesia hours billed per attending anesthesiologist per clinical day. Supervisory ratios (concurrency) were measured as mean monthly cases supervised concurrently by attending anesthesiologists. The quality of anesthesia care measures were based on monthly rates of critical incidents, patient injury, escalation of care, operational inefficiencies, and human error per 10,000 cases. Trends in quality at increasing productivity and concurrency levels in the university-based hospital from 1992-1997 were analyzed. Productivity was positively correlated with concurrency. Productivity levels ranged from 10 to 17 hours per anesthesiologist per clinical day. Concurrently ranged from 1.6 to 2.2 cases per attending anesthesiologist. Posner and Freund (1999) concluded that most aspects of quality of anesthesia care were apparently not affected by changing anesthesia care team composition of increased productivity and concurrency.

Although Posner and Freund's (1999) work attempts to link trends in quality with increased productivity and concurrency, more research needs to be conducted that addresses higher anesthesiologist-CRNA ratios than what was reported in their study (1.6 to 2.2 cases per anesthesiologists). With maximum concurrency of a range of ratios between 2 to 4 CRNAs per anesthesiologist, as stipulated in the Medicare Part B, TEFRA conditions of 1982, even greater levels of 
productivity can occur in anesthesia teams. It is up to the team members to establish criteria for the amount of supervision required for each case. Counter-productivity will surface in anesthesia care teams where CRNAs are not allowed to practice within their broad scope. In a collaborative fashion, both CRNAs and anesthesiologists can create new ways to approach the team concept.

Although, these studies have contributed significantly to the advancement of knowledge related to anesthesia care team structure, reimbursement, and productivity, the literature lacks in the understanding of how CRNAs perceive their contributions to the team care concept. The proposed study attempts to illuminate, from the CRNA's perspective, how they are utilized in the ACT setting based on individual scope of practice, what constitutes collaborative practice, and the relationship of these variables with stress in the workplace.

\section{Philosophical and Theoretical Basis for Nursing Practice}

Despite the supporting nurse anesthesia literature presented thus far, very few studies utilize a philosophical and/or theoretical perspective to guide the research questions. Most of these studies lack a theoretical focus that attempts to make a congruent connection to nurse anesthesia practice. The primary goal of theoretical thinking is based on the researcher's ability to organize empirical findings into a meaningful, coherent pattern. This pattern, or organized conceptual system, is necessary for a research study in moving toward generalizability.

The philosophical underpinnings for this study stem from a critical philosophy viewpoint, as a broad perspective in understanding the depiction of domination and conflict between nurses anesthetists and anesthesiologists in anesthesia care team environments. The theoretical framework in this study specifically focuses on the interrelated concepts of care and therapy in nursing practice, driving toward quality practice, as Kim (1998a) has conceptualized. The following section provides an overview of both the critical philosophy perspective and the quality practice framework in relation to anesthesia care team practice.

\section{Critical Philosophy Perspective of Nurse Anesthesia Practice}

$\operatorname{Kim}(1983,2000)$ has described a typology to delineate and organize nursing knowledge development. This typology include the domains of practice, the client, the client-nurse, and the environment. The concept of practice, according to Kim (1987) refers to the cognitive, behavioral, and 
social aspects of professional actions taken by a nurse in addressing clients' problems. The effectiveness of nursing practice depends on an understanding of how nurses think, make decisions, transfer knowledge into actions, or use available knowledge in actual practice.

Grando (1998) discusses the meaning of the advanced practice nursing domain. She states that "a domain is the area of responsibility and concern of a discipline" (p. 503). It is derived from the ideas, values, goals, technology, and knowledge of the field (Hahn, 1995). The domain of the advance practice nurse (APN) is extensive, encompassing a large arena of activities and knowledge. It varies according to the APN's individual scope of practice, knowledge, and expertise. In addition to delineating the concerns of a field, domains are also social constructs that provide boundaries between professions and disciplines (Grando, 1998). Typically, boundaries may be thought of as distinct and rigid, but they are not. They overlap and continually change and evolve with time (Mechanic, 1988). "APNs and physicians have many responsibilities in common, they collect and use data similarly, share the same tools, and perform the same procedures. However, they process the data differently and set different goals, which influences patient outcomes" (Grando, 1998, p. 506).

Kim (1998b) indicates that from the critical philosophy perspective, nursing practice is viewed as a form of social life in which different forms of domination, distortions, and misunderstandings are possible. Hence, any study of practice needs to incorporate an emancipatory project through which social life can be freed from domination and distortions (Habermas, 1984). Habermas (1971) claims that there are specific viewpoints from which we can apprehend social reality. These viewpoints represent three categories of knowledge, or cognitive interests, as Habermas calls them. They are identified as technical, practical, and emancipatory interests and are viewed as distinct but interrelated domains of knowledge. The technical cognitive interest focuses on technical control, with emphasis on practical reason in dealing with objects, and thus points to the empirical-analytical sciences. The practical cognitive interest is oriented to understanding in social life, with emphasis on reflective judgement and interpretive understanding, and hence points to historical-hermeneutic sciences. The emancipatory cognitive interest focuses on the freeing of individuals from constraints and domination, with emphasis on critical and self-reflection for mutual understanding, and thus points to critically oriented sciences. 
The knowledge created from the empirical-analytical and historical-hermeneutic sciences is fundamental in arriving at the knowledge that may be necessary for social existence, but this is not sufficient, according to Habermas (1971). Habermas is critical of both the empirical-analytical and the historical-hermeneutic. He argues, according to Kim and Holter (1995) that "any reduction of the social sciences to the understanding of subjective meanings fails to recognize that these understandings are themselves heavily influenced by a context that can limit both the scope of the individual situation and the possibility of changing it” (p. 209). Habermas stresses that the goal of systematic social sciences, such as economics, sociology, and political science, and the empirical-analytical sciences is to produce nomological knowledge, or law-like knowledge. He claims that there must be knowledge that is oriented to liberating individuals from the constraint of domination and distorted communication and allows them to be involved in the process of their own emancipation (Kim \& Holter, 1995).

The emancipatory interest in this form is concerned with the power relationship between theoretical knowledge and the objective domain of practical social life, which comes into existence as a result of systematically distorted communication. Kim and Holter (1995) citing Habermas (1971) explain that "critical theory strives to go beyond the law-like 'frozen' structure of nomology and encourages a process of reflection in the consciousness of those to whom the laws are about" (p. 210). The overall goal of critical theory is to shape a life free of all forms of unnecessary domination. Habermas believes that this life is based on emancipation and requires both enlightenment and actions. Hence, Kim and Holter (1995) explain, Habermas considers communicative action as the foundation as a way of attaining this goal. The following presentation is based on Kim and Holter's (1995) discussion of the basic concepts of Habermas's Theory of Communicative Action.

Two major concepts undergird Habermas's (1984) theory: communicative competence and ideal speech situation. Communicative competence refers to competence in speech and symbolic interaction as well as linguistic competence. To have communicative competence means the mastery of what Habermas calls an ideal speech situations. Habermas (1984) presents the four types of speech acts that he claims represent a general classification of speech acts necessary for an ideal speech situation: constitutive speech, representative speech, regulative speech, and communicative speech. The theory of communicative action is based on these speech acts which stems from his ideas about comprehensive 
rationality which also encompasses the theory of argumentation. His point of departure, Kim and Holter (1995) explain is the assumption that there is a close relationship between knowledge and rationality. He further claims that rationality concerns how a person acquires and uses knowledge, and is reflected in human actions. The communicative rationality (Kim \& Holter, 1995) thus becomes the basis for "the central experience of the unconstrained, unifying, consensus-bringing force of argumentative speech, in which different participants overcome their merely subjective views and, owing to the mutuality of rationally motivated conviction, assure themselves of both the objective world and the inter-subjectivity of their life-world" (p. 10).

Kim and Holter (1995) propose a theory of nursing practice with a focus on nurses' communicative action in developing a way of addressing nursings' emancipatory cognitive interest. The social climate that prevails in the current practice of nursing indicates an existence of oppression of different client groups and concentration of power in dominant groups. This oppressive state based on domination and distortions by the medical model has been true within the nurse-physician relationship for a long time. The reasons for this discrepancy is the focus of the use of critical theory as an appropriate philosophy of science perspective in addressing nurses and physicians relationships. Critical theorists would propose that before meaningful relationships can occur between nurses and physicians, certain conditions must be present which will facilitate communication aimed toward mutual understanding, consensus or agreement.

McLain (1988) in discussing Habermas (1971) states that "in every interaction or speech situation, a background consensus is presupposed in which four assumptions about the ideal speech situation; understanding, truth, sincerity, and legitimacy of the speaker, are held to exist" (p. 392). When any of these ideal assumptions are unmet, distorted communication, typical of most communication in the real world, results. Free communication, however, requires the speaker to call into question any problematic assumption, moving the interaction to a level of discourse about the distortion itself (McLain, 1988). The aim of such discussion is consensus based on generalizable interests, not negotiation, conflict resolution, or compromise based on individual interests. McLain (1988) purports that the critique of critical theory lies in the opportunity for members of society, through self-reflection and discourse, to determine how things ought to be. This critique is based, not 
on self-interest, but on the needs of the larger society. In understanding the practice relationships between nurses and physicians, both must acknowledge the generalizable interest of the practice as central, rather than what each professional may need or want for himself/herself.

According to Torgersen and Chamings (1994), many reasons are cited for the lack of effective practice relationships between medicine and nursing. A major reason has been that the healthcare delivery system has been rapidly changing and, as a result, medicine and nursing are facing significant challenges to their traditional roles. The climate is competition rather than collaboration, as nurses assume increasing responsibility for healthcare delivery through expanded and advanced practice roles (Kennedy, 1986).The anesthesiologist-CRNA relationship has been characterized, in general, by patterns of physician dominance and nurse deference with increasing conflict between the two groups (Torgersen \& Chamings, 1994). The many reasons cited for this pattern have included sex roles, education, economic factors, social status, age differences, and lack of understanding and sympathy for each other's perspectives. Another area of physician-nurse conflict relates to their overlapping areas of practice, especially within the ACT setting. The sharing of areas of responsibility not only fuels conflict, it also makes both parties unwilling to change their respective role relationships. This in turn, has made it extremely difficult for nursing to shed its "handmaiden to physician" role for one of collaborator and autonomous professional (Prescott \& Bowen, 1985). Perceived powerlessness and inability to use all of their professional skills through more collegial relationships with physicians are seen by nurses as barriers to professional practice and may influence overall quality of care (Schirger, 1978; Staum \& Gould, 1980). Eubanks (1991) reports that multiple forces, particularly the movement toward quality, are forcing reexamination of the ways physicians and nurses work together.

In summary, the literature has suggested that there are many reasons for nurses and physicians continuing to exhibit ineffective relationships. This has become particularly evident regarding the CRNA/anesthesiologist relationship in the ACT. Because both providers have overlapping responsibilities, and are afforded equal access to reimbursement by insurance companies and Medicare, significant conflicts occur in practice. In many ACT settings, the nurse anesthesia scope of practice is dominated and controlled by the anesthesiologists, which provokes a power differential between both providers. In addition, anesthesiologists continue to influence institutional mandates in hospitals, 
surgical centers, and office-based settings across the country. In most hospitals for instance, anesthesiologists serve as department directors with close associations to medical staff and administration, where major policy changes occur. Although nurse anesthetists are beginning to make strides in developing relationships outside the operating room, rarely are nurse anesthetist given the opportunity to serve on committees that influence policy change. For example, most hospital clinical privileging committees do not include CRNA members, even though CRNAs must apply for privileges. This dilemma encourages the depiction of domination and control by anesthesiologists toward CRNA scope of practice, and does little to promote quality patient care. Both parities need to establish mutual goals that represent cohesiveness and cooperation, to move toward a quality patient care perspective.

\section{A Framework for Quality Nursing Practice}

The backdrop for which Kim (1998a) proposes a framework for quality nursing practice is based on the unprecedented complexities in the current United States healthcare delivery system. Kim (1998a) points to several factors that motivate a need and desire to develop practice based theories. Kim (1998a) explains that, "during the last ten years, we have experienced the effects of many social, political, economic, organizational, scientific, technological, and professional as well as philosophical forces on the structures and processes involved in patient care" (p. 1). Such forces are founded upon the prevailing ideological commitments to cost-containment and cost-efficiency, accountability, scientific base of health care, and quality care.

Practice theories are those uṣed in the actual delivery of nursing care to clients. As Kim (1994) has illustrated, the nursing science community has somewhat ignored scientific questions related to the nurse as the agent of nursing work. There are limited nursing theories that address nursing practice per se. Kim (1994) uses clinical examples to explain how theories are utilized in practice to specifically address the nurse-agent in action. These theories include; "theories providing explanation about the patient's problems, theories providing the nurse with ideas about how to approach the patient, decisions-based theories about nursing actions, and theories addressing what happens in the actual delivery of nursing actions" (p. 146). Therefore, Kim (1994) proposes a framework that organizes these four sets of practice theories specifying two dimensions for classification: the dimensions of target and nurse-agent. 
The dimension of target is differentiated into "problem" versus "person" according to the focus of attention associated with the practice actions. The dimension of nurse-agent is differentiated into the phase of deliberation and the phase of enactment according to the phase in which practice actions are involved. Hence, the dimension of target is oriented to the client, whereas the dimension of nurse-agent is oriented to the practicing nurse. The targets of nursing practice are both clients presenting problems to be solved, and clients themselves as human beings. This means, according to Kim (1994), that nursing practice is oriented to bringing about the occurrence of a desired state (a teleological aspect). At the same time, nursing practice is also oriented to working with and attending to clients as human beings situated within the context of nursing service. Therefore, nursing practice coordinates two separate philosophies of practice: philosophy of therapy and philosophy of care (Kim, 1994, 1998a). Figure 1 provides the initial framework for Kim's model.

The philosophy of therapy focus orients the nurse to address patient's problems with therapeutic interventions and strategies. Kim (1994) points out that theories for what Habermas (1984) calls non-social and social strategic actions founded on the "technical cognitive" interest may belong to this type of practice theory. Nursing science has long espoused this type of practice theory, that is, developing specific prescriptive theories for solving clients' problems. This approach, Kim (1994) says, "suggests a re-thinking of the nature of practice theories so that the focus of the philosophy of therapy will be context-oriented"' (p. 148).

The philosophy of care, on the other hand, leads to the actions of the practitioner in relation to clients as human beings in need of support, care, understanding, and connection. The targets of practice with this orientation are human beings in an interactive context of nursing. "Clients and practitioners, as human beings, are engaged in interactive and intertwined human activities in which practice is a part of continuous human engagement" (Kim, 1994, p. 148). Hence, practice theories of this sort are "approach" theories; that is, they must deal with the interactive nature of phenomena that occur between nurses and clients (Kim, 1994). 
Figure 1 (Adapted from Kim, 2000, p. 133)

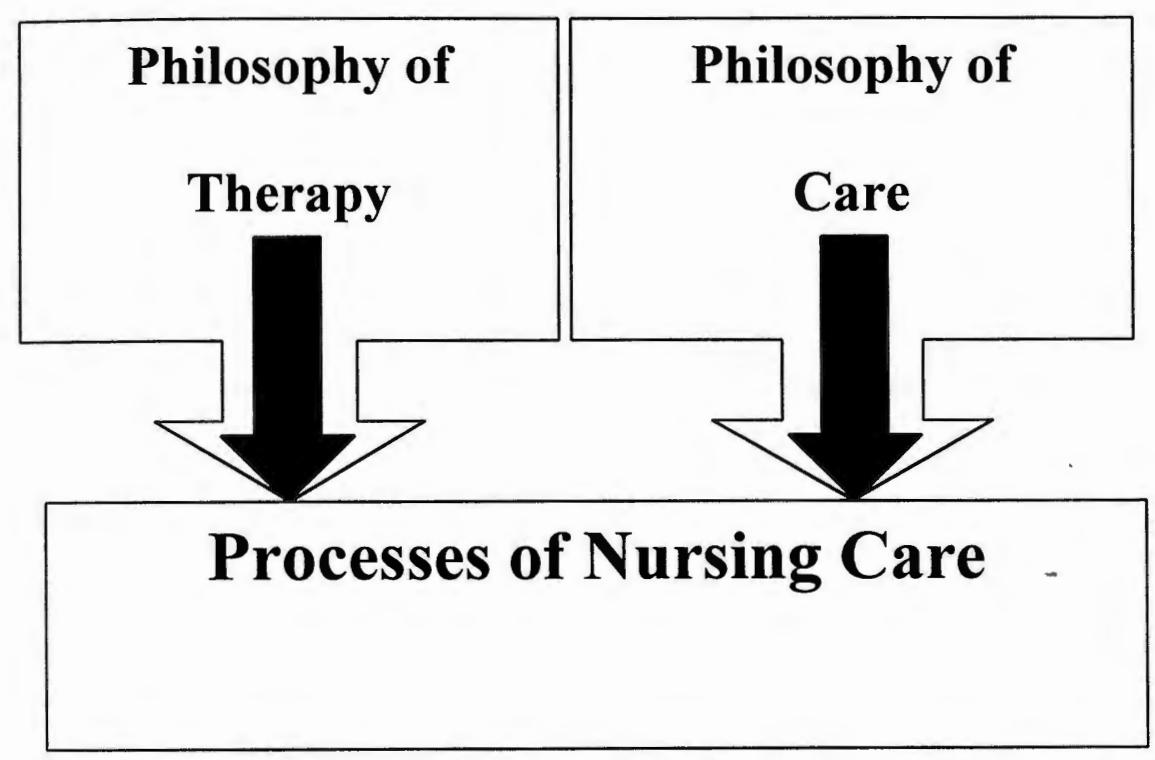


The dimension of nurse-agent refers to the domain specified by Kim (1987) as the practice domain. The practice contains at least two phases; the deliberation for action and the actual enactment (Kim, 1994). "The deliberation for action by the practitioner involves developing a program of action, manifestly or latently, as analytically separated from the enactment of action" (Kim, 1994, p. 149). It focuses on the assessment by the practitioner of the situation and the selection of a choice for action. The enactment phase is conceptualized in terms of "human actions" being done (performed, carried out, realized) by an agent.

Kim (1994), in defending the necessity of separating the phases of deliberations and enactment, first points out that "in the disciplines of human-service practice, enactment in practice invariably involves another human being (the client) who is also an enacting agent" (p. 152). Secondly, Kim (1994), explains that it is because connections between deliberation and enactment are not uniform and can take various forms according to differences in the nature of the practice setting. Kim (1994) uses the following examples: (1) a critical/emergency situation, where on-the-spot, immediate action responses are needed, (2) a delayed situation in which action is separated from deliberation by a prolonged time lag, or (3) a third-person situation, where deliberation is done by a nurse who delegates enactment to others or is delegated by others (i.e., advanced practice nurse delegated by physician).

The notion that nursing practice is guided by a philosophy of therapy and a philosophy of care, as $\operatorname{Kim}(1994,1998$ a) proposes, suggests that nurses may be framing their clinical situations and their engagements in practice based on these two philosophic orientations. The findings from some recent studies of nursing practice (Esposito, 1998, Dick, 1998, and Kennedy, 1999) have indicated that nurses are basing their practice on these two philosophies, and are engaged in defining clinical situations as one of the first steps in their deliberations.

The organization of Kim's (1998a) quality of nursing practice framework is based on the following four components: goals of patient care, the process of care, quality of care, and patient outcomes (Refer to Figure 2). The goal of patient care component is basically instrumentally oriented and consists of two categories of focus: goals related to client's clinical problems and organizational goals of efficient and effective use of resources. The goals related to the problems of living associated 
with being in a specific healthcare situation; the anesthesia care experience, initiates the quality of practice process.

The process of care component that Kim (1998a) proposes refers to the activities, performances, management, and instrumentation that occur in patient care. As stated earlier, she believes that nursing practice, traditionally, has been oriented to patient care through a philosophy of therapy and a philosophy of care. The philosophy of therapy focus orients nursing to address patient's problems with therapeutic interventions and strategies. The therapeutic components in anesthesia care, for example, are functions that both CRNAs and anesthesiologists can perform. The purposes are the ability to remedy (i.e., discomfort), remove (i.e., stimulation of nausea and vomiting), alleviate, control (i.e., pain), or treat patient's problems. The overall goal of the process of anesthesia care is to help patients to live the situation of health-care (i.e., surgery and anesthesia) as human beings.

In addition, this component also involves another dimension of processes because nursing care is delivered within an organized system of services rather than as an independent, individual practice system. This dimension involves both an individual-practitioner practice and a coordinated process. In the current health-care environment, the nature of coordinated process is governed by such structures as "care-teams". Thus, activities of nursing care must be considered in terms of continuity and coordination. Anesthesia care (within a collaborative situation between CRNA and anesthesiologist) involves both of these processes within the anesthesia care team structure. Therefore, the process of anesthesia care takes on an individual and coordinated practice focus.

Kim (1998a) illustrates how nursing practice even in a very simple situation involves a complex process, involving not only each individual nurse's specific practice, but also involves practice as a coordinated set of actions. Hence, nursing practice must be conceived to involve two parallel processes; one involving individual's practice that encompasses deliberation (informational processing, decision-making, and planning) and actions (actual doing of care), and the other involving coordination within specific care-teams and across care-teams involved in the total care of a given patient. In generalist nursing care, the nurses' responsibility for the coordination with given care-teams (nursing assistants) mostly involves the delegation of care activities. Kim (1998a) explains that nurses have the 
ability to communicate effectively with other health-care professionals in general nursing situations, through the use of delegation as the most common mode for the coordination of patient care activities.

In understanding the quality of practice component, Kim (1998a) proposes a conceptualization in terms of individual practice and coordinated practice in addressing both the philosophies of therapy and care. For the frame of individual practice, Kim (1998a) says that quality of practice needs to be considered in terms not only of practice performances, but also of practice activities' saliency and coherence within the total structure of patient care. In discussing the frame of coordinated practice, quality of practice must point to "cumulation", "complementarity", and "contiguity".

Cumulation refers to the processes of nursing practice in a coordinated system resulting in summative effects of nursing care provided by different caregivers. In the anesthesia care team, if an anesthesiologist is providing care along with a CRNA, both providers must be oriented to progressively adding the effects and influences in the care situation. Kim (1998a) explains that each provider practices independently but must build on each other's effect rather than paralleling each other.

Complementarity refers to the processes of nursing practice in a coordinated system resulting in complementary effects of nursing care provided by different caregivers. Kim (1998a) explains that what different caregivers are doing for patients must not be contradictory or replacing of each other's effects. One anesthesia provider must not dominate the other by changing the care focus. Anesthesia care providers must coordinate their work so that their practice influences patients in a complementary fashion.

Kim (1998a) posits that contiguity in practice in a coordinated system means that what different providers (care-givers) are doing are connected together as a network so that there is a movement toward progression in a systematic fashion. When practice is contiguous, it is possible to avoid omissions and errors. In a contiguous anesthesia care practice, there are rational, systematic connections with different providers to permit a continuous, progressive, harmonious attempt at providing quality anesthesia care.

The patient outcomes component of Kim's (1998a) framework provides a means to measure the results in the process of care components outlined. She addresses the confusion related to outcome assessment in nursing care situations. There are various interpretations and applications of the term 
outcome in practice and research. In citing Jennings and Staggers (1998), in their analysis of "the language of outcomes", Kim (1998a) suggests that the concept of "outcomes" is used in various meaning contexts, such as 'outcome studies, outcome research, outcomes management, performance measures, and outcome indicators'. Kim (1998a) focuses on patient outcomes in terms of individual patients. She proposes a conceptual approach to frame patient outcomes and "goals of patient care" that is based on orientations in both the philosophies of therapy and care. She posits that these outcomes are based on trajectories of transitional outcomes and readiness outcomes.

Kim's (1998a) inductively derived framework provides a foundation for developing a substantive theory for nursing emphasizing both outcome and quality of nursing practice. The generalizability of the framework has been shown in some studies: Dick (1998) examined how nurses' assess, recognize, and identify the care of acutely confused hospitalized elderly patients; Esposito (1998) explored the nature of nursing practice in patient-focused care; and Kennedy's (1999) work advanced a model of midwifery practice linking nurse midwifery practice process to outcomes. In all of these studies, there are indications that nurses are basing their practice on the philosophies of therapy and care, and are engaged in defining clinical situations as the first step toward deliberations.

\section{Quality Framework for Anesthesia Care Team Practice}

In the anesthesia care team (ACT), the quality of anesthesia care is related to how well the CRNA and anesthesiologist are able to effectively coordinate the anesthesia care activities together. In many instances, there are competing forces that impede the care-team concept. These competing forces stem from a long history dating back to the 1970s regarding the dominating influence of medicine on the practice of anesthesia care. In the ACT environment, both the individual practice process of the CRNA and the coordinated practice process of the CRNA/anesthesiologist dyad are in a continuous exchange of deliberation and delegated enactment. The focus of the CRNA individual practice process is based on the ability to provide anesthesia care as effectively and efficiently as possible. The goals of the coordinated practice process from the ACT perspective, thus, is greatly influenced by the relationship in the anesthesia care team dyad (Refer to Figure 3). 
Figure 2 Quality of Nursing Practice Framework

(An adaptation of Kim, 1998a)

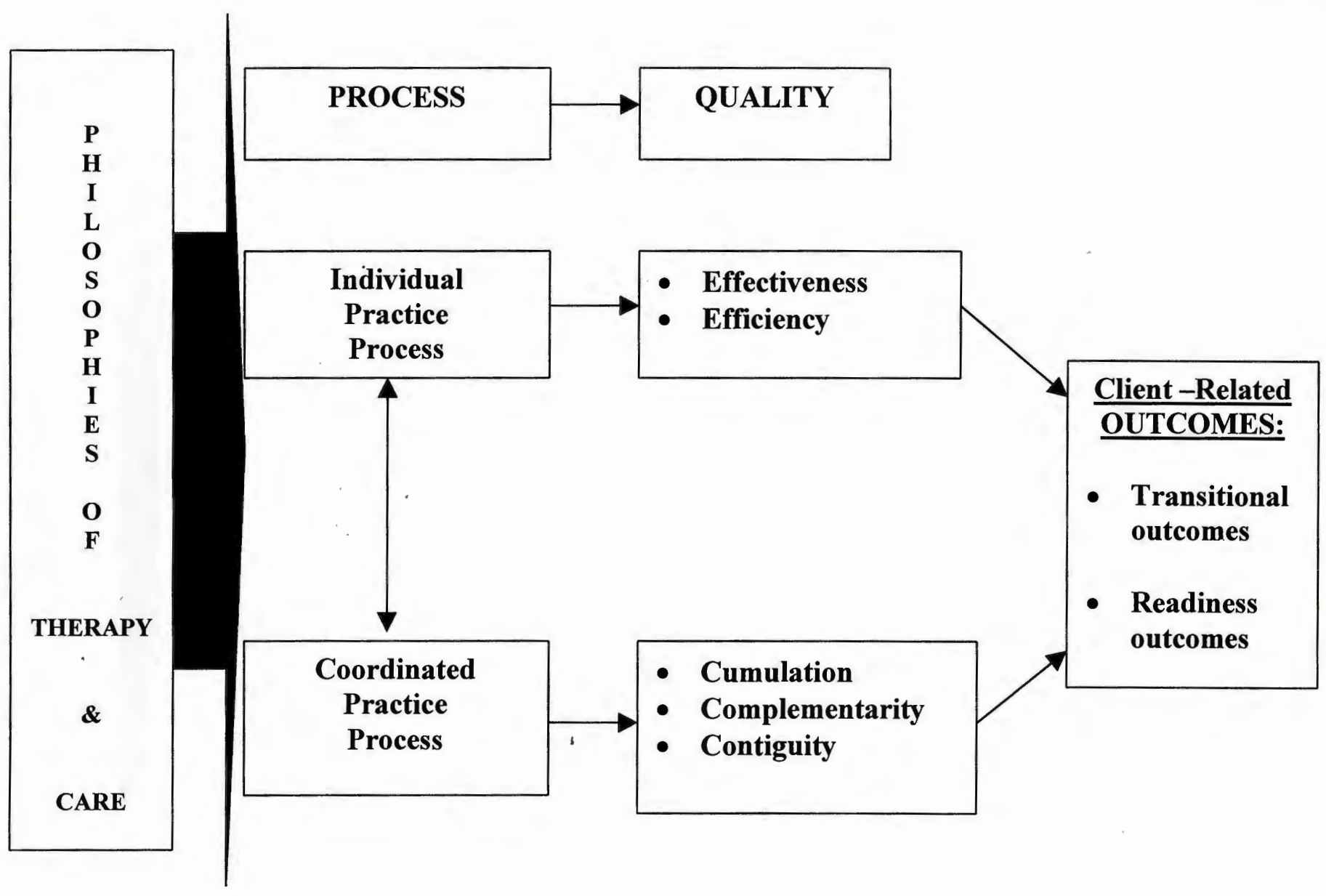


Figure 3 Collaborative Practice in the Anesthesia Care Team (An adaptation of Kim, 1998a)

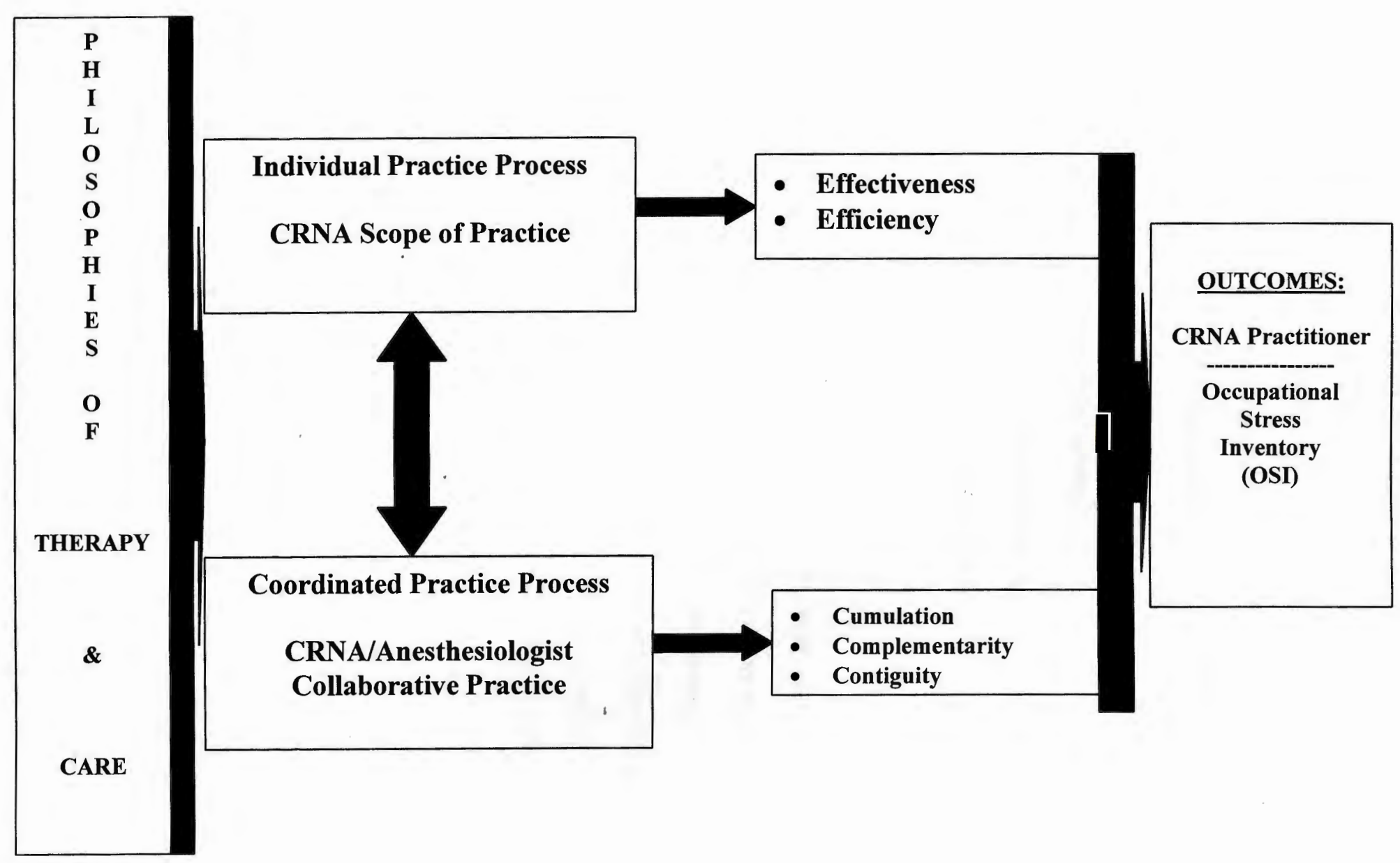




\section{Collaboration and Occupational Stress in the ACT}

The area of interest in the present study involves an elaboration of the process component of Kim's (1998a) framework. The process of care in the delivery of anesthesia team services involves both the individual CRNA practice process and the coordination of care by the CRNA/anesthesiologist dyad. As a way of understanding the interaction of these two components, the concept of collaboration is utilized. The chief objective in this study is to coherently link CRNA's perception of collaborative practice in ACTs to gauge the strength of the coordinated process in Kim's (1998a) framework. The interactive relationship between CRNA scope of practice (individual practice process) and collaboration (coordinated practice process) are viewed to influence occupational stress (as a provider outcome measure), as shown in

Figure 4.

The CRNA scope of practice characteristics, whether broad or restricted, may impact on collaboration. When CRNA scope of practice is dominated and controlled by the anesthesiologist in the dyad, this leads to an ineffective collaborative atmosphere, influencing the coordination of patient care. In addition, role-conflict and constraints occur, having a lasting affect on both the relationships in the dyad and occupational stress in both providers. In the following section, both the concepts of collaboration and occupational stress are examined from a nursing and organization behavior perspective. 
Figure 4

Collaborative Practice in the Anesthesia Care Team:

An Elaboration of Kim (1998a) Process Component

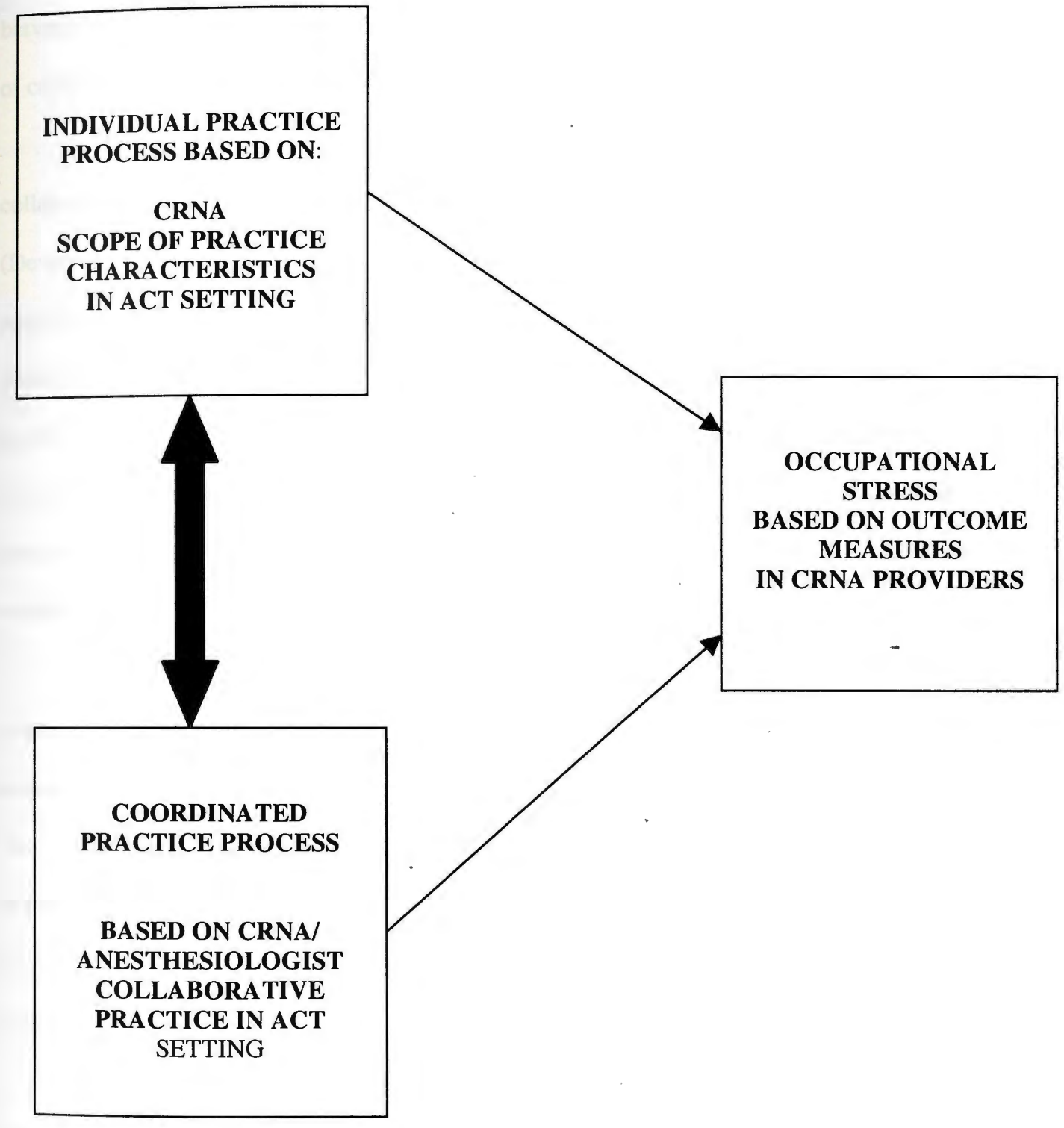




\section{Collaborative Practice}

Sullivan (1998) points out in her work, Collaboration: A Health Care Imperative that "in all spheres of nursing and health care--practice, education, administration, and research, the concept of collaboration is receiving much attention in the literature and has for many years" (p. 3). Joint practice between nurses and physicians has long been espoused as the most appropriate model for the delivery of comprehensive health care in all settings (McLain, 1988).

The National Joint Practice Commission (NJPC) attempted to increase nurse/physician collaboration and establish more appropriate nursing roles in the setting where most nurses function (Devereux, 1981). One purpose of the NJPC was to study and make recommendations about nursephysician relationships. The commission was originally made up of eight nurses and eight physicians named by the ANA and AMA. The NJPC defined joint practice as nurses and physicians collaborating as colleagues to provide patient care (1977). This definition, according to McLain (1988), equates joint practice with collegial collaboration, implying that mere proximity in the work situation does not ensure meaningful collaboration. Although it is suggested that collaboration is highly valued, on both sides, it is difficult to locate this concept within the real world of practice relationships

Collaboration defies easy definition or explanation. Most definitions adopt the principles of cooperative planning and decision making, shared incentives, mutuality, accountability, expertise, and common goals and responsibilities (ANA, 1980; Baggs \& Schmitt, 1988; Evans \& Carlson, 1992; Shortridge, McLain, \& Gilliss, 1986). Although many of the fore mentioned definitions and descriptions of collaboration have helped to add to the knowledge development thus far, they fail to convey one of the goals of the NJPC (1977) of understanding the rich variety and complexity of collaboration in health care.

Gleaned from the conceptual research literature related to nurse-physician collaboration, the following theoretical definition was advanced to guide the present study: The quality of collaborative practice in the anesthesia care team involves: A dynamic, transforming process (Kim, 1998a), of creating a power-sharing partnership (Sullivan, 1998), based on behavioral and communicative interactions (Kim \& Holter, 1995) between CRNAs and anesthesiologists that enable the knowledge and skills of both professionals to synergistically influence outcomes (Weiss \& Davis, 1985; Sullivan, 
1998 ) in the patient care provided and preserve the well-being of the anesthesia provider in the workplace, and organizational needs.

Organizational theorists, Kilman and Thomas (1977) proposed five modes of conflict resolution: competing, collaborating, compromising, avoiding, or accommodating. These modes reflect independent modes of interpersonal conflict behavior. This classification scheme was based on the earlier work of Rubel and Thomas (1976), who proposed a two-dimensional model which classified modes of conflict through the dimensions of cooperativeness and assertiveness. Combinations of these two dimensions yield five types of conflict behavior: competition (assertive and uncooperative), collaboration (assertive and cooperative), avoidance (unassertive and uncooperative), accommodation (unassertive and cooperative) and compromise (intermediate in both cooperativeness and assertiveness).

Several nurse researchers have utilized the Kilman and Thomas (1977) instrument to measure the concept of nurse-physician collaboration (Prescott \& Bowen, 1985; Weiss \& Davis, 1985; Baggs \& Ryan, 1990; and Torgersen \& Chamings, 1994). Prescott and Bowen (1985) used the Thomas and Kilman's (1977) work to develop a model for handling disagreements. Physicians and nurses from 15 general hospital participated in the study, completing a brief questionnaire and also participating in semi-structured interviews. Extensive data were gathered on disagreements that nurses and physicians had in decision making about patient care as one component of data gathered in this massive database.

Using the two-dimensional grid, data were plotted into the five modes. Competition was shown to be the most common mode for managing disagreements, followed by accommodation. The researchers judged competition to be a more desirable mode than accommodation for dealing with disputes, but found it to be less desirable than collaboration. Nurse disagreed with physicians most often regarding plan of care, specific orders, and patient disposition such as discharge from the hospital. The researchers noted: "Most disagreements are settled rather than resolved. Settling relies on compromise and imposed authority; resolutions are more integrative solutions that view disagreements more as problems to be solved" (Prescott \& Bowen, 1985, p. 132).

Most notably, Weiss and Davis (1985) used the Kilman and Thomas (1977) grid to develop two collaborative practice scales (CPS). One scale to measure physicians' collaborative behaviors and 
one to measure those of nurses. They geared their study to determine the reliability and validity of the CPS. Their instruments each included 30 forced-choice items that operationalized and measured the five modes of interpersonal problem solving: accommodation, competition, avoidance, compromise, and collaboration.

In general, Weiss and Davis (1985) found that nurses had difficulty engaging in problemsolving behaviors at the highest level (collaboration). They found that much of the difficulty was attributable to nurses' interpersonal weaknesses, such as discomfort accepting responsibility, having low regard for one's professional expertise, and indeed, having low regard for the profession itself. The RNs also had difficulty because of perceptions of physicians' lack of valuing of RN communication. Two theoretically relevant factors were delineated for each of the scales; a 9-item scale measuring direct assertion of professional expertise/opinions and active clarification of mutual responsibilities (assertiveness), and a 10-item scale measuring acknowledgement of the nurse's and physician's contribution to patient care and consensus development (cooperativeness). Thus, Weiss and Davis (1985) operationally define collaboration as: "Interactions between nurses and physicians based on assertiveness (attempting to satisfy one's own concerns), and cooperativeness (attempting to satisfy the other party's concerns) that enable the knowledge and skills of both professionals to synergistically influence the patient care being provided" (p. 299).

In a later study, Baggs and Ryan (1990) used the two-dimensional grid to study nurse satisfaction with collaborative practice in intensive care units (ICUs). Their sample consisted of the 68member staff of one ICU. All completed the Weiss and Davis CPS, as well as several other measures. Their hypotheses that "when ICU nurses perceive the decision-making process associated with patient transfer to be more collaborative, they were most satisfied" (p.390), was supported by the data. A significant positive correlation was found between collaboration and satisfaction in the specific decision-making situation for nurses. Baggs and Ryan (1990) point out that the CPS was extremely useful for gaining insights into how and why nurses and physicians in interactive practice settings, act as they do in settling disagreements over patient care approaches. However, the researchers also suggested that any instrument that measures collaboration must include "openness of communication, 
coordination, cooperation, and sharing during planning, and implementation of care" (Baggs and Schmitt, 1988, p. 148).

From the nurse anesthesia literature, Torgersen \& Chamings (1994) examined the collaborative perceptions that CRNAs and anesthesiologists have of each other in nurse anesthesia educational programs. Methods included a cross-sectional survey of all nurse anesthesia programs in the United States. Data were collected from the program directors and one anesthesiologist of each program. Results highlighted important areas of potential conflict between the two groups. Data reflected unequal and hierarchal relationships existing between CRNAs and anesthesiologists regarding shared responsibility, access, power, and recognition in healthcare decision making. Conclusions from this study show that there are definite philosophical and political issues that have an impact on nurse anesthesia education, and may have negative implications not only on programs of nurse anesthesia, but also to the entire field of anesthesiology.

\section{Occupational Stress}

Influence of Organizational Behavior: Stress in the workplace, as organizational behaviorists have explained (Johns, 1996), "is based on a process of interpersonal conflict that occurs when one person, group, or organizational sub-unit frustrates the goal attainment of another" (p. 446). In its classic, most extreme form, conflict often involves antagonistic attitudes and behaviors. As a result, the conflicting parities might develop a dislike for one another, and see each other as unreasonable. Antagonistic behaviors may include name calling, sabotage, or even physical aggression. In some, according to Johns (1996), the conflict process is managed in a collaborative way that keeps antagonism to a minimum. However, in many others, the conflict is hidden or suppressed and not nearly so obvious (Kolb \& Bartunek, 1992). This is particularly true in ACT settings, where anesthesiologists may restrict and control CRNA scope.

There are many factors that influence organizational conflict, these include; group identification and inter-group bias, interdependence, and differences in power, status, and culture. Johns (1996) points out that research has shown how identification with a particular group or class of people can set the stage for organizational conflict. For example, the CRNA (as an advanced practice nurse) and the anesthesiologist (as physician), represent two conflicting groups within an organizational 
structure (the ACT) that share in the provisions of anesthesia services. Interdependence is seen as conflict producing when individuals or sub-units are mutually dependent upon each other to accomplish shared goals. Interdependence may result in conflict for two reasons. First, as in the ACT, it necessitates interaction between the parties so that each can coordinate their interests. Conflict will not develop if the parties can "go it alone" (Johns, 1996). Second, interdependence implies that each party has some power over the other. It is relatively easy for one side or the other to abuse its power and create antagonism.

Conflict can occur when parties differ significantly in relation to power, status, or culture (Johns, 1996). If dependence is not mutual, but in one direction, the potential for conflict increases. In the ACT setting, if the anesthesiologist/CRNA dyad relies on a collaborative approach to accomplish its goals, and resistance occurs on either side, antagonism may ensue. Status, on the other hand, may provide little impetus for conflict when people or "lower" status are dependent upon those of "higher" status. This may be true in the ACT environment, when anesthesiologist owned groups employ CRNAs. A CRNA may be less apt to antagonize and cause conflict when the anesthesiologist "signs their paycheck".

Finally, when two or more very different cultures develop in an organization, the clash in beliefs and values can result in overt conflict. Although both CRNAs and anesthesiologists probably have similar beliefs and values pertaining to provisions of anesthesia services, there may be slight differences based on the medical and nursing philosophies of practice. In most nurses opinions, nursing practice emphasizes a more "holistic" approach to taking care of patients. For example, in anesthesia care practice, CRNA's are more apt to discuss the process of anesthesia care to patients and family members as a way of promoting effective nurse-client relationships.

Stress in Nurse Anesthesia Practice: Among the potential health hazards of working in an operating room, stress is well recognized. However, despite this wide recognition, there is very little information specifically directed toward understanding the nature of job-related stress among nurse anesthetists. Stress in the workplace can be extremely detrimental. It has been estimated that stressrelated outcomes cost organizations $\$ 50$ billion to $\$ 75$ billion per year (Ray \& Miller, 1994; Kendrick, 2000). These costs are directly related to increased absenteeism, decreased productivity, and increased 
job turnover. In addition, the National Institute for Occupational Safety and Health recognized the significance of occupational stress by declaring stress-related psychological disorders among the 10 leading work-related diseases and injuries (Quick, Murphy \& Hurrell, 1992).

Stress on the job is unavoidable and to a certain degree is desirable. Several factors determine the nature of the individual nurse anesthetist's response to stressful events. In one of the first stressrelated nurse anesthesia studies, Cavagnaro (1983) surveyed 82 CRNAs using a questionnaire. She identified stress factors based on the Stress Audit created earlier by Bailey, Steffen, \& Grout (1980). Respondents in Cavagnaro's (1983) study rated job-related interpersonal conflicts as the number one stressor.

Torgrsen and Chamings (1994), referring to the AANA (1990) study, explain that, in 1990 the Council on Public Interest in Anesthesia (a multidisciplinary body concerned with issues involving public safety in anesthesia care and which acts as an appellate body in credentialing of nurse anesthetists and their educational programs), along with the AANA, and Anesthesia Professional Liability Services, Inc., worked with the St. Paul Fire and Marine Insurance Company to conduct a human factors survey of all AANA members. In the survey, there were indications that CRNA/anesthesiologist relationships were a leading source of workplace stress and job dissatisfaction among CRNAs. The survey also revealed that the quality of the CRNA's relations with coworkers was one of the greatest risk areas affecting health and performance (Kendrick, 2000). Sixty percent of the respondents reported bad feelings between coworkers, and 50\% felt that working with people in general was stressful. In addition, the AANA (1990) study found that CRNAs who practiced in groups with more than 20 CRNAs and anesthesiologists reported more stress and job dissatisfaction than those practicing in smaller groups. Those working in university/hospital settings reported the highest stress.

Because stress is a personal emotion and stressors are perceived by each person, it is important to recognize what the individual caregiver considers to be stressful. Harris (1989) states that stress can be any physical, chemical or emotional factor that causes bodily or mental tension. Commonly used defense mechanisms include denial, intellectualization, reaction formation, and repression. Humor, denial, displacement of affect (anger), and projections are examples of coping strategies that are frequently employed. The success of these defense mechanisms depends on the degree of the 
individual's personal integrity, the range of his/her defense repertory, and the level of his/her coping abilities.

Examples of psychosocial stressors in the workplace, especially in the ACT setting, include responsibility, role ambiguity, role boundary, and concern for quality (Beehr \& Drexler, 1986). Other individual strains can be classified as vocational strain (trouble with quality or quantity of performance), psychological strain (moods and psychological malfunctioning), interpersonal strain (disruption in interpersonal relationships), and physical illness and complaints (Osipow \& Spokane, 1984).

Mitchell (1984) and Mitchell and Bray (1990) have studied the stressors faced by professional caregivers in emergency service areas. They outline techniques to assist caregivers to recognize the manifestations of stress in themselves and in their colleagues. They have also developed a protocol to assist the professional emergency service caregivers to cope effectively with stressors before they become disabling. Situations that Mitchell and Bray (1990) classified as critical incidents include, among others, death in the line of duty, serious injury to emergency personnel, traumatic death of children, and serious injuries to children.

Two different emphases have dominated the studies of organizational variables related to occupational stress and burnout (Maslach \& Jackson, 1984a). One focus has been the nature of the employee's personal relationship with clients. The second emphasis has been on the employeeorganization relationship, control, role clarity, social support, and expectation (Burke \& Richardsen, 1996). Studies generally find that the more stressful the contact with clients is the higher the burnout scores. Studies have also found negative effects stemming from interpersonal relationships with other colleagues. It seems that the nature of interaction with supervisors is related to a number of work stress measures (Bacharach, Bainberger, \& Mitchell, 1990).

Several measures of quantitative workload have been related to occupational stress and burnout. Leiter (1988b, 1991a, 1991b) has consistently found that work overload is significantly related to emotional exhaustion, but does not contribute to depersonalization or personal accomplishment. Role conflict and role ambiguity have been identified as important contributors to the development of occupational stress and burnout. Role conflict is the simultaneous occurrence of two or more sets of 
inconsistent, expected role behaviors (Farber, 1983) representing multiple sources of demand. Role ambiguity is the lack of clear, consistent information regarding the rights, duties, and responsibilities of the job, and how these duties and responsibilities can best be performed. Studies have found that where high levels of role conflict are present, professionals experience high levels of emotional exhaustion and fatigue as well as negative attitudes toward recipients of care (Frieson \& Sarros, 1986).

Lack of control or autonomy in one's job may also contribute to occupational stress and burnout (Jackson, 1983). Autonomy in terms of job content was related to personal accomplishment among teachers (Jackson, Schwab, \& Schuler, 1986). However, Landsbergis (1988) found, among health care workers, that job decision latitude contributed to burnout. Jobs that combined high workload demands with low decision authority were associated with higher levels of job strain.

Lack of social support may lead to occupational stress and burnout. An effective support group includes people who can provide emotional comfort, confront people when behavior is inappropriate, provide technical support in work-related areas, encourage individual growth, serve as active listeners, and share similar values, beliefs, and perceptions of reality (Pines, Aronson, \& Kafry, 1981). There is general agreement that stress-prone individuals are empathetic, sensitive, dedicated, idealistic, and people-oriented, but also anxious, obsessive, over-enthusiastic, and susceptible to overidentification with others (Cherniss, 1980b; Farber, 1983; Freudenberger \& Richelson, 1980).

Although there is a variety of instruments in the literature that measure various components of stress in the workplace, Osipow (1998) constructed a tool that provides the most comprehensive approach in understanding anesthesia care team practice. Osipow (1998) developed the Occupational Stress Inventory (OSI) for two primary reasons: (a) to develop generic measures of occupational stressors that would apply across different occupational levels and environment; and (b) to provide measures for an integrated theoretical model linking sources of stress in the work environment, the psychological strains experienced by individuals as a result of work stressors, and the coping resources available to combat the effects of stressors and to alleviate strain.

Occupational stress is measured by a set of six scales that are collectively called the

Occupational Roles Questionnaire (ORQ). To adequately measure the domain of occupational stress, several work roles that have been associated with stress in the literature were identified and defined ( 
Osipow, 1998; McLean, 1974). The following scales were constructed to measure these stress-inducing work roles: Role Overload (RO), Role Insufficiency (RI), Role Ambiguity (RA), Role Boundary (RB), Responsibility (R), and Physical Environment (PE).

Psychological strain is composed of four scales called the Personal Strain Questionnaire (PSQ), reflecting affective, subjective responses of various types. For the individual who is unable to cope effectively with various stressors in the workplace and/or other settings, strain can be classified into four major categories: Vocational Strain (VS), Psychological Strain (PSY), Interpersonal Strain (IS), and Physical Strain (PHS). Finally, to complete the model, the facets underlying the domain of coping resources were defined. Based largely on a review by Newman and Beehr (1979), coping resources are measured by the following four scaled that constitute the Personal Resources Questionnaire (PRQ): Recreation (RE), Self-Care (SC), Social Support (SS), and Rational/Cognitive Coping (RC).

A number of correlational and multivariate studies have used the OSI as an experimental measure to provide evidence of the relationship between stress, strain, and coping. These studies, according to Osipow (1998) include: Gallagher (1983) examining the relationship of perceived occupational stress to reported physical symptoms; Van Wagoner (1985) addressing stress, locus of control, and non-productive behavior in occupational settings; and, Alexander, Monk, and Jones (1985), investigating occupational stress, personal strain, and coping among medical residents and family members.

In the only study found in the nurse anesthesia literature, emphasizing the OSI, Kendrick (2000) utilizes the OSI to compare stress levels between practicing nurse anesthetists and students of nurse anesthesia educational programs. The study's aim was to compare stress, relationship styles, and interpersonal communication among the different groups. The mean score on the OSI for the four groups in the study (first-year, second-year, and third-year students, and CRNAs) was 133. One of the most interesting findings in Kendrick's (2000) work was how problems with role boundary, a subscale of the ORQ, was found to be the stressor affecting communication the most. According to Osipow and Spokane (1987), subjects scoring high in role boundary report being unclear about authority lines and having more than one person telling them what to do. This certainly applies to student nurse 
anesthetists, Kendrick (2000) implies, when they receive conflicting commands from staff CRNAs, anesthesiologists, surgeons, and didactic faculty members. In addition, CRNAs must deal with conflicting demands made by anesthesiologists and surgeons, as well.

\section{Summary}

It has often been said, according to Foster (1999), that the success of certified registered nurse anesthetists (CRNAs) stems from two sources. First, an enormous commitment to quality patient care services, and second, cost effectiveness. Although the second point may be argued by some, the first clearly cannot be disputed. Nurse anesthesia history has many examples of early CRNAs who were recognized nationally and internationally for their commitment to patient care and developing the pioneering techniques of anesthesia care delivery. However, CRNAs still face a variety of practice barriers in some facilities and health plans, although they can and do serve as the exclusive provider for the full range of anesthesia services at hospitals and ambulatory surgical facilities, and receive direct reimbursement from Medicare and many other health insurance plans.

Both CRNAs and anesthesiologists must always value their individual worth to the health-care delivery system. The challenge to both managed care and anesthesia providers is to overcome barriers and/or restrictions to CRNA scope of practice. The ultimate goal would be to create an anesthesia practice structure with incentives and opportunities for both CRNAs and anesthesiologists to work in a collaborative relationship. In a collaborative practice situation, both anesthesia providers can pool their energies and creativity toward a common goal of quality care. Foster (1999) explains: "Patients will be best served when nurses and physicians alike work in a collaborative fashion that exploits the talents of each; where active, respectful and interdependent consultation among colleagues would be commonplace" (p. 22). Collectively, greater effort should be made to explore each discipline's nature, substance, and potentials that would translate into substantively unique contributions to quality anesthesia care.

Despite the documented benefits of a collaborative relationship between nurses and physicians, collaborative practice remains the exception rather than the normative pattern for nurse-physician interaction. CRNAs and anesthesiologists in the ACT setting perform functions that are more similar than different. Each professional brings clinical expertise that is essential to the practice approaches in 
anesthesia care. Clearly, the ultimate goal of both professionals is in delivering quality anesthesia services. This present study attempts to provide a comprehensive understanding of the nature and characteristics necessary for collaborative practice to occur between CRNAs and anesthesiologist, aimed at improving the well-being of both practitioners. 


\section{CHAPTER III}

\section{METHODOLOGY}

\section{$\underline{\text { Research Design }}$}

A descriptive, correlational survey design was used to examine the relationship between individual CRNA scope of practice and collaboration in ACT settings, and occupational stress. Survey questionnaires are structured self-administered and are a popular method for collecting data to describe, compare, or explain knowledge, attitudes, and behavior (Fink, 1995). The most common way of distributing questionnaires is through the mail. Mailed questionnaires are economical and reach a large population in a relatively short time. One disadvantage of using mailed questionnaires is the potential for a low return rate. Fain (1999) points out that responses from $60 \%$ to $80 \%$ of a sample are considered excellent. Realistically, researchers can expect return rates from $30 \%$ to $60 \%$ for most studies (Dilman, 1978).

A survey design provides a quantitative description of a fraction of the population, which enables the researcher to generalize the findings to a larger population. This design, which is a nonexperimental approach, allows inferences about relationships among variables as they exist in natural setting, without direct intervention (Kerlinger, 1986). Many research studies involving human subjects are non-experimental in nature. The strengths of non-experimental research studies are in the notion that interesting problems to be investigated in nursing and other health related disciplines are not amenable to experimentation or that it is necessary to gain an understanding about the nature of relationships at a descriptive level as the first step in knowledge development. Although these studies do not manipulate or control variables, there are a number of advantages in using a survey design including less cost involved, availability of respondents, and the rapidity of turnover in data collection as well as its suitability for descriptive richness. Using a survey design, the following research questions were examined:

1. What are the characteristics of the anesthesia care team environment based on aspects of individual CRNA scope of practice?

2. What are individual CRNAs reported perceptions of collaboration between CRNAs and anesthesiologists, based on the Weiss and Davis (1985), Collaborative Practice Scale (CPS)? 
3. Is there a relationship between CRNAs reported individual scope of practice in ACT settings and collaboration?

More specifically,

a. Do CRNAs who report restrictions to individual scope of practice perceive lower collaboration?

b. Do CRNAs who report a broader individual scope of practice perceive higher collaboration?

4. Is there a relationship among CRNAs reported scope of practice, perception of collaboration, and occupational stress based on the Osipow (1998) Occupational Stress Inventory (OSI)?

a. When CRNAs report restrictions to individual scope of practice, what is the relationship between their perception of collaboration and occupational stress?

b. When CRNAs report a broader individual scope of practice, what is the relationship between their perception of collaboration and occupational stress?

\section{Sample and Sampling}

The population-base for this study was the active, practicing CRNA members of the American Association of Nurse Anesthetists (AANA). It is estimated that $95 \%$ of all CRNAs in the United States and Puerto Rico hold membership in the AANA (AANA membership, 1999). Although it would have been possible to draw a random sample from the entire listing of CRNAs in the US, it was decided to draw the study sample from the list of CRNAs in the six New England states. This was based on the desire to attain homogeneity in the sample in terms of the variability in the practice of CRNA in relation to anesthesiologists in ACT settings. However, it is believed that the practice characteristics of CRNA in the New England states were typical of those at the national level. The six New England states represented for the study sample were Connecticut (CT), Maine (ME), Massachusetts (MA), New Hampshire (NH), Rhode Island (RI), and Vermont (VT). The study sample was obtained from all certified registered nurse anesthetists (CRNAs) from the six (6) New England states. Based on the most recent AANA (2000) active membership list, the following numbers of CRNAs for each of the six (6) New England states were the bases from which the study sample was obtained: 


$\begin{array}{ll}\text { State } & \text { Certifi } \\ \text { CT } & 284 \\ \text { ME } & 130 \\ \text { MA } & 442 \\ \text { NH } & 108 \\ \text { RI } & 110 \\ \text { VT } & 50 \\ \text { Total (n) } & 1124\end{array}$

The sample size was decided using a power analysis formula (Cohen, 1977). A power analysis is necessary for determining sample size requirements and estimating the likelihood of committing a Type II error. A Type II error can occur when the researcher accepts the null hypothesis when it is false. In this case the researcher concludes that no relationship exists when in fact it does. The sample size was determined in order to fulfill the requirements for an adequate effect size and to perform a four (4) group ANOVA for analysis. The master table for sample size determination indicated that a sample of 192 subjects was needed for a low effect size (0.20), at a power of 0.8 for a $5 \%$ level, two-tailed test (Kraemer \& Thietman, 1987). Because the literature indicated that the general response rate on most surveys is about $30 \%$ to $60 \%$, this study required at least 600 subjects to yield the number of subjects needed for the study. Given that $89 \%$ of the sampled CRNAs practice in ACT settings, it is best to utilize as many CRNAs in the initial sample size. Therefore, all of the CRNA membership from each state was utilized in this study. The names were obtained from the computer listing of all active CRNA members of the American Association of Nurse Anesthetists (AANA), who practice in the six (6) New England states.

The AANA (1999) membership survey showed that $73 \%$ of all CRNAs in the United States and Puerto Rico practice with anesthesiologists in the ACT settings. Based on the AANA (1999) membership survey, the overall response rate was $60 \%$. CRNA respondents from the New England states indicated higher percentages $(89 \%)$ of medical direction than the national average (73\%). The following table represents the percentages of CRNAs practicing in medical direction by 
anesthesiologists in the New England states based those responding to the survey for each state (AANA, 1999).

$\begin{array}{lll}\text { State } & \underline{\text { Valid n }} & \text { Percentage in Medical Direction (\%) } \\ \text { CT } & 151 & 91 \\ \text { ME } & 79 & 75 \\ \text { MA } & 280 & 93 \\ \text { NH } & 62 & 65 \\ \text { RI } & 49 & 90 \\ \text { VT } & 33 & 61 \\ \text { All States } & 14,629 & 73 \text { (national mean) } \\ \text { Overall NE } & 647 & 89 \text { (NE mean) }\end{array}$

\section{Instrumentation}

\section{Individual CRNA Scope of Practice Tool (SOP)}

There are no tools available specifically addressing the measurement of ACT practice characteristics. Many of the tools that describe components of practice have been derived primarily from the AANA annual membership survey. Although an extremely valuable tool, the membership survey fails to address the salient features of practice in the anesthesia care team. For this reason, it was necessary to develop an instrument to solicit information about the respondent's description of their individual ACT setting in this study. The items in the scope of practice tool address the demographics of the individual CRNA respondents, as well as specific scope of practice components.

Promulgated by the research of health care economists (Rosenbach \& Cromwell, 1988;

Cromwell. 1996), indicating the cost effectiveness of CRNA contributions to total anesthesia workload, the AANA (1996) constructed a position statement on nurse anesthetists and anesthesiologists practicing together. Individual CRNA scope of practice items in the tool created for this study were devised from the position statement based on the following concepts: 
a. CRNAs are responsible for their actions in the care of patients and in the provision of anesthesia services.

b. CRNAs practice according to their licensure, certification and expertise.

c. The anesthesiologist is the medical specialist who provides perioperative services and functions collaboratively with the CRNA in the provision of anesthesia and related services.

d. Patient care needs should dictate appropriate personnel resources of both anesthesiologists and CRNAs, rather than predetermined numerical ratios.

The scope of practice (SOP) tool was developed incorporating three components thought critical for the concept pertaining to: (a) the TEFRA (1982) requirements (pre-anesthetic assessment, implementing the anesthesia plan, induction, maintenance, and post-anesthesia care), (b) patient-CRNA interactions, (c) individual CRNA's personal performance of various anesthetic techniques (i.e., general anesthesia, subarachnoid blocks, and epidural anesthesia).

There is a total of 41 items on the SOP tool. These items were pre-tested for content clarity and appropriateness on five CRNAs who were not practicing in the New England states at the time. The scope of practice score is obtained by adding ratings of all items. The range of ratings are 41-205. The SOP tool is shown in Appendix B-Scope of Practice (SOP) tool.

\section{Collaborative Practice Scale (CPS)}

Weiss and Davis (1985) developed the collaborative practice scale (CPS) to assess the degree to which the interactions of nurses and physicians synergistically influence patient care. Two theoretically relevant factors for two scales were delineated as a 9-item scale measuring direct assertion of professional expertise/opinions and active clarification of mutual responsibilities (assertiveness scale), and a 10-item scale measuring acknowledgement of the nurse's and physician's contribution to patient care and consensus development (cooperativeness scale). The CPS (shown in Appendix C) identifies collaboration as having a high degree of both assertiveness and cooperativeness, in contrast to modes in which one may yield completely to the other's concerns, may strive to satisfy one's own concerns with no regard for the other's, or may compromise some important concerns. Collaboration involves attempts to find integrative solutions where both parties' concerns are recognized and 
important concerns are not compromised. It merges the insights of persons with differing perspectives, and consensus is gained among those involved in the problem-solving effort through examination and working through of reservations regarding particular aspects of the decision .

Weiss and Davis (1985) conducted extensive research to determine the validity and reliability of the CPS. In their work, construct validity testing was utilized to closely evaluate the existence of the two dimensions of assertiveness and cooperativeness. Ninety-five (95) nurses and 94 physicians completed the test-retest versions of the scales. In addition, measures of attitudes toward shared responsibility and their mode of handling differences of opinion obtained.

During the analysis, some additional findings emerged that may have implications for predictive validity. First, according to Weiss and Davis (1985), there was a significant difference between male and female physicians in their scores on Factor 2 (cooperativeness). The female physicians $(n=14)$ had higher scores than the male physicians $(n=75)$. Predictive variables for the nurses in the analysis were their educational background and their role in health care. Nurses who described themselves as clinicians $(n=80)$ were significantly lower in their CPS scores $($ mean $=39.2)$ than nurses whose primary role was as an educator, administrator, or researcher $(n=15$, mean $=43.9)$. In addition, nurse with a baccalaureate degree or above $(n=73)$ showed significantly higher Factor 1 (assertiveness) scores (mean $=21.2$ ), than nurses with a diploma or an associate degree.

In their reliability testing, Cronbach's alpha coefficients for nurse and physician CPS scales were reported (Weiss \& Davis, 1985). The alpha coefficients reported were based on initial testing (nurses $=.80$ and physicians $=.84$ ), and re-testing (nurses $=.83$ and physicians $=.85$ ), indicating that total scale and factor coefficients for each scale remained high. Spearman correlations to assess the relationship between factors within the scales, as well as the relationship of factors to the total CPS score, gave further support for the measure's internal consistency. The two factors in the nurse scale were correlated at $r_{I}=.41$, while factors in the physician scale were correlated at $r_{1}=.54$, both with $p<$ .001. Factors were more highly correlated with their total scale scores, ranging from .73 (factor 1 , assertiveness) to .93 (factor 2, cooperativeness) for the nurse CPS, and .87 (factor 1, assertiveness) and .88 (factor 2, cooperativeness) for the physician CPS. Every item on the nurse and physician CPS was also significantly correlated with its factor score as well as its total CPS score. For physicians, the 
correlation ranged from $r_{l}=.51$ to $r_{l}=.77$, and for nurses they ranged from $r_{l}=.52$ to $r_{l}=.80$, all significant at $p<.001$ (Weiss \& Davis, 1985). The scoring of the scale was based on subjects responses of the two dimensions of assertiveness and cooperativeness and total score. The assertiveness scale is based on 9 items which ranges from a low score of 9 to a high score of 54. The cooperativeness scale is based on 10 items which ranges from a low score of 10 to a high score of 60 . The range for total score is 19 to 114 .

The collaborative practice scale in this study is a modification and revision from the original work of Weiss and Davis (1985). Permission to modify the CPS and tailor it to the CRNA/anesthesiologist relationship in anesthesia care team practice was granted by Weiss (Refer to Appendix D-electronic mail letter). Modifications to the tool were primarily focused on replacing the term "physicians" with "anesthesiologists", and using the phrase "anesthesia care decisions" or "anesthesia care plan" instead of "health care decisions" or "health care plan". In order to maintain consistency throughout all of the scales and questionnaires in the study, the range of Likert scale responses was reduced from a 1-6 to 1-5 scale. This decision was made based on the CPS undergoing major revisions, and it would be impossible to change the existing scale in the OSI-R. In the final revision of the CPS, the assertiveness scale is based on 9 items which ranges from a low score of 9 to a high score of 45 . The cooperativeness scale is based on 10 items which range from a low score of 10 to a high score of 50 . The range for total score is 19 to 95 .

\section{Occupational Stress Inventory (OSI)}

Occupational Stress Inventory is composed of three parts measuring occupational stress in terms of occupational role related stress (ORQ), psychological strain (PSQ), and coping resourses (PRQ), and was developed by Osipow \& Spokane(1981, \& 1987; and Osipow, 1998) as shown in Appendix E .Occupational stress in relation to role is measured by a set of six sub-scales that are collectively called the Occupational Roles Questionnaire (ORQ). The following sub-scales were constructed to measure these stress-inducing work roles (Osipow, 1998): Role Overload (RO), Role Insufficiency (RI), Role Ambiguity (RA), Role Boundary (RB), Responsibility (R), and Physical Environment (PE). The ORQ is based on 10 items in each of the six scales, to a total of 60 items. 
Psychological strain called the Personal Strain Questionnaire (PSQ) is composed of four subscales, reflecting affective, subjective responses of various types. For the individual who is unable to cope effectively with various stressors in the workplace and/or other settings, strain can be classified into four major categories: Vocational Strain (VS), Psychological Strain (PSY), Interpersonal Strain (IS), and Physical Strain (PHS). The PSQ is based on 10 items in each of the 4 sub-scales, to a total of 40 items.

Finally, to complete the model, the facets underlying the domain of coping resources were defined. Based largely on a review by Newman and Beehr (1979), coping resources are measured by the following four sub-scales that constitute the Personal Resources Questionnaire (PRQ): Recreation (RE), Self-Care (SC), Social Support (SS), and Rational/Cognitive Coping (RC). The PRQ is based on 10 items in each of the 4 sub-scales, to a total of 40 items.

The initial step in scale construction was a comprehensive definition for each of the facets identified in the model, and establishing validity and reliability testing approaches. Using the definitions as a guide, a pool of items approximately twice the size of the final number of desired items was written for each scale. Items were then selected that appeared to possess the greatest face validity (Osipow, 1998). These items were compiled into Form E-1, the first version of the scales (Osipow \& Spokane, 1981).

Studies were then conducted to determine the reliability and internal consistency of Form E-1 of the OSI. Two-week test-retest reliabilities based on a sample of 31 employed adults for total questionnaire scores (sum of scores across scales) were .90 for the ORQ, .94 for the PSQ, and .88 for the PRQ. Two-week test-retest reliabilities for the individual scales ranged from .56 to .94 (Osipow \& Spokane, 1981).

Based on the data from reliability studies, item changes were made. Many items were reworded and/or replaced. Reliability data also indicated that some scales could be shortened so that each of the scales consisted of equal number of 10 items. The resulting scales, designated as Form E-2 (Osipow \& Spokane, 1983), constituted the form later published as the OSI (Osipow \& Spokane, 1987). For the current OSI-R (Osipow, 1998), a similar process of item modification was used. Those items that had performed less than ideally or that were not clear to respondents, were revised or dropped. In 
the revised version, 26 of the total 140 items were changed or replaced -- 14 items in the ORQ, 6 in the PSQ, and 6 in the PRQ.

Validity data for the OSI and OSI-R are derived from five principle sources: (a) convergent validity studies; (b) factor analyses; (c) correlational studies of the relationships of the scales to variables of practical and theoretical importance; (d) studies using the scales as outcome measures following stress reduction treatment; and (e) studies of the stress, strain, and coping model employing comparisons of selected criterion groups (Osipow, 1998). To date, a number of these studies have appeared in print along with numerous unpublished studies and dissertations.

In order to compare the two OSI versions, data were collected on a sample of 45 highway patrol cadets using both the OSI and the OSI-R. The resulting correlations reflect considerable agreement between the two forms. Each of the 17 correlation coefficients was equal to or greater than .63 and all were statistically significant. Overall, 3 correlations were in the .60 to .69 range, 10 in the .70 to .79 range, 3 in the .80 to .89 range, and 1 in the .90 or above range.

In the final analysis, according to Osipow (1998), "because the correlations of items between the two versions were relatively high, this suggested that the two versions are similar enough to generalize the validity testing" (p. 24). Therefore, validity studies of the original OSI published through 1987 are included in subsequent text in addition to several recent studies using the OSI-R as further validation of the model.

Reliability estimates were conducted in two ways. First, an analysis of test-retest reliability data was conducted by administering the OSI-R to a sample of 62 Air Force cadets over a 2-week period. Correlations among the total questionnaire score and the 14 individual scales of the ORQ, PSQ, and the PRQ, ranged from a low of .39 for Self-Care (SC) to a high of .74 for the total PSQ score. Only two correlations were less than .50 , and all correlations between the two test administrations were significant at the .01 level (Osipow, 1998). The second reliability estimate used was an internal consistency analysis with the normative sample. Alpha coefficients for OSI-R total questionnaire scores were .88 for the ORQ, .93 for the PSQ, and .89 for the PRQ. 


\section{Demographics and Practice Characteristics of CRNAs}

The demographic items included in the questionnaire were (a) employment status and arrangement, (b) practice characteristics in terms of type of setting, in-patient bed-size, trauma center status, the manner in which the CRNA provides services (medically-directed, non-medically directed, or supervised), CRNA/anesthesiologist ratio, (c) primary practice setting state and zip code,, and (d) demographic data on age, gender, years of experience as a CRNA, and educational level (Refer to Appendix A).

\section{Protection of Human Subjects}

The human subject committee of the University of Rhode Island, Office of Compliance granted an expedited institutional review and approval before initiation of the proposed study. An expedited review was granted on January 9, 2001 (Refer to Appendix F). All study procedures were carried out by the principle investigator upon IRB approval. The questionnaires that were mailed out, were accompanied by an explanatory letter which served as the informed consent (Appendix G). Respondents were informed to tear away the letter and keep for their own reference to the study and consent. In an effort to track the response rate and the mailing out of a reminder card, after one month, each envelope had an id number placed for this purpose. The reminder cards (Refer to Appendix $\mathrm{H}$ ) were mailed out by a volunteer research assistant. The research assistant utilized her mailing address, electronic mail address, and phone number, and requested that respondents may contact her for replacement questionnaires. This provided the researcher with further security in maintaining total anonymity of the respondents. In no way was the researcher able to connect respondents to their returned questionnaire forms.

\section{Data Collection}

The data for this study were collected in February of 2001 using the mailed questionnaires. A address list of CRNAs working in the six New England states who were members of AANA in 2001 was obtained so that questionnaires could be distributed to them by mail. Each questionnaire had an id number coded only for the purpose of tracking whether or not the questionnaire was returned. The questionnaires, accompanied by the explanatory letter, and a pre-addressed, stamped envelope was 
mailed out in mid-February, 2001. Respondents were requested to return them by the end of February 2001. Reminder postcards were mailed in early March 2001. The postcard also included a telephone number and email address of a research assistant, if a replacement questionnaire was needed.

- Steps in the Administration of the Survey

1. Mailed survey with a follow-up sequence to obtain high response rate (Babbie, 1990; Creswell, 1994).

2. Initial mailing with cover letter and explanation of project.

3. 2 weeks later, a mailing of a postcard as a reminder to complete and send in the questionnaire. This process was completed within 6 weeks.

4. Each participant was given a complete URI-Institutional Review Board approved informed consent for their own records.

- The mailed questionnaire was constructed in the following order:

1. CRNA demographic \& practice information Questionnaire.

2. Scope of Practice Questionnaire.

3. Collaborative Practice Scale CPS (Weiss \& Davis, 1985), revised with permission.

4. Occupational Stress Inventory (Revised) OSI-R (Osipow, 1998).

\section{Methods of Data Analysis}

All data analyses were carried out using the SPSS-PC program. Descriptive analyses regarding practice characteristics and demographics of the sample were obtained in terms of distribution, frequencies, variability, all measures of central tendency, and SD. In terms of missing data and survey designs, the literature suggests that research results may be jeopardized when missing data reaches $15 \%$ of the sample being studied (Fink, 1995). In the current study, item-item assessment of missing data points ranged from $0-38$, with a mean of only $5 \%$ of the total sample $(n=347)$, therefore lowering the potential for erroneous conclusions. The second set of analysis involved reliability testing using Cronbach's alpha for the measures (SOP, CPS, and OSI) adopted in the study. Sub-scales for each of the measures were then obtained to be applied to testing the study questions. The third set of 
analysis was carried out to examine the research questions advanced in the study, applying correlational analysis, t-test, ANOVA, and partial correlations. 


\section{CHAPTER IV}

\section{RESULTS}

This study examined the relationship between Certified Registered Nurse Anesthetists' (CRNAs') scope of practice and collaboration in anesthesia care team (ACT) settings, and occupational stress. The instruments used were a demographic tool utilized to describe characteristics of the CRNA respondents, a CRNA scope of practice (SOP) tool, developed to solicit information about individual practice in ACTs, a modified version of the Weiss \& Davis (1985) collaborative practice scale (CPS), and the Osipow (1998) occupational stress inventory (OSI). This chapter presents the findings and analyses of the data, describing the sample characteristics first, followed by the analyses related to the measures used in the study, and then the analyses pertaining to the research questions.

\section{Sample Characteristics .. Demographics and Practice}

Questionnaire packets, accompanied by an explanatory letter were mailed to all active, practicing CRNAs from the six (6) New England states $(n=1,124)$ in February of 2001. The packets included the demographic response questionnaire, the scope of practice tool, the collaborative practice instrument, and the occupational stress inventory. Respondents returned the questionnaires throughout February and March of 2001. Reminder postcards were mailed in late March 2001. The postcard also included a telephone number and email address of a research assistant, if a replacement questionnaire was needed. Of the 1,124 distributed questionnaires, 347 (31\%) were completed and returned. All of the returned questionnaires were utilized in the data analysis. As indicated throughout the analyses, several question items were not answered by individual respondents and were identified as "missing data" in the tables. Table 1 provides an overview of each New England state response rate.

In an effort to validate the study population responses as representative of the national population of nurse anesthetists, background characteristics were compared to the available data from 14,629 members of the AANA responding to the 2000 AANA Membership Survey. Since $95 \%$ of nurse anesthetists are members of the professional association (AANA), and 60\% of the members returned the 2000 AANA Membership Survey, including all six New England state members, this data were used to represent the nurse anesthetists profession in several of the questionnaire items. By 
examining the similarities and differences between data sets, it can be seen that demographic characteristics were comparable.

Table 1

Respondents' State of Primary Practice

\begin{tabular}{|c|c|c|c|c|}
\hline & Frequency (n) & $\begin{array}{c}\text { Percent } \\
(\%)\end{array}$ & $\begin{array}{c}\text { Total Possible } \\
\text { Sample n } \\
(\%)\end{array}$ & $\begin{array}{c}\text { Percent } \\
\text { returned } \\
(\%)\end{array}$ \\
\hline State: & & & & \\
\hline Connecticut (CT) & 63 & 18.2 & $284(25.3)$ & 22.2 \\
\hline Maine (ME) & 46 & 13.3 & $130(11.5)$ & 35.4 \\
\hline Massachusetts (MA) & 146 & 42.1 & $442(39.3)$ & 33.0 \\
\hline New Hampshire $(\mathrm{NH})$ & 42 & 12.1 & $108(9.6)$ & 38.9 \\
\hline Rhode Island (RI) & 30 & 8.6 & $110(9.8)$ & 27.3 \\
\hline Vermont (VT) & 11 & 3.2 & $50(4.4)$ & 22.0 \\
\hline Other & 3 & 0.9 & - & - \\
\hline Missing Data & 6 & 1.7 & - & - \\
\hline Total & 347 & 100.0 & $1124(100.0)$ & 30.9 \\
\hline
\end{tabular}


Table 2 identifies CRNA respondents' employment status, employment arrangement, practice setting, and hospital bed size. More than $77 \%(\mathrm{n}=268)$ of the respondents worked full-time, $24 \%$ practiced on a part-time basis (less than 35 hours per week). A majority of the respondents identified their practice arrangement as an anesthesiology group (60.8\%). This is significantly greater than the national survey, which noted this group as $37.9 \%$. Most respondents identified their primary practice setting as a community hospital $(58.8 \%)$, followed by university affiliated at $27.4 \%$, and university medical center at 5.2\%. In the national survey (AANA, 2000), the three hospital settings were combined in the survey to total $82.2 \%$. In regards to hospital bed size, most respondents $(42.2 \%)$ described their primary practice facility as $101-300$ beds. This compares with the national survey of $36.7 \%$.

Table 3 describes the surgical specialty services available at each respondent's primary practice setting. These specialty areas include trauma, obstetrics, cardio-pulmonary, pediatrics, and neurosurgery. Although most specialty services are available in each setting, based on the scope of practice instrument described in the following section, most respondents were not actually administering anesthetics in these specialty areas. It is important to note that, although a clinical setting provides these specialty services, CRNAs are not always involved in these surgical cases. Many time these cases are managed solely by anesthesiologists, further restricting CRNA scope.

In Table 4, respondents' characteristics based on age, gender, and highest level of education and/or credentials are identified. The age range for most respondents (60.8\%) were between 30 and 49 years, with a large number in the 50-64 age group. This statistic compares with the national survey of $61.4 \%$ in the $30-49$ age group. In addition, this trend may influence a rapid change and account for an increase in retirees in the next $10-15$ years. Although very few men enter nursing as a career choice (approximately 6\%), male nurses are over-represented in nurse anesthesia practice. In this study, there were $62.8 \%$ female respondents and $35.2 \%$ males. In the national survey, there were $55.7 \%$ females and $42.3 \%$ male respondents. Although the Council on Accreditation of Nurse Anesthesia Educational programs has mandated the graduate level Master's degree for entry for CRNA practice, only $49.3 \%$ of the respondents were master's prepared, with only $0.3 \%(n=1)$ at the doctoral level. A large number of respondents (19\%) were prepared at the certificate level. Because the national survey does request 
information regarding educational preparation of their respondents, the data was unclear on specific credentials. Therefore, it was difficult to compare this study data with the national survey. Table 5 identifies the number of years respondents have been practicing as a registered nurse $(\mathrm{RN})$ and as a CRNA. The mean number of years as an RN was 23.67, and the mean as a CRNA was 16.50 years.

The characteristic data available in Tables 6,7 , and 8 are of special interest in addressing this study's overall research questions. Table 6 specifically identifies whether the respondent practices in an anesthesia care team (ACT) setting. This is crucial in understanding the relationship among scope of practice and occupational stress variables explained later. More than $88 \%$ of the respondents identified their practice as ACT, compared to $73 \%$ in the national survey data. However, this percentage for the study sample is similar to the percentage (89\%) of all CRNAs in the New England states reported by the AANA membership survey (2000). In addition, it is noted in Table 7 that there are more anesthesiologists practicing in the six New England states than there are CRNAs. This is based on the respondents mean number of anesthesiologists (14.44) practicing in their primary setting compared to 12.33 for CRNAs. This disparity is unusual in the sense that nationally, Medicare and private insurance groups have advocated an increased utilization of CRNAs in ACTs to help reduce the cost of anesthesia services, and increase access especially in medically underserved areas. Finally, Table 8 also points out that most respondents $(85.27 \%)$ describe their practice as medically-directed by an anesthesiologist. Typically, medical direction includes the ability of an anesthesiologist to concurrently direct up to a maximum of four (4) CRNAs.

In an effort to maintain external validity and representativeness in the sample, 1124 questionnaires were mailed out to all practicing CRNAs residing in the six New England states, with an expectation of obtaining at least 200 returns. Based on the sample size determination, at least 192 respondents were required for a low effect size $(0.20)$, at a power of 0.8 for a $5 \%$ level, two-tailed test. Therefore 341 questionnaires were returned representing a return rate of $31 \%$. This was a sufficient rate of response for the sample to assure the principle of sampling effect size and power. In general, the CRNA respondent sample was representative of the New England population of practicing CRNAs, and comparable to the national population of CRNAs 
Table 2

Employment Status, Arrangement, Setting, and Bed Size:

Comparison of the Study Sample and AANA Survey

$$
\text { Frequency (n): } \quad \text { Percent (\%) in Study: } \quad \text { Percent (\%) in }
$$

AANA Survey

\section{Emplovment Status:}

Full-time

268

77.2

75.7

Part-time

72

20.7

24.3

Unemployed

1

0.3

$-$

Missing Data

6

1.7

Total

341

98.3

100

Hospital

78

22.5

33.0

Office/Clinic

6

1.7

1.4

Ambulatory Surgical

2

0.6

1.4

Center

College, University,

School

$$
6
$$

1.7

2.3

Physician group

211

60.8

37.9

CRNA-Only group

3

0.9

3.9

VA Center

7

2.0

1.5 
Table 2 (Continued)

\begin{tabular}{lccc}
\hline $\begin{array}{l}\text { Employment } \\
\text { Arrangement: }\end{array}$ & Frequency (n): & Percent (\%) in Study: & $\begin{array}{c}\text { Percent (\%) in } \\
\text { AANA Survey }\end{array}$ \\
Missing Data & 6 & 1.7 & 2.0 \\
Total & 341 & 98.3 & 93.6 \\
& & & \\
\hline
\end{tabular}

Practice Setting:

Community Hospital

Office

Clinic

Ambulatory Surgical

Center

Other

Missing Data

Hospital Bed Size:

$1-100$

66

147

71

20.5

14.4
204

3

4

14

4.0

0.9

0.5

6

1.7

1.2
10.6

Does not apply

$500+$

36

19

5.6

6.4 
Table 2 (Continued)

\begin{tabular}{lccc}
\hline Hospital Bed Size: & Frequency (n): & Percent (\%) in Study: & $\begin{array}{c}\text { Percent (\%) in } \\
\text { AANA Survey }\end{array}$ \\
Missing Data & 8 & 2.3 & 1.0 \\
Total & 339 & 97.7 & 99
\end{tabular}

* AANA combined all hospital settings (community, university, and medical center) **AANA combined office, clinic and surgical center settings

Table 3

Available Anesthesia Specialty Services in Primary Practice Setting

$$
\begin{array}{llll}
\text { Yes (n) } & \text { Percent (\%) } & \text { No (n) } & \text { Percent (\%) }
\end{array}
$$

\section{Specialty Services:}

\begin{tabular}{lcccc} 
Trauma & 248 & 71.5 & 93 & 26.8 \\
Obstetrical & 265 & 76.4 & 76 & 21.9 \\
Cardio-Pulmonary & 204 & 58.8 & 135 & 38.9 \\
Pediatrics & 302 & 87.0 & 39 & 11.2 \\
Neuro-surgical & 245 & 70.6 & 95 & 27.4 \\
Missing Data & 6 & 1.7 & 6 & 1.7 \\
\hline
\end{tabular}


Table 4

$\underline{\text { Respondents Age, Gender, and Highest Academic Credential: }}$

Comparison of the Study Sample and AANA Survey

$$
\begin{array}{lll}
\text { Frequency }(n) & \text { Percent }(\%) & \text { Percent }(\%) \text { AANA }
\end{array}
$$

\begin{tabular}{lccc}
\hline Age: & & & \\
Under 30 & 1 & 0.3 & 1.1 \\
$30-49$ & 211 & 60.8 & 61.4 \\
$50-64$ & 120 & 34.6 & 32.7 \\
$65+$ & 8 & 2.3 & 1.3 \\
Missing Data & 7 & 2.0 & 3.4 \\
Total & 340 & 98.0 & \\
& & & 96.6 \\
\hline
\end{tabular}

\section{Gender:}

Female

218

62.8

55.7

Male

122

35.2

42.3

Missing data

7

2.0

2.0

Total

340

98.0

98

\section{Highest Credential:}

Diploma/Certification

66

19.0

Associate Degree

13

3.7 
Table 4 (Continued)

\begin{tabular}{lccc}
\hline Highest Credential: & Frequency (n) & Percent (\%) & Percent (\%) AANA \\
$\begin{array}{l}\text { (Continued) } \\
\text { Bachelors Degree }\end{array}$ & 89 & 25.6 & $*$ \\
Masters Degree & 171 & 49.3 & $*$ \\
Doctoral Degree & 1 & 0.3 & $*$ \\
Missing Data & 7 & 7 & $*$ \\
Total & 340 & 340 & $*$ \\
& & & \\
\end{tabular}

*Not specifically available in AANA survey results

Table 5

Number of Years as an RN and as a CRNA

\begin{tabular}{lcccc}
\hline & Respondents (n) & Range & $\begin{array}{c}\text { Mean in } \\
\text { years }\end{array}$ & Standard Deviation \\
\hline \# Years as RN & 341 & $4-47$ & 23.67 & 8.76 \\
\# Years as CRNA & 340 & $1-42$ & 16.50 & 10.27 \\
& & & & \\
\hline
\end{tabular}

Table 6

\section{Anesthesia Care Team as Primary Practice Setting}

\begin{tabular}{lccc}
\hline \multicolumn{1}{c}{ Response: } & Frequency (n) & Percent (\%) & \% AANA* \\
\hline ACT (yes) & 308 & 88.8 & 73 \\
ACT (no) & 33 & 9.5 & 27 \\
Missing Data & 6 & 1.7 & -- \\
Total & 341 & 98.3 & -- \\
\hline *AANA provides mean values for percentage of medical direction
\end{tabular}


Table 7

Number of CRNAs and Anesthesiologists in Primary Practice Setting

\begin{tabular}{lcccc}
\hline & Respondents (n) & Range & $\begin{array}{c}\text { Mean } \\
\text { Number }\end{array}$ & Standard Deviation \\
\hline \# of CRNAs & 335 & $1-60$ & 12.33 & 9.92 \\
\# of MDAs & 335 & $0-80$ & 14.44 & 15.50 \\
\hline
\end{tabular}

Table 8

Medical Direction in Primary Practice Setting

\begin{tabular}{lcc}
\hline & Respondents (n) & $\begin{array}{c}\text { Percentage } \\
(\boldsymbol{\%})\end{array}$ \\
\hline Medically Directed & 290 & 85.27 \\
Non-medically Directed & 23 & 6.82 \\
Unsupervised & 28 & 8.11 \\
Total & 341 & 100 \\
\hline
\end{tabular}

\section{Findings Related to the Measures in the Study}

\section{Scope of Practice Tool}

Overview of Results. The scope of practice (SOP) tool was developed and utilized to solicit information regarding respondents' practice in ACTs. Only those respondents who identified their primary practice setting as ACT were asked to answer the SOP questions. Each item in the SOP tool reflects specific practice components. The items included questions ranging from the pre-anesthesia evaluation, development of an anesthesia care plan, intra-operative care, post-anesthesia care, and specific anesthesia care procedures and skills, as described in the preceding chapter.

There were a total of 41 items on the SOP tool. The score on the SOP tool was obtained by adding ratings of all items, with a score range of 41-205. In Table 9, the mean score and standard deviation for each of the items for Part I of the SOP tool are shown. The items for Part I for the 
questions \#1-24 pertain to specific anesthesia care activities based on the AANA (1996) position paper addressing nurse anesthetists practicing together with anesthesiologists. In questions $1-4$, the focus is on the pre-anesthesia patient assessment and acquisition of informed consent. The mean scores in these items (2.23-2.77) indicates that CRNAs practicing in ACTs are only occasionally to half of the time, performing these functions. Incidentally, this is the most critical time in forming a relationship with the patient---a primary nursing role responsibility. Mean scores on SOP questions 5, 6, and 9 were 2.553.60, indicating that CRNAs in ACTs are actively engaged in ordering pre-anesthetic medications, and developing an anesthesia care plan. However, SOP questions 7 and 8 reveal lower mean scores (1.781.93), in activities associated with requesting consultations and diagnostic tests/studies.

Respondents scored higher means in SOP questions 10 and 11 (4.10-4.15), which clearly shows the involvement of CRNAs in initiating the planned anesthetic, and discussing the process with the patient. Most of the SOP item questions related to the intraoperative phase of the anesthesia process (questions 10-18) report higher mean scores. In question 12, which focuses on managing an induction without an anesthesiologist present, the mean score was lower at 2.04. Indicating that CRNAs are less frequently personally performing an anesthetic induction without medical direction.

As described earlier, CRNAs practicing in ACTs are less often involved with the activities associated with the pre-anesthetic evaluation and interacting with the patient. This same phenomenon also occurs in the post-anesthesia phase of the patient's experience. Lower mean score were reported in questions 19-21 (1.34-2.44), suggesting that CRNAs are never or only occasionally personally involved with post-anesthesia follow-up and discharging patients from post-anesthesia recovery areas.

Table 10 represents the remaining SOP questionnaire items (Part II) reflecting CRNA responses in the personal performance of specific anesthetic techniques and types of specialty cases. In relation to personally performing general anesthesia and monitored anesthesia care (MAC), in questions 25 and 31 , as suspected, mean scores were significantly higher (4.71 \& 4.77). However in items focusing on other techniques including performing subarachnoid blocks, epidural anesthesia, brachial plexus blocks, in questions $26-28$, the mean scores were significantly lower (1.37-2.81). This may suggest that anesthesiologists may be performing these procedures, further limiting the CRNA's individual scope of practice, or, merely that these procedures are not performed very often. 
It was found that most CRNAs in ACTs are personally performing the insertion of arterial lines, with a mean score of 3.46. However, the insertion of pulmonary artery catheters and central venous catheters are performed less frequently (mean scores of $1.52 \& 1.82$ ). This may also indicate that the anesthesiologists may be performing these procedures or, these procedures are less frequently required for surgery. There has been a significant trend toward less frequent utilization of invasive monitoring devices for surgical procedures in the past 10 years, which may contribute to the lowered mean scores in this case.

Finally, although many of the respondents identified the inclusion of the five specialty anesthetic services presented in Table 10 (including trauma, obstetrics, cardio-pulmonary, pediatrics, and neuro-surgical), very few actually were personally involved in these anesthetic cases. The highest mean score (3.57) was reported in providing anesthesia services to pediatric patients. Very few respondents (mean of 1.34) were personally involved with managing the anesthesia related to cardiopulmonary surgery and bypass. This may be related to the limited number of acute care hospitals providing cardio-pulmonary services and surgery. Another suggestion is that respondents may be personally involved with the anesthesia for thoracic cases and not cardiac cases. This indicates the need to separate out these two distinct case populations in further research using the SOP tool.

Reliability of the SOP Tool. Inter-item correlations among the total questionnaire scores and the 2 individual scales; Scale A (items 1-24) reflecting anesthesia care activities from pre-anesthesia to post anesthesia care, and Scale B (items 25-41) reflecting personal performance of anesthesia techniques and specialty scores were conducted, and shown in Appendix I. There were no substantial or significant negative correlations in the item-to-item relations, which suggests that the tool is within the same theoretical structure.

Studies were conducted to determine the reliability of the SOP tool by Cronbach's alpha coefficients for Scale A, B, and total questionnaire. Thus, total scale and individual sub-scales factor coefficients for each were high upon the reliability testing as shown in Table 4. These findings indicated that the SOP tool developed in this study is a reliable measure with a high degree of internal consistency in examining CRNAs scope of practice in ACTs. 
Table 9

Scope of Practice Tool with Mean Scores and Standard Deviations (Questions 1-24)

\begin{tabular}{llll}
\hline Question Items & N & Mean Score & $\begin{array}{c}\text { Standard } \\
\text { Deviation }\end{array}$ \\
\hline
\end{tabular}

(Range for each item $=1$ to 5 )

1. Perform pre-anesthetic assessment.

2. Document pre-anesthetic assessment.

3. Discuss the purpose, risks, and benefits of the anesthetic with the patient

4. Obtain informed consent from the patient and/or designated person.

5. Order pre-anesthetic medications.

6. Administer pre-anesthetic medications.

7. Requests consultations.

310

2.77

1.25

310

2.82

1.30

310

2.89

1.20

8. Request diagnostic tests/studies.

309

309

2.55

306

3.60

1.23

309

1.78

.83

310

1.93

.75

9. Develop, implement the anesthesia plan.

305

3.60

1.11

10. Initiate the planned anesthetic technique (general, regional, or sedation).

307

4.10

.95

11. Discuss the process in induction of general anesthesia with the patient.

310

4.15

.99

12. Manage the induction of anesthesia without anesthesiologist presence.

13. Administer anesthetics and adjunct drugs.

309

2.04

1.05

309

4.75

.55

14. Monitor the patient's response to surgery and anesthesia.

15. Select and apply appropriate non-invasive monitoring modalities.

16. Select and insert appropriate invasive monitoring modalities.

17. Manage the patient's airway and pulmonary status.

310

4.96

310

4.79

310

3.25

18. Manage emergence and recovery from anesthesia without anesthesiologist presence.

19. Provide post-anesthesia evaluation and care.

20. Communicate with the patient during the post-

21. Discharge patients from the post-anesthesia care area.

22. Initiate and modify pain relief therapy.

23. Discuss the pain management plan with the patient. 


\section{Table 10}

\section{Scope of Practice Tool with Mean Scores and Standard Deviations (Questions 25-41)}

\section{Question Items}

(Range for each item $=1$ to 5)

25. Administer General anesthesia.

26. Administer Subarachnoid Block.

27. Administer Epidural anesthesia.

28. Administer Brachial Plexus Block.

29. Administer Bier Block.

30. Administer Ophthalmologic Block.

31. Manage Monitored Anesthesia Care (MAC).

32. Manage Acute Pain.

33. Manage Chronic Pain.

34. Insert Arterial Catheters.

35. Insert Pulmonary Artery Catheters.

36. Insert Central Venous Pressure Catheters.

37. Manage Cardio-pulmonary Bypass Anesthesia.

38. Manage Obstetric Anesthesia.

39. Manage Pediatric Anesthesia.

40. Manage Intra-cranial Anesthesia.

41. Manage Trauma Anesthesia.

\section{N Mean Score}

310

312

311

312

310

312

312

311

312

312

312

312

312

312

312

312

312

4.71

2.81

1.94

1.37

3.55

1.08

4.77

3.20

1.28

3.46

1.57

1.82

1.34

2.22

3.57

2.90

2.73
Standard

\section{Deviation}

68

\subsection{4}

1.37

.89

1.54

.44

.68

1.53

.76

1.30

1.14

1.24

.96

1.39

1.44

1.61

1.45 
Table 11

Scope of Practice Tool Scale Range, Means, and Standard Deviations

\begin{tabular}{|c|c|c|c|c|c|}
\hline $\begin{array}{l}\text { Scope of Practice Tool } \\
\text { (SOP) }\end{array}$ & $\begin{array}{l}\text { Scale } \\
\text { Range }\end{array}$ & $\begin{array}{l}\text { Scale } \\
\text { Means }\end{array}$ & $\begin{array}{c}\text { Scale } \\
\text { Variance }\end{array}$ & $\begin{array}{l}\text { Standard } \\
\text { Deviation }\end{array}$ & $\begin{array}{c}\text { Alpha } \\
\text { Coefficient }\end{array}$ \\
\hline $\begin{array}{l}\text { Scope of Practice (A) } \\
\text { Items 1-24 } \\
\text { (Anesthesia Process) }\end{array}$ & $24-120$ & 74.86 & 140.97 & 11.87 & .85 \\
\hline $\begin{array}{c}\text { Scope of Practice (B) } \\
\text { Items } 25-41 \\
\text { (Anesthesia Procedures) }\end{array}$ & $17-85$ & 44.26 & 102.84 & 10.14 & .79 \\
\hline $\begin{array}{l}\text { Scope of Practice }(\mathrm{T}) \\
\text { Items } 1-41\end{array}$ & $41-205$ & 119 & 351.39 & 18.75 & .87 \\
\hline
\end{tabular}

\section{Collaborative Practice Scale}

Overview of Results. A modified Weiss and Davis (1985) collaborative practice scale (CPS) was used to assess individual CRNA's perception of collaborative practice in ACTs. -Only those respondents that perceived their practice as ACT were asked to answer the CPS questions. As mentioned in Chapter III, the CPS consists of two theoretically relevant factors which delineates two scales, a 9-item scale measuring the degree with which the CRNA directly asserts professional expertise and opinions when interacting with the anesthesiologist in ACT. Cooperativenss reflects the degree with which the CRNA clarifies with the anesthesiologist mutual expectations regarding the nature of shared responsibilities in patient care.

Tables 12 and 13 provides an item by item mean score of the respondents on the CPS instrument. Tables 14 and 15 provide an overview of the frequencies of assertiveness and cooperativeness based on high, low, and intermediate degrees. The results in this study revealed that the overall mean CPS scores (the combination of both scales) was 53.81 with a range of 19-95. The CPS-assertiveness mean score was 24.16, with a range of 9-45 and, the CPS-cooperativeness mean score was 29.67 , with a range of $10-50$. Although the study respondents did not perceive their practice in ACTs as highly collaborative, the mean results were greater than previously reported CRNA studies. 
Torgensen and Chamings (1994) reported lower mean scores on both CPS-A and CPS-C. Their reported mean values were 19.55 for CPS-A, and 20.38 for CPS-C. Although there are differences between these two sets of results, it is important to understand that each study examined very different CRNA respondents. In the Torgensen and Chamings (1994) study, the sample consisted of CRNAs $(n=60)$ practicing with anesthesiologists in nurse anesthesia educational programs. In the current study, only $1.7 \%(n=6)$ identified their practice arrangement as in a college, university, or school. Therefore, the results in the present study are more representative of CRNAs in general, based on settings and arrangements, in terms of understanding degrees of collaborative practice.

Table 12

\section{Collaborative Practice Scale with Item Mean Scores and Standard Deviations}

\section{(Assertiveness Questions 1-9)}

\begin{tabular}{|c|c|c|c|}
\hline $\begin{array}{l}\text { Question Items } \\
\text { (Range for each item }=1 \text { to } 5 \text { ) }\end{array}$ & $\mathbf{N}$ & $\begin{array}{l}\text { Item } \\
\text { Mean }\end{array}$ & $\begin{array}{l}\text { Standard } \\
\text { Deviation }\end{array}$ \\
\hline $\begin{array}{l}\text { I. ask anesthesiologists about their expectations } \\
\text { regarding the degree of my involvement in anesthesia } \\
\text { care decisions. }\end{array}$ & 309 & 1.92 & 1.04 \\
\hline $\begin{array}{l}\text { 2. I negotiate with the anesthesiologist to establish our } \\
\text { responsibilities for discussing different kinds of } \\
\text { information with patients and families. }\end{array}$ & 309 & 1.84 & 1.08 \\
\hline $\begin{array}{l}\text { 3. I clarify the scope of my professional expertise when it } \\
\text { is greater than the anesthesiologist thinks it is. }\end{array}$ & 309 & 2.94 & 1.47 \\
\hline $\begin{array}{l}\text { 4. I discuss with the anesthesiologist the degree to which I } \\
\text { want to be involved in planning aspects of patient care. }\end{array}$ & 309 & 2.77 & 1.45 \\
\hline $\begin{array}{l}\text { 5. I suggest to the anesthesiologist patient care approaches } \\
\text { that I think would be useful. }\end{array}$ & 309 & 3.71 & 1.19 \\
\hline $\begin{array}{l}\text { 6. I discuss with the anesthesiologist areas of practice that } \\
\text { reside more within the realm of nursing than medicine. }\end{array}$ & 309 & 1.94 & 1.17 \\
\hline $\begin{array}{l}\text { 7. I tell the anesthesiologist when, in my judgement, } \\
\text { his/her anesthesia care orders seem inappropriate. }\end{array}$ & 309 & 3.31 & 1.48 \\
\hline $\begin{array}{l}\text { 8. I tell the anesthesiologist of any difficulties I foresee in } \\
\text { the patient's ability to deal with anesthesia care options } \\
\text { and their consequences. }\end{array}$ & 309 & 3.89 & 1.25 \\
\hline $\begin{array}{l}\text { 9. I inform the anesthesiologist about areas of practice } \\
\text { that are unique to nurse anesthesia. }\end{array}$ & 309 & 1.86 & 1.24 \\
\hline CPS-A: Assertiveness Scale (Range $=9$ to 45 ) & 309 & 24.16 & 7.31 \\
\hline
\end{tabular}




\section{Table 13}

Collaborative Practice Scale with Mean Scores and Standard Deviations

\section{(Cooperativeness Questions 10-19)}

\begin{tabular}{llll}
\hline Question Items & N & Mean Score & $\begin{array}{c}\text { Standard } \\
\text { Deviation }\end{array}$
\end{tabular}

(Range for each item $=1$ to 5 )

10. I reinforce the value of medical care by the

$308 \quad 2.55 \quad 1.36$

anesthesiologist when talking to patients.

11. I ask the anesthesiologist's assessment of

308

2.51

what may be needed to strengthen the patient's response to anesthesia.

12. I discuss with the anesthesiologist the similarities and differences in nursing and medical approaches to patient care.

13. I consider the anesthesiologist's opinion when developing an anesthesia care plan.

14. I discuss areas of agreement and disagreement

with the anesthesiologist in an effort to develop mutually agreeable anesthesia care goals.

15. I discuss with the anesthesiologist the degree planning and implementing aspects of anesthesia care.

16. I work toward consensus with the anesthesiologist regarding the best approach in caring for the patient.

17. I discuss with the anesthesiologist his/her expectations regarding the degree of their involvement in the anesthesia care decisionmaking process.

18. I acknowledge to the anesthesiologist those aspects of anesthesia care where he/she has more expertise than I do.

19. I clarify whether the anesthesiologist or I will have the responsibility for discussing different kinds of information with patients and/or families. 
Reliability of the Collaborative Practice Scale (CPS). Inter-item correlations among the total questionnaire scores and the 2 individual scales; CPS-A (assertiveness) measuring CRNA assertion of professional expertise/opinion, and CPS-C (cooperativeness) measuring CRNA clarification of mutual responsibilities for patient care were conducted, and are shown in Appendix J. There were no significant negative correlations found in the analysis. Reliability testing using Cronbach's alpha coefficients for the total CPS (CPS-T), CPS-A (assertiveness), and CPS-C (cooperativeness) are reported in Table 16, and includes the original reliability and validity testing conducted on the CPS by Weiss and Davis (1985). Total scale and factor coefficients for each were high upon reliability testing and comparable to the alpha coefficients reported in the original study by Weiss and Davis (1985). This analyses indicated that the CPS tool is a reliable tool that measures assertiveness and cooperativeness, with a high degree of internal consistency in a similar way as reported in the original tool development.

\section{Table 14}

Collaborative Practice Scale with Frequency in CPS

(Assertiveness) Questions 1-9

\begin{tabular}{lccc}
\hline \multicolumn{1}{c}{ Assertiveness (CPS-A) } & Range of Scores & $\begin{array}{c}\text { Frequency } \\
(\mathbf{N})\end{array}$ & $\begin{array}{c}\text { Percent } \\
(\mathbf{\%})\end{array}$ \\
\hline Low CPS-A & $9-20$ & 105 & 30.3 \\
Intermediate CPS-A & $21-32$ & 166 & 47.8 \\
High CPS-A & $33-45$ & 38 & 11.0 \\
Total (N) & & $\mathbf{3 0 9}$ & \\
\hline
\end{tabular}

Table 15

Collaborative Practice Scale with Frequency in CPS

(Cooperativeness) Questions 10-19

\begin{tabular}{lccc}
\hline Cooperativeness (CPS-C) & Range of Scores & $\begin{array}{c}\text { Frequency } \\
(\mathbf{N})\end{array}$ & $\begin{array}{c}\text { Percent } \\
(\boldsymbol{\%})\end{array}$ \\
\hline Low CPS-C & $10-23$ & 72 & 20.7 \\
Intermediate CPS-C & $24-36$ & 186 & 53.6 \\
High CPS-C & $37-50$ & 50 & 14.4 \\
Total (N) & & $\mathbf{3 0 8}$ & \\
\hline
\end{tabular}


Table 16

\section{Alpha Coefficients for Collaborative Practice Scale and}

\section{Comparison to Reported Reliability Analyses}

\begin{tabular}{ccc}
\hline $\begin{array}{c}\text { Collaborative Practice } \\
\text { Scale (CPS) } \\
\text { Factors }\end{array}$ & $\begin{array}{c}\text { Alpha Coefficients } \\
\text { (CRNA Study } \\
\text { Respondents) }\end{array}$ & $\begin{array}{c}\text { Alpha Coefficients } \\
\text { (Reported RN Respondents; } \\
\text { Weiss \& Davis, 1985) }\end{array}$ \\
\hline $\begin{array}{c}\text { CPS Questions 1-9 } \\
\text { (Assertiveness) } \\
\text { Factor 1 }\end{array}$ & .82 & .73 \\
$\begin{array}{c}\text { CPS Questions 10-19 } \\
\text { (Cooperativeness) } \\
\text { Factor 2 }\end{array}$ & .82 & .77 \\
CPS Questions 1-19 \\
(Total Score)
\end{tabular}

\section{Occupational Stress Inventory}

The OSI-R is a concise measure of 3 dimensions of occupational role relatëd stress:

occupational stress (ORQ), psychological strain (PSQ), and coping resources (PRQ). The occupational stress domain is assessed by a set of 6 scales that are collectively called the "Occupational Roles Questionnaire" (ORQ). The ORQ scales include: Role Overload, Role Insufficiency, Role Ambiguity, Role Boundary, Responsibility, and Physical Environment.

In the present study all respondents were asked to complete the Occupational Stress Inventory. Revised (OSI-R). Table 17 presents the descriptive statistics for each scale in the OSI-R with reported means and standard deviations for all respondents in the sample, with comparison to reported analysis from Ospipow (1998), which utilized a sample of 45. In comparison to Osipow's (1998) findings, there were no significant differences in mean scores on each of the OSI-R subscales in the study respondents.

For the ORQ and PSQ scales, high scores suggest significant levels of occupational stress and psychological strain, respectively. Total scores above 70 indicate a strong probability of maladaptive stress, debilitating strain, or both (Osipow, 1998). Total scores in the range of 60-69 suggest mild 
levels of maladaptive stress and strain. Total scores in the range of 40-59 are within one standard deviation of the mean and should be interpreted as being within normal range. Scores below 40 indicate a relative absence of occupational stress or psychological strain (Osipow, 1998). For the PRQ scales, high scores indicate highly developed coping resources. For these scales, total scores below 30 indicate a significant lack of coping resources. Total scores in the range of 30-39 suggest mild deficits in coping skills. Total scores in the range of 40-59 indicate average coping resources, whereas higher total scores (>60) indicates increasingly strong coping resources (Osipow, 1998).

The sample distribution based on total scores on the ORQ, PSQ, and PRQ, are presented in Table 18. Interestingly, none of the respondents scored less than 70 on the ORQ subscale, suggesting that CRNA respondents are experiencing higher levels of occupational role stress, in general. CRNA scores on the PSQ showed that $63.7 \%(n=221)$ identified with greater than 60 scores, and $25.4 \%(n=$ 88 ) had scores between 40-59. This suggests that a majority of respondents experience higher levels of psychological strain. In terms of the PRQ, a majority of respondents $(90.5 \%, n=314)$ were more likely to have highly developed coping resources to deal with role stress and psychological strain.

Although this study concentrates on understanding occupational stress in terms of anesthesia care team practice, data was also collected in reference to those CRNA respondents $(n=31)$ who did not identify their primary practice as ACT. Table 19 provides the means, standard deviations, and ttesting for non-ACT respondents. There are no reported significant differences between ACT and nonACT respondents in terms of the OSI-R. Mean values for each scale and sub-scale of the OSI-R were almost identical in the two groups. Therefore, occupational stress is not a determining factor in relation to working in a team setting and/or in a non-team setting. 
Table 17

Descriptive Statistics for Occupational Stress Inventory-Revised (OSI-R):

Study Sample Compared with Reported Scale Score Samples

Study Sample

Osipow (1998)

\begin{tabular}{lccccc}
\hline $\begin{array}{l}\text { OSI-R Scales and } \\
\text { Sub-Scales }\end{array}$ & Range & Mean & $\begin{array}{c}\text { Stand. } \\
\text { Dev. }\end{array}$ & Mean & $\begin{array}{c}\text { Stand. } \\
\text { Dev. }\end{array}$ \\
\hline $\begin{array}{l}\text { Occupational Roles } \\
\text { Questionnaire (ORQ) }\end{array}$ & & & & & \\
Role Overload (RO) & $10-50$ & 19.75 & 5.68 & 26.42 & 6.00 \\
Role Insufficiency (RI) & $10-50$ & 21.02 & 7.16 & 18.82 & 6.51 \\
Role Ambiguity (RA) & $10-50$ & 19.05 & 5.43 & 19.84 & 6.34 \\
Role Boundary (RB) & $10-50$ & 21.00 & 6.41 & 22.18 & 6.25 \\
Responsibility (R) & $10-50$ & 26.29 & 5.77 & 27.80 & 5.35 \\
Physical Environment (PE) & $10-50$ & 23.38 & 7.14 & 29.56 & 9.19 \\
Total ORQ Score & $60-300$ & 131.38 & 25.05 & 130.49 & 20.62 \\
\hline
\end{tabular}


Table 17 (Continued)

Study Sample $\quad \underline{\text { Osipow (1998) }}$

\begin{tabular}{|c|c|c|c|c|c|}
\hline $\begin{array}{l}\text { OSI-R Scales and } \\
\text { Sub-Scales }\end{array}$ & Range & Mean & $\begin{array}{l}\text { Stand. } \\
\text { Dev. }\end{array}$ & Mean & $\begin{array}{l}\text { Stand. } \\
\text { Dev. }\end{array}$ \\
\hline \multicolumn{6}{|c|}{$\begin{array}{l}\text { Personal Strain Questionnaire } \\
\text { (PSQ) }\end{array}$} \\
\hline Vocational Strain (VS) & $10-50$ & 14.54 & 4.17 & 16.18 & 6.12 \\
\hline Psychological Strain (PSY) & $10-50$ & 18.29 & 6.71 & 20.82 & 7.60 \\
\hline Interpersonal Strain (IS) & $10-50$ & 18.91 & 5.32 & 21.68 & 6.67 \\
\hline Physical Strain (PHS) & $10-50$ & 19.80 & 6.84 & 19.78 & 7.29 \\
\hline Total PSQ Score & $40-200$ & 71.33 & 19.35 & 77.55 & 23.73 \\
\hline \multicolumn{6}{|l|}{$\begin{array}{l}\text { Personal Resources } \\
\text { Questionnaire }(P R Q)\end{array}$} \\
\hline Recreation (RE) & $10-50$ & 30.18 & 7.33 & 28.71 & 5.62 \\
\hline Self-Care (SC) & $10-50$ & 29.02 & 6.44 & 28.82 & 5.89 \\
\hline Social Support (SS) & $10-50$ & 43.00 & 7.23 & 42.60 & 7.54 \\
\hline Rational/Cognitive (RC) & $10-50$ & 37.41 & 5.68 & 36.84 & 6.30 \\
\hline Total PRQ Score & $40-200$ & 139.37 & 19.85 & 136.98 & $18 . \overrightarrow{59}$ \\
\hline
\end{tabular}


Table 18

Sample Distribution for

Occupational Stress Inventory-Revised (OSI-R):

Total Scores for OSI-R Frequency Percentage

(n) (\%)

\begin{tabular}{|c|c|c|}
\hline $\begin{array}{l}\text { Occupational Roles } \\
\text { Questionnaire (ORQ) }\end{array}$ & & \\
\hline$>70$ & 288 & $82.9 \%$ \\
\hline $60-69$ & 0 & 0 \\
\hline $40-59$ & 0 & 0 \\
\hline$<40$ & 0 & 0 \\
\hline Missing Data & 59 & $17.1 \%$ \\
\hline Total (n) & 347 & \\
\hline $\begin{array}{l}\text { Psychological Strain } \\
\text { Questionnaire (PSQ) }\end{array}$ & & \\
\hline$>60$ & 221 & $63.7 \%$ \\
\hline $40-59$ & 88 & $25.4 \%$ \\
\hline $30-39$ & 0 & 0 \\
\hline$<30$ & 0 & 0 \\
\hline Missing Data & 38 & $10.9 \%$ \\
\hline Total (n) & $347^{\circ}$ & \\
\hline $\begin{array}{l}\text { Personal Resources } \\
\text { Questionnaire (PRQ) }\end{array}$ & & \\
\hline$>60$ & 314 & $90.5 \%$ \\
\hline $40-59$ & 0 & 0 \\
\hline $30-39$ & 0 & 0 \\
\hline$<30$ & 0 & 0 \\
\hline Missing Data & 33 & $9.5 \%$ \\
\hline Total (n) & 347 & \\
\hline
\end{tabular}


Table 19

Means, Standard Deviation, and T-test Comparing Occupational Stress Inventory-Revised (OSI-

R) with ACT and Non-ACT Practice Settings

ACT

NON-ACT

T-test

\begin{tabular}{|c|c|c|c|c|c|c|c|}
\hline $\begin{array}{l}\text { OSI-R Scales and } \\
\text { Sub-Scales }\end{array}$ & Range & Mean & $\begin{array}{l}\text { Stand. } \\
\text { Dev. }\end{array}$ & Mean & $\begin{array}{l}\text { Stand. } \\
\text { Dev. }\end{array}$ & F-value & Sig. \\
\hline \multicolumn{8}{|l|}{$\begin{array}{l}\text { Occupational Roles } \\
\text { Questionnaire (ORQ) }\end{array}$} \\
\hline Role Overload (RO) & $10-50$ & 19.87 & 5.08 & 20.65 & 6.74 & .51 & .49 \\
\hline Role Insufficiency (RI) & $10-50$ & 21.07 & 7.20 & 20.63 & 6.49 & .35 & .74 \\
\hline Role Ambiguity (RA) & $10-50$ & 19.03 & 5.33 & 19.00 & 5.18 & .90 & .98 \\
\hline Role Boundary (RB) & $10-50$ & 22.09 & 6.31 & 22.10 & 7.88 & .03 & .99 \\
\hline Responsibility (R) & $10-50$ & 26.31 & 5.76 & 27.32 & 6.26 & .43 & .36 \\
\hline $\begin{array}{l}\text { Physical Environment } \\
\text { (PE) }\end{array}$ & $10-50$ & 23.62 & 7.27 & 22.84 & 8.13 & .37 & .57 \\
\hline \multicolumn{8}{|l|}{ Total ORQ Score } \\
\hline $\begin{array}{l}\text { Personal Strain } \\
\text { Questionnaire (PSQ) }\end{array}$ & & & & & & \multicolumn{2}{|l|}{-} \\
\hline Vocational Strain (VS) & $10-50$ & 14.60 & 4.10 & 14.77 & 5.35 & .48 & .84 \\
\hline $\begin{array}{l}\text { Psychological Strain } \\
\text { (PSY) }\end{array}$ & $10-50$ & 18.48 & 6.71 & 18.53 & 7.16 & .42 & .97 \\
\hline Interpersonal Strain (IS) & $10-50$ & 19.08 & 5.27 & 19.60 & 6.73 & .22 & .62 \\
\hline Physical Strain (PHS) & $10-50$ & 20.07 & 7.01 & 21.00 & 8.18 & .39 & .50 \\
\hline Total PSQ Score & $40-200$ & 71.97 & 19.27 & 73.90 & 22.54 & .42 & .61 \\
\hline $\begin{array}{l}\text { Personal Resources } \\
\text { Questionnaire (PRQ) }\end{array}$ & & & & & & & \\
\hline Recreation (RE) & $10-50$ & 30.03 & 7.28 & 31.03 & 7.72 & .86 & .46 \\
\hline Self-Care (SC) & $10-50$ & 28.91 & 6.34 & 29.70 & 7.23 & .52 & .52 \\
\hline Social Support (SS) & $10-50$ & 42.95 & 7.10 & 44.43 & 6.76 & .32 & .27 \\
\hline $\begin{array}{l}\text { Rational/Cognitive } \\
\text { (RC) }\end{array}$ & $10-50$ & 37.34 & 5.71 & 37.01 & 7.29 & .03 & .83 \\
\hline Total PRQ Score & $40-200$ & 138.95 & 19.43 & 142.76 & 20.97 & .46 & .32 \\
\hline
\end{tabular}


Reliability of the Occupational Stress Inventory-Revised (OSI-R). Intercorrelations among the total questionnaire scores and the 14 individual scales of the ORQ, PSQ, and the PRQ in Osipow's (1998) analysis, with the current study, compare favorably, and are presented in Table 20. As would be expected from the underlying model, a substantial and significant negative correlation (-.54 in Osipow's, and -.53 in the current study) was found between the PSQ and PRQ total scores. A similar negative correlation was found between the ORQ and PRQ total scores (-.33 in Osipow's and -.34 in the current study). Conversely, a positive correlation was found between the ORQ and PSQ total scores (.59 in Osipow's and .62 in the current study). These findings were also supported by the pattern of correlations among individual scales. Thus, high levels of coping were correlated with low levels of strain and stress, supporting the model that resources (PRQ) correlate negatively with stress (ORQ) and strain (PSQ).

Reliability estimates were conducted utilizing an internal consistency analysis with the Osipow (1998) reported alpha coefficients from the reported normative sample. A summary of the alpha coefficients are shown in Table 21. Alpha coefficients for the OSI-R total questionnaire scores in the normative sample and in this study were comparable and high. This indicates that this tool is a highly reliable measure of occupational related role stress and coping when applied to a CRNA population, showing high levels of internal consistency.

Based on the reliability estimates conducted, the three measures applied in this study were found to be reliable with reported high internal consistency. Further reliability testing would be advisable and appropriate in future studies. In terms of the SOP tool, although quite reliable in this study, may require further evaluation to improve the clarity of question items, and content validity. Although the items in the CPS were modified (with permission) to articulate the CRNA and anesthesiologist working relationship, there was consistency in the current study when compared to the original reliability and validity testing done by Weiss and Davis (1985). Clearly, the OSI-R, which has undergone the most rigorous reliability and validity testing by Osipow (1998) and associates, provided the most reliable and highest level of internal consistency in the current study. 
Table 20

\section{Occupational Stress Inventory-Revised (OSI-R) Scale Intercorrelations (Osipow, 1998) - Lower Table Triangle}

\section{Occupational Stress Inventory-Revised (OSI-R) Scale Intercorrelations of CRNA Study - Upper Table Triangle (Bold)}

\begin{tabular}{|c|c|c|c|c|c|c|c|c|c|c|c|c|c|c|c|c|c|}
\hline $\begin{array}{l}\text { Sub- } \\
\text { Scales }\end{array}$ & RO & RI & $\mathbf{R A}$ & RB & $\mathbf{R}$ & PE & ORQ & VS & PSY & IS & PHS & PSQ & RE & SC & SS & RC & PRQ \\
\hline RO & & $.17^{* *}$ & $.34^{\star * *}$ & $.40^{* *}$ & $.50^{* *}$ & $.29^{\star *}$ & $.65^{\star \star \star}$ & $.35^{\star \star}$ & $.29 * *$ & $.27^{\star \star *}$ & $.30^{\star \star}$ & $.36^{\star \star}$ & $-.22^{* *}$ & -.11 & $-.16^{* *}$ & $-.13^{*}$ & $-.22^{\star \star}$ \\
\hline RI & .05 & & $.44^{* *}$ & $.44^{* \star}$ & .02 & $.21^{* *}$ & $.60^{\star \star *}$ & $.56^{\star *}$ & $.38 * *$ & $.29 \star \star$ & $.24^{* *}$ & $.41^{* *}$ & $-.25^{\star \star}$ & $-.14^{\star *}$ & $-.27 * *$ & $-.15^{\star *}$ & $-.28^{\star \star}$ \\
\hline $\mathbf{R A}$ & $.28^{* *}$ & $.44^{* *}$ & & $.56^{* *}$ & $.17^{\star \star}$ & $.21^{* *}$ & $.66^{\star *}$ & $.47^{\star *}$ & $.40^{\star \star *}$ & $.34^{\star \star *}$ & $.30^{* \star}$ & $.42^{* *}$ & -.27 ** & $-.23^{\star *}$ & $-.30 * *$ & $-.39 * *$ & $-.39 * *$ \\
\hline RB & $.42^{* *}$ & $41^{* *}$ & $.56^{* *}$ & & $.43^{* *}$ & $.42^{* *}$ & $.81^{* *}$ & $.44^{* *}$ & $.47^{* \star}$ & $.44^{* *}$ & $.35^{\star \star}$ & $.51^{* \star}$ & $-.17^{* *}$ & $-.2 .0^{* \star}$ & $-.16^{\star *}$ & $-.22 * *$ & $-.25^{\star \star}$ \\
\hline $\mathbf{R}$ & $.49^{* *}$ & $-.10^{* *}$ & $.07 *$ & $.29 * *$ & & $.38^{\star \star *}$ & $.61^{* \star}$ & $.26^{* *}$ & $.32^{\star *}$ & $.35^{\star \star}$ & $.35^{\star \star *}$ & $.39^{\star *}$ & $-.15^{\star \star}$ & $-.15^{\star *}$ & -.09 & -.05 & $-.16^{\star \star}$ \\
\hline PE & $.13^{* *}$ & .01 & $.09 * *$ & $.21^{* *}$ & $.25^{* *}$ & & $.65^{\star \star}$ & $.26^{\star \star}$ & $.31^{* *}$ & $.41^{\star *}$ & $.35^{\star \star}$ & $.40^{* *}$ & $-.12^{\star}$ & $-.11^{*}$ & $-.13^{\star}$ & -.04 & $-.14^{\star}$ \\
\hline ORQ & $.62 * *$ & $.51^{* *}$ & $.64^{* *}$ & $.77^{* *}$ & $.54^{* *}$ & $.55^{* *}$ & & $.58^{\star \star}$ & $.54^{\star \star}$ & $.53^{* *}$ & $.47^{\star \star}$ & $.62^{\star \star \star}$ & $-.27^{* *}$ & $-.21^{\star *}$ & $-.27^{\star \star}$ & $-.22^{* \star}$ & $-.34^{* *}$ \\
\hline VS & $.33^{* *}$ & $.56^{* *}$ & $.49 * *$ & $.53^{* *}$ & $.17^{* *}$ & $.11^{* *}$ & $.59^{* *}$ & & $.54^{\star *}$ & $.47^{\star *}$ & $.39 * *$ & $.67^{\star *}$ & $-.22^{* *}$ & $-.18^{\star \star}$ & $-.31 * *$ & $-.28 * *$ & $-.34 * *$ \\
\hline PSY & $.33^{* *}$ & $.34 * *$ & $.41^{* *}$ & $.51^{* *}$ & $.24^{* *}$ & $.14 * *$ & $.53^{* *}$ & $.65^{* *}$ & & $.71^{\star \star \star}$ & $.70^{\star *}$ & $.90^{\star *}$ & $-.34^{\star \star}$ & -.31 ** & $-.38^{\star \star}$ & $-.34^{\star *}$ & $-.46^{\star *}$ \\
\hline IS & $26^{* *}$ & $.25^{* *}$ & $38^{* *}$ & $.43^{* *}$ & $22 * *$ & $19^{* *}$ & $47^{* *}$ & $.50^{* *}$ & $.69 * *$ & & $.64^{* *}$ & $.85^{\star \star}$ & $-.28^{\star *}$ & $-.22^{* *}$ & $-.40^{* *}$ & $-.27^{* *}$ & $-.41 * *$ \\
\hline PHS & $29 * *$ & $26^{* *}$ & $.30^{* *}$ & $.43^{* *}$ & $.23^{* *}$ & $16^{* *}$ & $.45^{* *}$ & $.53 * *$ & $.72 * *$ & $.63 * *$ & & $.86^{\star *}$ & $-.40^{* *}$ & $-.44^{\star *}$ & $-.33^{* \star}$ & $-.34^{* *}$ & $-.53^{\star *}$ \\
\hline PSQ & $.35^{* *}$ & $40^{* *}$ & $.46^{* *}$ & $.56^{* *}$ & $.25^{* *}$ & $18^{* *}$ & $.59^{* *}$ & $.76^{* *}$ & $.91^{* *}$ & $.83^{* *}$ & $.87 * *$ & & $-.40^{\star *}$ & $-.36^{\star *}$ & $-.42^{\star *}$ & $-.38^{\star \star}$ & $-.53 * *$ \\
\hline RE & $-.20 * *$ & $-.17^{* *}$ & $-.24 * *$ & $-.18^{* *}$ & -.06 & .04 & $-.21 * *$ & $-.20 * *$ & $-.35 * *$ & $-.30^{* *}$ & $-.36^{* *}$ & $-.37^{* *}$ & & $.46^{* *}$ & $.38^{\star *}$ & $.45^{\star \star}$ & $.79^{\star \star}$ \\
\hline SC & $-.09 * *$ & $-.20 * *$ & -.20 & $-.16^{* *}$ & .01 & -.06 & $-.19 * *$ & $-.25 * *$ & $-.27 * *$ & $-.21^{* *}$ & $-.40^{* *}$ & $-.34^{* *}$ & $.43^{* *}$ & & $.26^{* *}$ & $.40^{\star \star}$ & $.71^{\star *}$ \\
\hline SS & $-.14^{* *}$ & $-.27^{* *}$ & -.42 & $-.30 * *$ & -.04 & $-.12^{* *}$ & $-.35^{* *}$ & $-.34^{* *}$ & $-.40 * *$ & $-.49^{* *}$ & $-.38 * *$ & $-.48^{* *}$ & $.30^{* *}$ & $.30 * *$ & & $.40^{* *}$ & $.71^{\star * *}$ \\
\hline $\mathbf{R C}$ & -.05 & $-.12 * *$ & -.36 & $-.19 * *$ & .04 & -.04 & $-.19 * *$ & $-.29 * *$ & $-.35^{* *}$ & $-.30 * *$ & $-.30 * *$ & $-.37 * *$ & $.41 * *$ & $.41^{* *}$ & $.42^{* *}$ & & $.74^{\star \star}$ \\
\hline PRQ & $-.17 * *$ & $-.27^{* *}$ & -.42 & $-.29 * *$ & -.02 & $-.07 *$ & $-.33 * *$ & $-.38 * *$ & $-.47 * *$ & $-.46^{* *}$ & $.50^{* *}$ & $-.54 * *$ & $.72 * *$ & $.72 * *$ & $.73 * *$ & $.75^{* *}$ & \\
\hline
\end{tabular}

Note: $N=983 . R O=$ Role Overload; $R I=$ Role Insufficiency; $R A=$ Role Ambiguity; $R B=$ Role Boundary; $R=$ Responsibility; $P E=$ Physical Environment; $O R Q=$ Occupational Role Questionnaire; $V S=$ Vocational Strain; $P S Y=$ Psychological Strain; $I S=$ Interpersonal Strain; $P H S=$ Physical Strain; $P S Q=$ Personal Strain Questionnaire; $R E=$ Recreation; $S C=$ Self-Care; $S S=$ Social Support; $R C=$ Rational/Cognitive; $P R Q=$ Personal Resources Questionnaire.

${ }^{*} p<.05 * * p<.01$ 
Table 21

Alpha Coefficients for Occupational Stress Inventory in the Study

With Comparisons to Reported Reliability Analyses

$\begin{array}{cc}\text { OSI-R Scale } & \text { Alpha Coefficients } \\ \text { And Sub-Scales } & \text { For Study Sample } \\ & \text { r (n) }\end{array}$
Alpha Coefficients
(Osipow, 1998)
$r(n=45)$

\section{Occupational Roles \\ Questionnaire (ORQ)}

Role Overload (RO)

$.77(331)$

.74

Role Insufficiency (RI)

$.85(332)$

.64

Role Ambiguity (RA)

$.72(331)$

.72

Role Boundary (RB)

$.77(329)$

.63

Responsibility (R)

$.68(329)$

.71

Physical Environment (PE)

$.78(329)$

.93

Total ORQ Score

$.89(319)$

.82

\section{Personal Strain Questionnaire \\ (PSQ)}

Vocational Strain (VS)

$.71(326)$

.64

Psychological Strain (PSY)

$.89(326)$

.75

Interpersonal Strain (IS)

$.74(311)$

.71

Physical Strain (PHS)

$.87(321)$

.73

Total PSQ Score

$.93(309)$

.84

Personal Resources

Questionnaire (PRQ)

Recreation (RE)

$.81(320)$

.79

Self-Care (SC)

$.70(321)$

.73

Social Support (SS)

.87 (320)

.75

Rational/Cognitive (RC)

$.77(320)$

.72

Total PRQ Score

$.89(314)$

.88 


\section{Findings Related to the Research Questions}

The initial model that guided the conceptualization of the research questions is shown in Figure 5, which was derived from the theoretical ideas embedded in Figure 4. The model has suggested that CRNA scope of practice may be influenced by the environmental factors of the anesthesia care team, and that CRNAs' perceived characteristics of relationships between anesthesiologists and themselves are influenced by their scope of practice. Furthermore, it was also conjectured that both scope of practice and collaboration impact on the CRNAs experience of occupational stress.

\section{Research Question \#1: What are the characteristics of the anesthesia care team environment based on aspects of individual CRNA scope of practice?}

As reported earlier, Table 11 represents the mean scores of CRNA respondents on the 41 items used to describe scope of practice in ACTs. Correlational analysis and t-tests were performed to identify relationships between employment arrangement, hospital bed size, gender, educational level or credentials, years of experience as an RN and as a CRNA, specialty services, and quantity of CRNAs and anesthesiologists based on higher and lower reported SOP. In an effort to separate two groups of reported SOP values, higher and lower SOP scores were identified using 119 as the mid-point score on the SOP. Relationships between mean values for major aspects of individual CRNA characteristics and, higher and lower SOP scores are presented in Table 22. Only the CRNA respondents that identified their primary practice as in an anesthesia care team setting are included in these analyses.

There were no differences identified in terms of the numbers of CRNAs, the number of anesthesiologists in the ACT, educational level, and years of experience as a CRNA related to scope of practice (SOP). There were no significant correlations between hospital bedsize and scope of practice. However, there was a difference in the SOP according to the educational level. There were no significant differences according to gender, although the male respondents tended to have higher SOP scores. There were differences between those respondents employed by hospitals versus those employed by physician groups. Higher scores on SOP were reported by hospital employed CRNAs, compared to physician group employees. 
Figure 5

Initial Model for the Conceptualization of the Research Questions

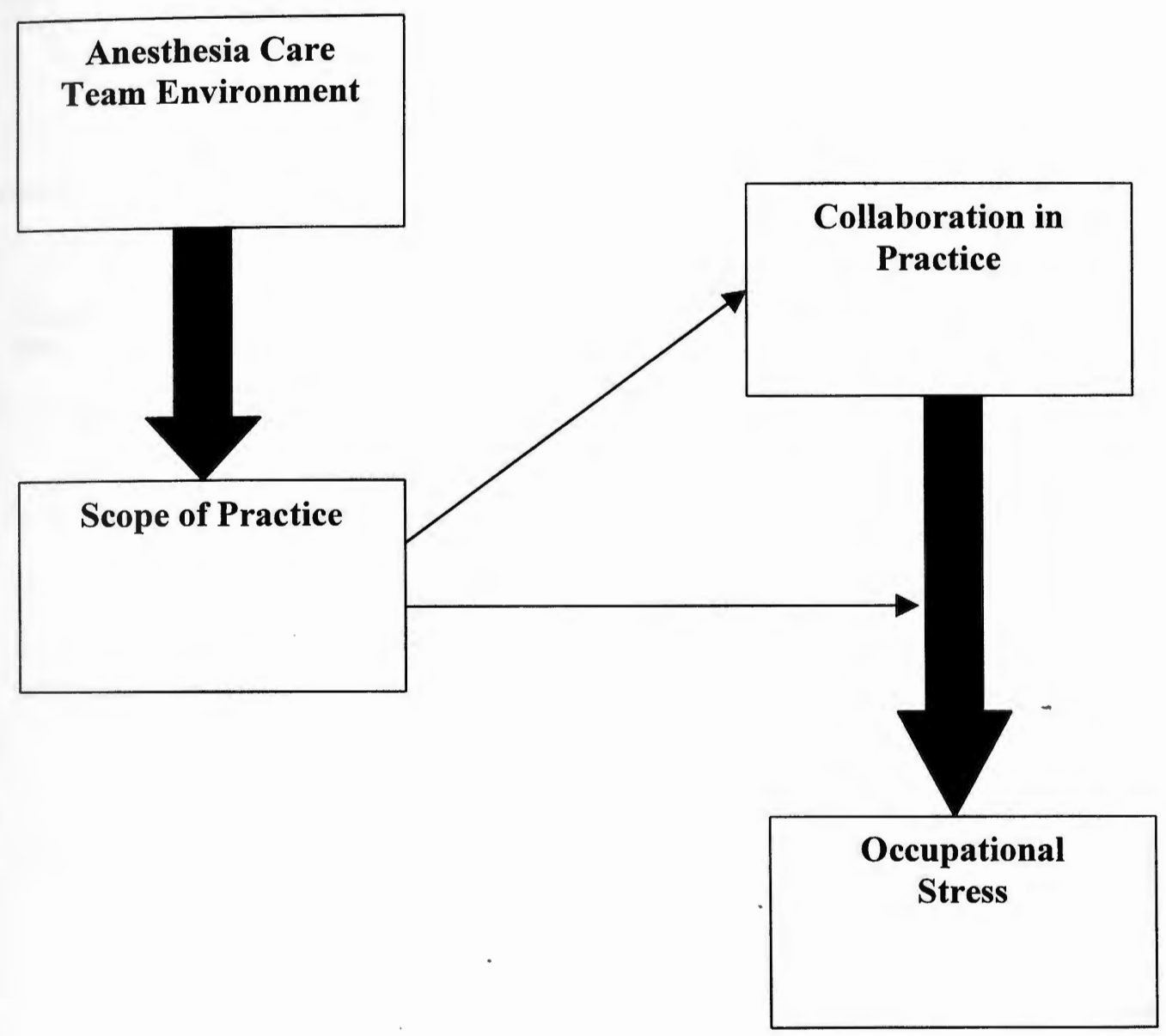


Table 22

Means, Standard Deviation, and T-test Comparing

Employment Arrangement, Hospital Bedsize, Gender, and

Educational Level/Credential with Scope of Practice Measures

\begin{tabular}{|c|c|c|c|c|c|}
\hline \multirow[t]{2}{*}{ Factor } & \multirow[t]{2}{*}{$\mathbf{N}$} & \multirow{2}{*}{$\begin{array}{c}\text { Mean } \\
\text { Total Scope of } \\
\text { Practice Score } \\
\text { (SOP-T) } \\
\text { (Range 41 to 205) }\end{array}$} & \multirow{2}{*}{$\begin{array}{c}\text { Standard } \\
\text { Deviation } \\
\text { Total Scope } \\
\text { of Practice } \\
\text { Score } \\
\text { (SOP-T) } \\
\end{array}$} & \multicolumn{2}{|c|}{ t-Test } \\
\hline & & & & F Valt & e (Sig.) \\
\hline \multicolumn{6}{|l|}{$\begin{array}{l}\text { Employment } \\
\text { Arrangement: }\end{array}$} \\
\hline $\begin{array}{l}\text { Hospital } \\
\text { Physician Group }\end{array}$ & $\begin{array}{c}59 \\
189\end{array}$ & $\begin{array}{l}124.85 \\
117.27\end{array}$ & $\begin{array}{l}20.90 \\
17.21\end{array}$ & 3.74 & $(.050)^{*}$ \\
\hline \multicolumn{6}{|c|}{ Hospital Bedsize: } \\
\hline $\begin{array}{l}>300 \text { beds } \\
<300 \text { beds }\end{array}$ & $\begin{array}{l}109 \\
175\end{array}$ & $\begin{array}{l}119.61 \\
118.90\end{array}$ & $\begin{array}{l}18.64 \\
18.90\end{array}$ & .076 & $(.783)$ \\
\hline \multicolumn{6}{|l|}{ Gender: } \\
\hline $\begin{array}{l}\text { Female } \\
\text { Male }\end{array}$ & $\begin{array}{l}184 \\
100\end{array}$ & $\begin{array}{l}117.54 \\
121.83\end{array}$ & $\begin{array}{l}18.98 \\
18.12\end{array}$ & .683 & - $(.410)$ \\
\hline \multicolumn{6}{|l|}{ Credential: } \\
\hline $\begin{array}{l}\text { Masters and Higher } \\
\text { Masters and Lower }\end{array}$ & $\begin{array}{l}142 \\
141\end{array}$ & $\begin{array}{l}120.26 \\
117.97\end{array}$ & $\begin{array}{l}20.00 \\
17.40\end{array}$ & 4.10 & $(.044)^{*}$ \\
\hline
\end{tabular}

$*=$ The mean difference is significant at the .05 level

Table 23 provides the mean scores, standard deviations, and t-Test comparing SOP-B scores with actual performance of specific specialty services. In Table 23 there were reported significant differences between the availability of specialty anesthesia services and whether respondents actually performed these services in terms of SOP-B. The SOP-B consist of 17 items (\#25-41) focusing on the CRNA's personal performance of anesthesia techniques and specialty services in the anesthesia care team setting. Items $37-41$ are related to the five specialty anesthesia care services identified in the demographic tool (trauma, cardio/pulmonary, OBS, pediatrics, and neurosurgical). The total score range on the SOP-B was 17-85. There were differences seen in relation to scores on the SOP-B based on the CRNA's ability to perform the specialty anesthetic populations. Those respondents who answered "yes" to question \#5 in the initial demographic tool, addressing the 5 anesthesia specialty 
services, had higher mean scores on the SOP-B, as expected. Significant mean differences were seen in all specialties except neurosurgical (Table 23).

An ANOVA was conducted next to compare the variances of all SOP scores and the 5 specialty service, and are reported in Table 24 . The results showed that there were no significant differences based on the SOP-A and SOP-T. However, as suspected, there were significant differences in terms of SOP-B $(p=.000)$. This would seem to indicate that CRNAs who have access to the specialty cases are more apt to be personally involved in these specialty populations. The contrast between groups by Tukey HSD method (Table 25), as a multiple comparison procedure was performed in which all possible differences between pairs were computed, and any difference that yielded an absolute value that exceeds HSD was declared to be significant.

Based on the results in this study, CRNAs engaged in various types of specialty procedure practices. The five specialty practices examined in this study were, trauma, obstetrics, cardiopulmonary, pediatrics, and neurosurgery. CRNAs were stratified into groups ranging from 1 to 5 (1 indicating engagement in providing services to one specialty, 2 indicating two of the specialties, up to all 5 specialty services). There were significant differences between groups 1 and 5 (one specialty and 5 specialties), and between groups 3 and 5 ( 3 specialties and 5 specialties), which had significant differences in mean scores at the .05 level.

In summary, the goal of research question \#1 was to describe the characteristics of the CRNA respondents in relation to aspects of scope of practice in anesthesia care team environments. These results are vital in understanding the essence of anesthesia care team practices. Although there were very few differences reported in terms of CRNA practice characteristics and degree of SOP, hospital employed CRNAs reported higher SOP scores, in comparison to anesthesiologist-owned groups. One may argue that when CRNAs are employed by anesthesiologists in these settings, CRNAs reported lower SOP scores, ultimately restricting their full scope. This may indicate that the anesthesiologists have more control in determining the level of scope the CRNA may be engaged in the particular setting. In contrast, when CRNAs are employed by a hospital, there are less restrictions to CRNA practice based on higher SOP scores. In addition, in terms of specialty procedure practices, there was a relationship between how many specialty procedures CRNAs were actually engaged in, and the level of 
SOP. Those CRNAs who reported higher numbers of active engagement in specialty procedures, reported higher SOP scores.

Table 23

Means, Standard Deviation, and t-Test Comparing

Specialty Services with Scope of Practice-B Measures

Items 25-41

\begin{tabular}{|c|c|c|c|c|c|}
\hline $\begin{array}{c}\text { Specialty Services } \\
\text { Factor }\end{array}$ & $\mathbf{N}$ & $\begin{array}{c}\text { Mean } \\
\text { Scope of Practice } \\
\text { Score } \\
\text { (SOP-B) } \\
\text { (Range 17 to 85) }\end{array}$ & $\begin{array}{c}\text { Standard } \\
\text { Deviation Scope } \\
\text { of Practice Score } \\
\text { (SOP-B) }\end{array}$ & $\begin{array}{l}\mathbf{F} \\
\text { Value }\end{array}$ & (Sig.) \\
\hline Trauma & & & & & \\
\hline $\begin{array}{l}\text { Yes } \\
\text { No }\end{array}$ & $\begin{array}{r}227 \\
78\end{array}$ & $\begin{array}{l}45.31 \\
41.18\end{array}$ & $\begin{array}{r}9.91 \\
10.30\end{array}$ & .336 & $(.002)^{*}$ \\
\hline OBS & & & & & \\
\hline $\begin{array}{l}\text { Yes } \\
\text { No }\end{array}$ & $\begin{array}{r}242 \\
63\end{array}$ & $\begin{array}{l}45.89 \\
37.97\end{array}$ & $\begin{array}{r}9.49 \\
10.26\end{array}$ & .367 & ${ }_{*}^{(.000)}$ \\
\hline $\begin{array}{c}\text { Cardio/Pulmonar } \\
\mathbf{y}\end{array}$ & 193 & 45.26 & 10.10 & - & \\
\hline $\begin{array}{l}\text { Yes } \\
\text { No }\end{array}$ & 110 & 42.30 & 10.01 & .010 & $(.014)^{*}$ \\
\hline Pediatrics & & & & & \\
\hline $\begin{array}{l}\text { Yes } \\
\text { No }\end{array}$ & $\begin{array}{r}275 \\
30\end{array}$ & $\begin{array}{l}44.70 \\
40.12\end{array}$ & $\begin{array}{l}10.00 \\
10.90\end{array}$ & .276 & $(.020)^{*}$ \\
\hline Neurosurgical & & & & & \\
\hline $\begin{array}{l}\text { Yes } \\
\text { No }\end{array}$ & $\begin{array}{r}237 \\
67\end{array}$ & $\begin{array}{l}44.73 \\
42.39\end{array}$ & $\begin{array}{r}10.20 \\
9.82\end{array}$ & .082 & $(.095)$ \\
\hline
\end{tabular}

$*=$ The mean difference is significant at the .05 level 
Table 24

One Way Analysis of Variance (ANOVA) of Scope of Practice and Specialty Anesthesia Services

\begin{tabular}{|c|c|c|c|c|c|c|c|c|}
\hline \multicolumn{4}{|c|}{ Source of Variance } & $\begin{array}{l}\text { SS } \\
329.107\end{array}$ & $\begin{array}{r}d f \\
5\end{array}$ & $\begin{aligned} M S \\
65.821\end{aligned}$ & $\begin{array}{r}\boldsymbol{F} \\
.462 \\
\end{array}$ & $\begin{array}{ll}\boldsymbol{P} & \\
& \\
.804\end{array}$ \\
\hline SOP-A & $\begin{array}{l}\text { Between } \\
\text { Groups } \\
\text { Within C } \\
\text { Total }\end{array}$ & $\begin{array}{l}\text { (Combi } \\
\text { Linear } \\
\text { Term } \\
\text { Ips }\end{array}$ & $\begin{array}{l}\text { Unweighted } \\
\text { Weighted } \\
\text { Deviation }\end{array}$ & $\begin{array}{r}329.107 \\
.277 \\
.191 \\
328.916 \\
39894.151 \\
40223.259 \\
\end{array}$ & $\begin{array}{r}5 \\
1 \\
1 \\
4 \\
280 \\
285 \\
\end{array}$ & $\begin{array}{r}65.821 \\
.277 \\
.191 \\
82.229 \\
142.479\end{array}$ & $\begin{array}{l}.462 \\
.002 \\
.001 \\
.577\end{array}$ & $\begin{array}{r}.804 \\
.965 \\
.971 \\
.679\end{array}$ \\
\hline SOP-B & $\begin{array}{l}\text { Between } \\
\text { Groups } \\
\text { Within C } \\
\text { Total } \\
\end{array}$ & $\begin{array}{l}\text { (Combi } \\
\text { Linear } \\
\text { Term }\end{array}$ & $\begin{array}{l}\text { Unweighted } \\
\text { Weighted } \\
\text { Deviation }\end{array}$ & $\begin{array}{r}2624.016 \\
1432.735 \\
2496.463 \\
127.553 \\
28493.634 \\
31117.650 \\
\end{array}$ & $\begin{array}{r}5 \\
1 \\
1 \\
4 \\
297 \\
302 \\
\end{array}$ & $\begin{array}{r}524.803 \\
1432.735 \\
2496.463 \\
31.888 \\
95.938\end{array}$ & $\begin{array}{r}5.470 \\
14.934 \\
26.022 \\
.332\end{array}$ & $\begin{array}{r}.000^{*} \\
.000^{*} \\
.000^{*} \\
.856\end{array}$ \\
\hline SOP-T & $\begin{array}{l}\text { Between } \\
\text { Groups } \\
\text { Within G } \\
\text { Total }\end{array}$ & $\begin{array}{l}\text { (Combi } \\
\text { Linear } \\
\text { Term }\end{array}$ & $\begin{array}{l}\text { Unweighted } \\
\text { Weighted } \\
\text { Deviation }\end{array}$ & $\begin{array}{r}2733.510 \\
1295.767 \\
2141.029 \\
592.481 \\
96087.146 \\
98820.656\end{array}$ & \begin{tabular}{r|}
5 \\
1 \\
1 \\
4 \\
276 \\
281
\end{tabular} & $\begin{array}{r}546.702 \\
1295.767 \\
2141.029 \\
148.120 \\
348.142\end{array}$ & $\begin{array}{r}1.570 \\
3.722 \\
6.150 \\
.425\end{array}$ & $\begin{array}{l}.169 \\
.055 \\
.014 \\
.790\end{array}$ \\
\hline
\end{tabular}

$*=$ The mean difference is significant 
Table 25

Tukey HSD Multiple Comparisons for

Scope of Practice-B and Specialty Anesthesia Services

\begin{tabular}{|c|c|c|c|c|c|}
\hline & \multicolumn{2}{|c|}{$\begin{array}{l}\text { Specialty Practice } \\
\text { Levels }(1-5)+\end{array}$} & Mean Diff. & $\begin{array}{c}\text { Standard } \\
\text { Error }\end{array}$ & $P$ \\
\hline \multirow[t]{4}{*}{ SOP-B } & 1 & 2 & -2.2500 & 3.4630 & .987 \\
\hline & & 3 & -3.3318 & 3.1313 & .896 \\
\hline & & 4 & -7.2428 & 3.0063 & .153 \\
\hline & & 5 & -8.4339 & 2.9702 & $.050^{*}$ \\
\hline \multirow[t]{3}{*}{ SOP-B } & 2 & 3 & -1.0818 & 2.4099 & .998 \\
\hline & & 4 & -4.0028 & 2.2450 & .227 \\
\hline & & 5 & -6.1839 & 2.1965 & -.055 \\
\hline \multirow[t]{2}{*}{ SOP-B } & 3 & 4 & -3.9110 & 1.6891 & .188 \\
\hline & & 5 & -5.1021 & 1.6239 & $.021^{*}$ \\
\hline SOP-B & 4 & 5 & -1.1912 & 1.3674 & .953 \\
\hline
\end{tabular}

+ Refers to the number of specialty services that CRNA respondents answered "yes"

$*=$ The mean difference is significant at the .05 level 


\section{Research Question \#2: What are individual CRNAs reported perceptions of collaboration} between CRNAs and anesthesiologists, based on the collaborative practice scale (CPS)?

The two factors which delineates the two scales of the CPS are items 1-9 measuring CRNA's perception of assertiveness in the ACT, and items 10-19 focusing on CRNA's measures of cooperativenss. Four (4) items in the CPS-A scale revealed lower mean scores of less than a 2 rating (occasionally to never). These four items (refer to Table 12) were related to ACT member (CRNA and anesthesiologist) regarding expectations of personal involvement in anesthesia care decisions (item \#1), discussing different kinds of information with patients (item \# 2), discussing areas of practice that are in the realm of nursing or medicine (item \# 6), and areas of practice that are unique to nurse anesthesia (item \#9). On the CPS-C scale (Items \#10-19), only one item had mean scores below a rating of 2. Item \#12 revealed, again, that CRNA respondents do not discuss with the anesthesiologist, the similarities and differences between approaches to patient care from a nursing perspective.

The five modes of conflict resolution were suggested by Weiss and Davis (1985).

Collaboration has a high degree of both assertiveness and cooperativeness, in contrast to modes in which one may yield completely to the other's, may strive to satisfy one's own concerns with no regard for others, or may compromise some important concerns. High scores in CPS (A) and lower scores in CPS (C) would indicate a preference for competition. Low scores in CPS (A) and low scores in CPS (C) would indicate a preference for avoidance. A Lower score in the CPS (A) and high score in CPS (C) would indicate an accommodating preference. Finally, an intermediate score in both the CPS (A) and CPS (C) would reveal a preference toward compromise when handling interpersonal differences.

Tables 26 and 27 present the percentage of CRNA respondents in terms of mean scores reflecting the five (5) modes of conflict resolution. Based on the results of the CPS measures reported earlier, very few CRNAs practicing in ACTs perceive their individual practice as collaborating with anesthesiologists. In terms of mode preferences, most CRNAs (37.7\%) in the study identified with compromise as the primary mode of conflict resolution in ACT practice, followed by avoidance (23.5\%), competition (17.5\%), collaboration (15.0\%), and accommodation (6.3\%). The distribution in theses five modes by CRNA respondents is an interesting indication that CRNAs tend to be more 
passive (67.5\% in compromise, avoidance, and accommodation) than active (32.5\%, with competition and collaboration) in their relationships with anesthesiologists.

In summary, although the notion of categorizing respondents in the five modes of conflict resolution may seem appropriate in exploring evidence of collaboration, Weiss and Davis (1985) purported that in their CPS instrument, a key theoretical feature was absent. Organizational behavior theorists have proposed that the key element necessary to move towards collaboration stems from the interactive processes involved in clarifying between participants, which was only eluded to in one item of the CPS (item \#2). Weiss and Davis (1985) explain that without more items focusing on the use of negotiating skills, it is difficult to correlate each mode of preference, and would reflect a flaw in the instrument's validity. Therefore, in this study, the analyses for research questions \#3 and \#4, presented next, utilized the CPS tool based on high and low CPS measures, instead of categorizing groups in the five mode preferences.

Table 26

\section{Collaborative Practice Scale with}

\section{Frequency in Individual Mode Preferences}

\begin{tabular}{lcc}
\hline \multicolumn{1}{c}{ CPS Mode Preference } & $\begin{array}{c}\text { Frequency } \\
(\mathbf{N})\end{array}$ & $\begin{array}{c}\text { Percent } \\
(\%)\end{array}$ \\
\hline Accommodation & 19 & 6.3 \\
\hline Collaboration & 46 & 15.0 \\
\hline Competition & 54 & 17.5 \\
\hline Avoidance & 71 & 23.5 \\
\hline Compromise & 116 & 37.7 \\
\hline Total $(\mathrm{N})$ & 308 & \\
\hline
\end{tabular}


Table 27

Collaborative Practice Scale with

Mean Scores in Each Mode Preference

\begin{tabular}{|c|c|c|c|c|}
\hline $\begin{array}{l}\text { Collaborative Practice Scale } \\
\text { Mode Preferences }\end{array}$ & Range & $\mathbf{N}$ & Mean & $\begin{array}{l}\text { Standard } \\
\text { Deviation }\end{array}$ \\
\hline \multicolumn{5}{|l|}{$\operatorname{CPS}(\mathbf{A})$} \\
\hline Avoidance & $(9-22)$ & 71 & 17.90 & 4.86 \\
\hline Accommodation & $(9-22)$ & 19 & 17.07 & 2.58 \\
\hline Competition & $(23-45)$ & 54 & 35.74 & 2.60 \\
\hline Collaboration & $(23-45)$ & 46 & 32.07 & 5.63 \\
\hline Compromise & $(23-33)$ & 116 & 26.30 & 3.35 \\
\hline Total & $(9-45)$ & 306 & 24.18 & 7.31 \\
\hline \multicolumn{5}{|l|}{ CPS(C) } \\
\hline Avoidance & $(10-28)$ & 71 & 19.80 & 3.26 \\
\hline Accommodation & $(29-50)$ & 19 & 31.21 & 3.49 \\
\hline Competition & $(10-28)$ & 54 & 19.56 & 4.21 \\
\hline Collaboration & $(29-50)$ & 46 & 41.24 & 3.16 \\
\hline Compromise & $(29-42)$ & 116 & 30.83 & 3.61 \\
\hline Total & $(10-50)$ & 306 & 29.63 & 7.49 \\
\hline \multicolumn{5}{|l|}{ CPS(T) } \\
\hline Avoidance & $(19-40)$ & 71 & 37.70 & 6.70 \\
\hline Accommodation & $(38-72)$ & 19 & 66.95 & 3.46 \\
\hline Competition & $(33-73)$ & 54 & 46.63 & 5.91 \\
\hline Collaboration & $(52-95)$ & 46 & 73.30 & 7.47 \\
\hline Compromise & $(52-75)$ & 116 & 57.12 & 5.55 \\
\hline Total & $(19-95)$ & 306 & 53.81 & 13.37 \\
\hline
\end{tabular}




\section{Research Question \#3: Is there a relationship between CRNAs reported individual scope of} practice in ACT settings and collaboration?

a. Do CRNAs who report restrictions to scope of practice perceive lower collaboration?

b. Do CRNAs who report a broader individual scope of practice perceive higher collaboration?

As the first step, the relationship between SOP and perceived level of collaboration was examined

as simple correlations (Pearson correlation coefficients). Based on Table 28, positive correlations are seen throughout all scales of SOP and CPS. This would indicate that higher levels of SOP in all three scales yielded higher CPS scores. As a second step, the relationship between CRNAs reported scope of practice in ACTs and collaboration was examined with ANOVA to compare the high, intermediate, and low SOP groups on the CPS levels. Based on the reported mean scores and standard deviations for the SOP instrument in the sample, three groups were identified as the low SOP (scores ranging 41-103), the intermediate SOP (ranging 104-164), and high SOP (ranging 165-205). Table 29 provides the mean scores on CPS scales by these three groups of SOP. Although most of the respondents fell into the intermediate SOP group $(n=200)$, there are group differences in the mean scores on the CPS. Higher mean scores on the total CPS (57.58) were reported in groups with a broader scope of practice, lower mean scores on the CPS (47.59) in more restricted practices, and intermediate scores on the CPS (54.15).

Table 30 provides the ANOVA results comparing the variances and means between all three SOP groups (low, intermediate, and high) on the three measures on the CPS (CPS-A, CPS-C, and CPST). The ANOVA reports significant differences between groups on all CPS scales (CPS-A, $p=.001$; CPS-C, $p=.021$; and CPS-T, $p=.002$ ). The contrast between groups by Tukey HSD method (Table 31), as a multiple comparison procedure, was performed in which possible differences between pairs were computed, and any difference that yielded an absolute value that exceeded HSD was declared to be significant. There were significant differences between the low SOP and intermediate SOP groups on each CPS (CPS-A, $p=.013$; CPS-C, $p=.032$, and CPS-T, $p=.009$ ), and between the low SOP and high 
SOP groups (CPS-A, $p=.001$; CPS-C, $p=.031$, and CPS-T, $p=.002$ ), but no differences between the intermediate and high SOP groups (CPS-A, CPS-C, and CPS-T; $p$ range=.122-.727).

These results indicate that the low SOP group in general perceive lower levels of both assertiveness and cooperation in their practices, than those who view their scope of practice to be at the intermediate or high levels. This suggests that the restriction in the CRNA's scope of practice seems to coexist with lower levels of collaboration. These finding support the research question in that there is a significant relationship between the scope of practice and perceived level of collaboration in ACT practice. The results indicate that a strong, significant relationship exist between CRNAs reported SOP and CPS. CRNAs who reported a lower, more restricted SOP, perceive their individual ACT practice setting as less collaborative. CRNAs who reported a higher, broader SOP, perceive their ACT setting as more collaborative in nature.

Table 28

Pearson Correlations Based on Total Scores on

Scope of Practice, Collaboration, and Occupational Stress

\begin{tabular}{llrrr} 
& & & & \\
\cline { 3 - 5 } & & & & \\
\hline SOP-A & Pearson Correlation & $.249^{* *}$ & $.176^{* *}$ & $.234^{* *}$ \\
& Sig. (2-tailed) & .000 & .003 & .000 \\
& $\mathrm{~N}$ & 286 & .285 & 283 \\
\hline SOP-B & Pearson Correlation & $.146^{*}$ & .107 & $.142^{*}$ \\
& Sig. (2-tailed) & .011 & .063 & .014 \\
& $\mathrm{~N}$ & 303 & 302 & 300 \\
\hline SOP-T & Pearson Correlation & $.239^{* *}$ & $.173^{* *}$ & $.227^{* *}$ \\
& Sig. (2-tailed) & .000 & .004 & .000 \\
& $\mathrm{~N}$ & 282 & 281 & 279
\end{tabular}

* Correlation is significant at the 0.05 level (2-tailed)

** Correlation is significant at the 0.01 level (2-tailed) 
Table 29

Means and Standard Deviations for Scope of Practice and

Collaborative Practice Scales

\begin{tabular}{cccc}
\hline $\begin{array}{c}\text { Levels of SOP Based on } \\
\text { CPS Sub-Scales* }\end{array}$ & $N$ & Mean & $\begin{array}{c}\text { Standard } \\
\text { Deviation }\end{array}$
\end{tabular}

\section{$\underline{C P S-A}$}

Low SOP

42

20.90

6.95

Intermediate SOP

200

24.31

6.68

High SOP

40

26.72

9.11

282

24.15

7.26

Total

\section{CPS-C}

Low SOP

Intermediate SOP

High SOP

42

199

40

281

Total

\section{$\underline{\text { CPS-T }}$}

Low SOP

Intermediate SOP

High SOP

Total

${ }^{*} \mathrm{CPS}-\mathrm{A}=$ Assertiveness; $\mathrm{CPS}-\mathrm{C}=$ Cooperativeness; $\mathrm{CPS}-\mathrm{T}=$ Total

42

47.60

14.05

197

54.15

11.92

40

57.58

17.19

279

53.66

13.37 
Table 30

Measures of Analysis of Variance (ANOVA) of Scope of Practice and Collaborative Practice Scales

\begin{tabular}{|c|c|c|c|c|c|c|c|}
\hline \multicolumn{3}{|c|}{ Source of Variance } & $S S$ & $d f$ & $M S$ & $F$ & $\boldsymbol{P}$ \\
\hline $\begin{array}{ll}\text { CPS-A } & \text { Between } \\
& \text { Groups } \\
& \\
& \text { Within Gro } \\
& \text { Total } \\
\end{array}$ & $\begin{array}{l}\text { (Combined) } \\
\text { Linear } \\
\text { Term } \\
\text { ps }\end{array}$ & $\begin{array}{l}\text { Unweighted } \\
\text { Weighted } \\
\text { Deviation }\end{array}$ & \begin{tabular}{r|}
712.67 \\
604.03 \\
698.41 \\
14.25 \\
14094.37 \\
14807.04 \\
\end{tabular} & $\begin{array}{r}2 \\
1 \\
1 \\
1 \\
279 \\
281 \\
\end{array}$ & \begin{tabular}{r|}
356.33 \\
694.03 \\
698.41 \\
14.25 \\
50.52 \\
\end{tabular} & $\begin{array}{r}7.05 \\
13.74 \\
13.83 \\
.282\end{array}$ & $\begin{array}{r}.001^{*} \\
.000 \\
.000 \\
.596\end{array}$ \\
\hline $\begin{array}{l}\text { CPS-C Between } \\
\text { Groups } \\
\\
\text { Within Gr } \\
\text { Total } \\
\end{array}$ & $\begin{array}{l}\text { (Combined) } \\
\text { Linear } \\
\text { Term } \\
\text { aps } \\
\end{array}$ & $\begin{array}{l}\text { Unweighted } \\
\text { Weighted } \\
\text { Deviation }\end{array}$ & $\begin{array}{r}431.25 \\
354.47 \\
361.13 \\
70.12 \\
15384.68 \\
15815.93 \\
\end{array}$ & $\begin{array}{r}2 \\
1 \\
1 \\
1 \\
278 \\
280 \\
\end{array}$ & $\begin{array}{r}215.63 \\
354.47 \\
361.13 \\
70.12 \\
55.34\end{array}$ & $\begin{array}{l}3.90 \\
6.41 \\
6.53 \\
1.27\end{array}$ & $\begin{array}{r}.021^{*} \\
.012 \\
.011 \\
.261\end{array}$ \\
\hline $\begin{array}{c}\text { CPS-T Between } \\
\text { Groups } \\
\\
\text { Within Gro } \\
\text { Total }\end{array}$ & $\begin{array}{l}\text { (Combined) } \\
\text { Linear } \\
\text { Term } \\
\text { aps }\end{array}$ & $\begin{array}{l}\text { Unweighted } \\
\text { Weighted } \\
\text { Deviation }\end{array}$ & $\begin{array}{r}2205.64 \\
2040.50 \\
2063.50 \\
142.14 \\
47453.33 \\
49658.97 \\
\end{array}$ & $\begin{array}{r}2 \\
1 \\
1 \\
1 \\
276 \\
276 \\
\end{array}$ & $\begin{array}{r}1102.82 \\
2040.50 \\
2063.50 \\
142.14 \\
171.93\end{array}$ & $\begin{array}{r}6.41 \\
11.87 \\
12.00 \\
.827\end{array}$ & $\begin{array}{l}.002 * \\
.001 \\
.001 \\
.364\end{array}$ \\
\hline
\end{tabular}

$*=$ Statistically significant result 
Table 31

Tukey HSD Multiple Comparisons for

Scope of Practice and Collaborative Practice Scales

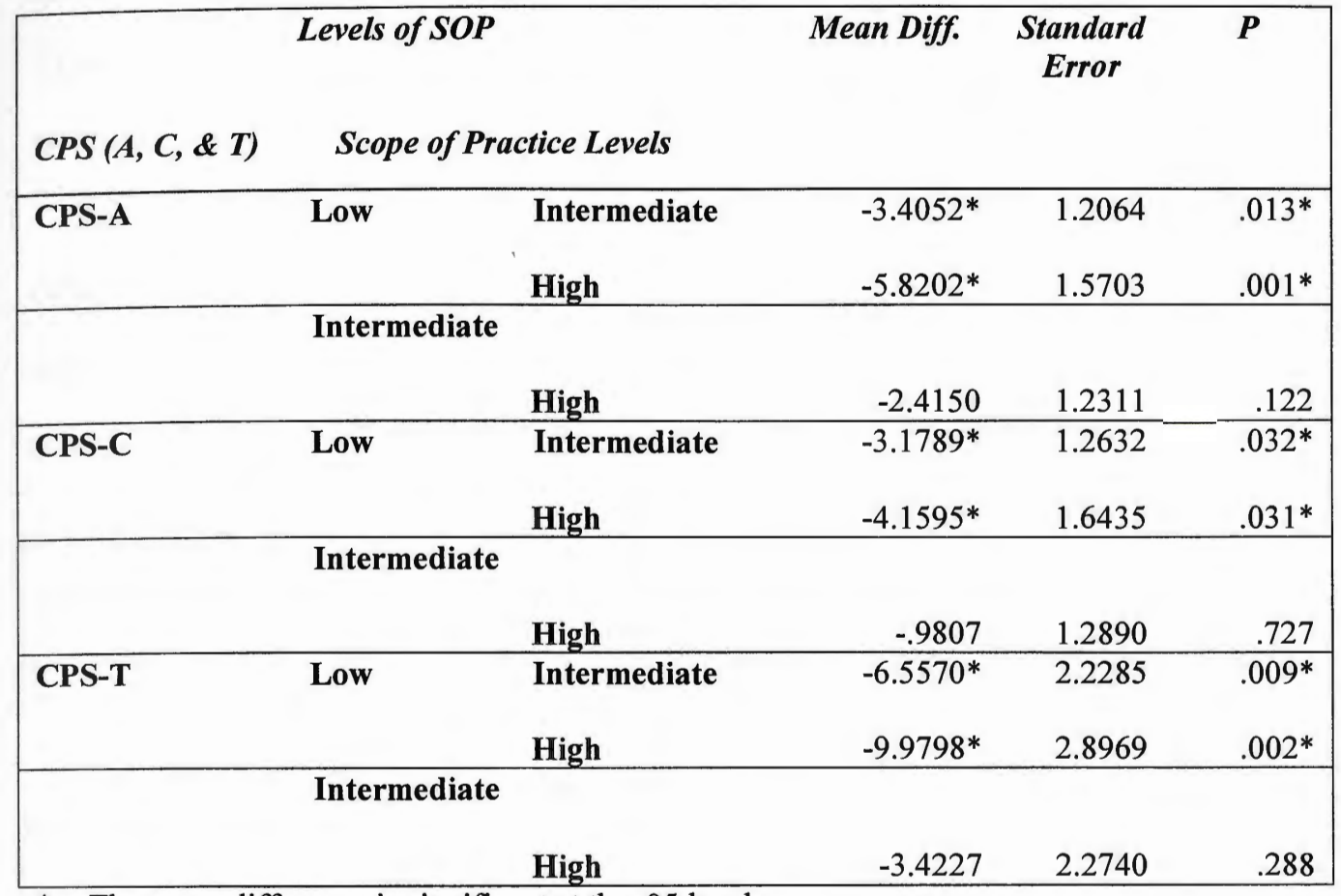

$*=$ The mean difference is significant at the .05 level

Research Questions \#4: Is there a relationship among CRNAs reported scope of practice, perception of collaboration, and occupational stress?

a. For CRNAs who report restrictions to individual scope of practice, what is the relationship between their perception of collaboration and occupational stress?

b. For CRNAs who report a broader individual scope of practice, what is the relationship between their perception of collaboration and occupational stress?

Relationship Between Scope of Practice and Occupational Stress. As shown in Table 21, there were positive correlations in reference to the relationship between ORQ-T and PSQ-T $(r=.623)$. As described earlier, similar scores in each of these subscales (ORQ-T and PSQ-T) would indicate levels of occupational stress and psychological strain, respectively. A negative correlation is seen in regards to the PSQ-T and the PRQ-T ( $r=-.524)$, indicating that with lower scores on PSQ-T, higher scores on the PRQ-T would reflect appropriate utilization of coping resources in managing occupational stress. The opposite is also clear, that higher PSQ-T scores and lower PRQ scores would reflect lack of 
utilization of coping resources. In analyzing the findings in the PRQ subscale, it is critical to understand that higher scores on the PRQ are considered positive in terms of respondents using personal resources, in an effort to compensate for higher stress scores in ORQ and PSQ subscales. Tables 32, 33 , and 34 provide a descriptive analysis of levels of respondent's reported SOP, compared to means and standard deviations of respondent's reported OSI measure.

Although there were general tendencies in the low, intermediate, and high SOP groups scoring differently on the OSI subscales, only two sub-scales were found to be significantly different among the groups according to the ANOVA procedure performed, as shown in Tables 35, 36, and 37. The two subscales were: ORQ-Role Overload (RO), and ORQ-Responsibility (R). On these two measures, the higher SOP groups had higher levels of role overload related stress and responsibility related stress than the lower SOP groups. These were also shown in Table 38, in which the group contrasts are indicated by the Tukey HSD comparison method. As shown in Table 38, there were significant group differences in these measures between all groups, except for ORQ-RO between the intermediate and higher SOP groups. There were significant differences between low and intermediate, and low and high scope of practice groups on role overload related stress (ORQ-RO), but not between the intermediate and high SOP groups. On the other hand, there were significant differences between all groups on responsibility (ORQ-R) related stress.

Analyzed differently, significant positive relationships were seen with ORQ-RO subscale with SOP-A (r=.196), SOP-B (r=.133,) SOP-T $(r=196)$ as shown in Table 39. These findings indicate that the higher the SOP regardless of its dimension, the higher the stress related to role overload. This may mean that as scope of practice increases, CRNAs may perceive increasing levels of demands regarding their role. Significant negative correlations were seen with ORQ-RI (role insufficiency) and both the SOP-B (skills and procedures ( $r=.153)$, and SOP-T $(r=-.139)$. Thus, higher scores on role insufficiency with SOP-B and SOP-T, would suggest that CRNAs who score lower in personally performing many of the skills and procedures in the SOP-B and SOP-T have higher role insufficiency in terms of the ACT setting.

There were further positive correlations seen between ORQ-R (responsibility) in relation to SOP-A $(r=.253)$, SOP-B $(r=.175)$, SOP-T $(r=.265)$, indicating the higher the scores on SOP, 
Table 32

Means and Standard Deviations for Scope of Practice and

Occupational Stress Inventory-Occupational Roles Questionnaire (ORO)

\begin{tabular}{|c|c|c|c|}
\hline $\begin{array}{c}\text { Levels of SOP } \\
\text { Based on OSI with Sub- } \\
\text { Scales* }\end{array}$ & $N$ & $\begin{array}{c}\text { Mean } \\
\text { OSI Measures }\end{array}$ & $\begin{array}{l}\text { Standard } \\
\text { Deviation }\end{array}$ \\
\hline $\begin{array}{l}\text { ORO-RO* } \\
\text { Low SOP } \\
\text { Intermediate SOP } \\
\text { High SOP } \\
\text { Total } \\
\end{array}$ & $\begin{array}{r}41 \\
191 \\
39 \\
271 \\
\end{array}$ & $\begin{array}{l}17.20 \\
19.85 \\
21.90 \\
19.75 \\
\end{array}$ & $\begin{array}{l}5.40 \\
5.52 \\
5.87 \\
5.68 \\
\end{array}$ \\
\hline $\begin{array}{l}\text { ORQ-RI* } \\
\text { Low SOP } \\
\text { Intermediate SOP } \\
\text { High SOP } \\
\text { Total }\end{array}$ & $\begin{array}{r}41 \\
191 \\
40 \\
272 \\
\end{array}$ & $\begin{array}{l}22.61 \\
20.97 \\
19.63 \\
21.02 \\
\end{array}$ & $\begin{array}{l}8.34 \\
7.11 \\
5.81 \\
7.16\end{array}$ \\
\hline $\begin{array}{l}\text { ORQ-RA* } \\
\text { Low SOP } \\
\text { Intermediate SOP } \\
\text { High SOP } \\
\text { Total }\end{array}$ & $\begin{array}{r}41 \\
190 \\
40 \\
271 \\
\end{array}$ & $\begin{array}{l}19.78 \\
19.11 \\
18.03 \\
19.05\end{array}$ & $\begin{array}{l}5.46 \\
5.42 \\
5.42 \\
5.43\end{array}$ \\
\hline $\begin{array}{l}\text { ORO-RB* } \\
\text { Low SOP } \\
\text { Intermediate SOP } \\
\text { High SOP } \\
\text { Total } \\
\end{array}$ & $\begin{array}{r}39 \\
191 \\
39 \\
269 \\
\end{array}$ & $\begin{array}{l}20.69 \\
22.20 \\
22.31 \\
22.00\end{array}$ & $\begin{array}{l}6.02 \\
6.57 \\
5.93 \\
6.41\end{array}$ \\
\hline $\begin{array}{l}\text { ORQ-R* } \\
\text { Low SOP } \\
\text { Intermediate SOP } \\
\text { High SOP } \\
\text { Total }\end{array}$ & $\begin{array}{r}39 \\
191 \\
40 \\
270 \\
\end{array}$ & $\begin{array}{l}23.64 \\
26.31 \\
28.75 \\
26.29 \\
\end{array}$ & $\begin{array}{l}5.20 \\
5.64 \\
5.89 \\
5.77 \\
\end{array}$ \\
\hline $\begin{array}{l}\text { ORQ-PE} \\
\text { Low SOP } \\
\text { Intermediate SOP } \\
\text { High SOP } \\
\text { Total }\end{array}$ & $\begin{array}{r}40 \\
189 \\
39 \\
268 \\
\end{array}$ & $\begin{array}{l}21.63 \\
23.38 \\
25.23 \\
23.38 \\
\end{array}$ & $\begin{array}{l}6.45 \\
7.11 \\
7.63 \\
7.14 \\
\end{array}$ \\
\hline $\begin{array}{l}\text { ORO-Total } \\
\text { Low SOP } \\
\text { Intermediate SOP } \\
\text { High SOP } \\
\text { Total } \\
\end{array}$ & $\begin{array}{r}37 \\
188 \\
37 \\
262 \\
\end{array}$ & $\begin{array}{l}124.49 \\
131.92 \\
135.51 \\
131.38 \\
\end{array}$ & $\begin{array}{l}24.28 \\
25.51 \\
22.60 \\
25.05\end{array}$ \\
\hline
\end{tabular}

* $\mathrm{RO}=$ Role Overload; $\mathrm{RI}=$ Role Insufficiency; $\mathrm{RA}=$ Role Ambiguity; $\mathrm{RB}=$ Role Boundary; RESP= Responsibility; $\mathrm{PE}=$ Physical Environment 
Table 33

Means and Standard Deviations for Scope of Practice and

Occupational Stress Inventory-Psychological Strain Questionnaire (PSQ)

\begin{tabular}{|c|c|c|c|}
\hline $\begin{array}{c}\text { Levels of SOP } \\
\text { Based on OSI with Sub- } \\
\text { Scales* }\end{array}$ & $\boldsymbol{N}$ & $\begin{array}{c}\text { Mean } \\
\text { OSI Measures }\end{array}$ & $\begin{array}{l}\text { Standard } \\
\text { Deviation }\end{array}$ \\
\hline $\begin{array}{l}P S Q-V S^{*} \\
\text { Low SOP } \\
\text { Intermediate SOP } \\
\text { High SOP } \\
\text { Total }\end{array}$ & $\begin{array}{r}40 \\
188 \\
39 \\
267 \\
\end{array}$ & $\begin{array}{l}14.20 \\
14.80 \\
13.64 \\
14.54 \\
\end{array}$ & $\begin{array}{l}3.98 \\
4.34 \\
3.43 \\
4.17\end{array}$ \\
\hline $\begin{array}{l}\text { PSQ-PSY* } \\
\text { Low SOP } \\
\text { Intermediate SOP } \\
\text { High SOP } \\
\text { Total }\end{array}$ & $\begin{array}{r}40 \\
188 \\
39 \\
267 \\
\end{array}$ & $\begin{array}{l}19.30 \\
18.37 \\
17.08 \\
18.30\end{array}$ & $\begin{array}{l}7.74 \\
6.41 \\
7.05 \\
6.71\end{array}$ \\
\hline $\begin{array}{l}\text { PSQ-IS* } \\
\text { Low SOP } \\
\text { Intermediate SOP } \\
\text { High SOP } \\
\text { Total }\end{array}$ & $\begin{array}{r}36 \\
179 \\
39 \\
254\end{array}$ & $\begin{array}{l}18.69 \\
19.15 \\
17.97 \\
18.91 \\
\end{array}$ & $\begin{array}{l}4.77 \\
5.48 \\
5.07 \\
5.32\end{array}$ \\
\hline $\begin{array}{l}\text { PSO-PHS* } \\
\text { Low SOP } \\
\text { Intermediate SOP } \\
\text { High SOP } \\
\text { Total } \\
\end{array}$ & $\begin{array}{r}38 \\
185 \\
39 \\
262 \\
\end{array}$ & $\begin{array}{l}19.42 \\
20.06 \\
18.92 \\
19.80 \\
\end{array}$ & $\begin{array}{l}7.19 \\
6.83 \\
6.62 \\
6.84 \\
\end{array}$ \\
\hline $\begin{array}{l}\text { PSQ-Total } \\
\text { Low SOP } \\
\text { Intermediate SOP } \\
\text { High SOP } \\
\text { Total }\end{array}$ & $\begin{array}{r}35 \\
178 \\
39 \\
252\end{array}$ & $\begin{array}{l}71.89 \\
72.03 \\
67.62 \\
71.33\end{array}$ & $\begin{array}{r}20.6 \\
19.35 \\
18.10 \\
19.35\end{array}$ \\
\hline
\end{tabular}

*VS= Vocational Strain; PSY= Psychological Strain; IS= Interpersonal Strain;

PHS $=$ Physical Strain 
Table 34

Means and Standard Deviations for Scope of Practice and

Occupational Stress Inventory-Personal Resources Questionnaire (PRQ)

\begin{tabular}{|c|c|c|c|}
\hline $\begin{array}{c}\text { Levels of SOP } \\
\text { Based on OSI with Sub- } \\
\text { Scales* }\end{array}$ & $N$ & $\begin{array}{c}\text { Mean } \\
\text { OSI Measures }\end{array}$ & $\begin{array}{l}\text { Standard } \\
\text { Deviation }\end{array}$ \\
\hline $\begin{array}{l}\text { PRQ-RE } \\
\text { Low SOP } \\
\text { Intermediate SOP } \\
\text { High SOP } \\
\text { Total } \\
\end{array}$ & $\begin{array}{r}38 \\
185 \\
38 \\
261 \\
\end{array}$ & $\begin{array}{l}32.39 \\
29.62 \\
30.68 \\
30.18 \\
\end{array}$ & $\begin{array}{l}7.88 \\
7.17 \\
7.29 \\
7.33 \\
\end{array}$ \\
\hline $\begin{array}{l}P \boldsymbol{P R} \boldsymbol{Q} \boldsymbol{S C} \boldsymbol{C}^{*} \\
\text { Low SOP } \\
\text { Intermediate SOP } \\
\text { High SOP } \\
\text { Total }\end{array}$ & $\begin{array}{r}39 \\
185 \\
38 \\
262 \\
\end{array}$ & $\begin{array}{l}30.64 \\
28.63 \\
29.21 \\
29.02 \\
\end{array}$ & $\begin{array}{l}6.56 \\
6.42 \\
6.32 \\
6.44 \\
\end{array}$ \\
\hline $\begin{array}{l}\boldsymbol{P R Q}-S_{S}^{*} \\
\text { Low SOP } \\
\text { Intermediate SOP } \\
\text { High SOP } \\
\text { Total }\end{array}$ & $\begin{array}{r}39 \\
186 \\
37 \\
262 \\
\end{array}$ & $\begin{array}{l}42.21 \\
42.77 \\
44.95 \\
42.99 \\
\end{array}$ & $\begin{array}{l}8.05 \\
7.42 \\
4.73 \\
7.23 \\
\end{array}$ \\
\hline $\begin{array}{l}\boldsymbol{P R Q}-\boldsymbol{R} C^{*} \\
\text { Low SOP } \\
\text { Intermediate SOP } \\
\text { High SOP } \\
\text { Total }\end{array}$ & $\begin{array}{r}39 \\
186 \\
37 \\
262 \\
\end{array}$ & $\begin{array}{l}37.82 \\
37.19 \\
38.05 \\
37.41 \\
\end{array}$ & $\begin{array}{l}5.89 \\
5.72 \\
5.30 \\
5.68 \\
\end{array}$ \\
\hline $\begin{array}{l}\text { PRQ-Total } \\
\text { Low SOP } \\
\text { Intermediate SOP } \\
\text { High SOP } \\
\text { Total }\end{array}$ & $\begin{array}{r}38 \\
184 \\
35 \\
257\end{array}$ & $\begin{array}{l}143.26 \\
138.13 \\
141.66 \\
139.37 \\
\end{array}$ & $\begin{array}{l}20.83 \\
20.38 \\
15.14 \\
19.85 \\
\end{array}$ \\
\hline
\end{tabular}

* $\mathrm{RE}=$ Recreation; $\mathrm{SC}=$ Self-Care; $\mathrm{SS}=$ Social Support; $\mathrm{RC}=$ Rational/Cognitive 
Table 35

Analysis of Variance (ANOVA) for Scope of Practice and

Occupational Stress Inventory-Occupational Roles Questionnaire (ORQ)

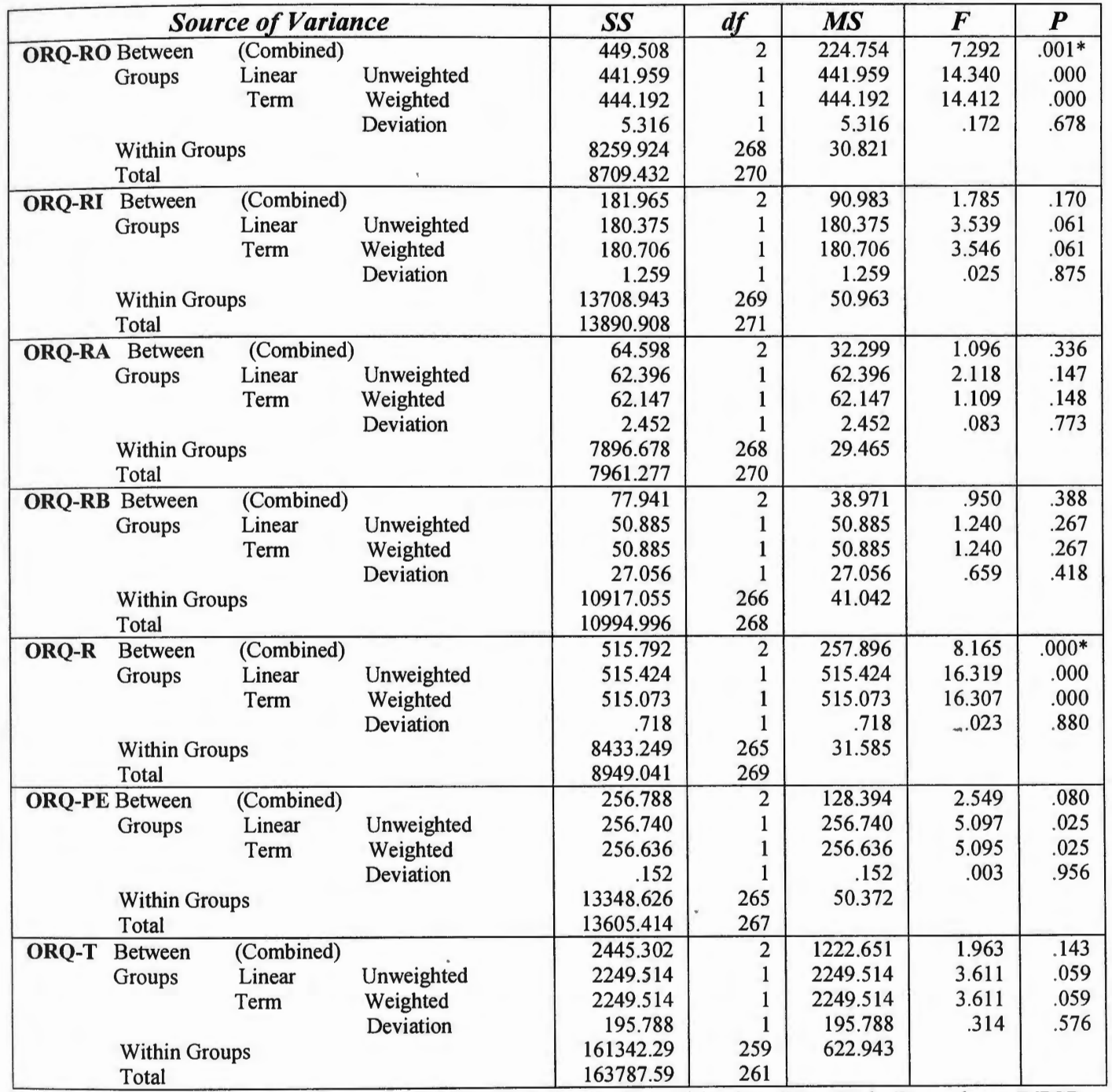

$\mathrm{RO}=$ Role Overload; $\mathrm{RI}=$ Role Insufficiency; $\mathrm{RA}=$ Role Ambiguity; $\mathrm{RB}=$ Role Boundary; $\mathrm{RESP}=$ Responsibility; $\mathrm{PE}=$ Physical Environment

$*=$ Statistically significant result 
Table 36

Analysis of Variance (ANOVA) for Scope of Practice and

Occupational Stress Inventory-Psychological Strain Questionnaire (PSQ)

\begin{tabular}{|c|c|c|c|c|c|c|c|c|}
\hline \multicolumn{4}{|c|}{ Source of Variance } & SS & $d f$ & $\mathbf{M S}$ & $\boldsymbol{F}$ & $\boldsymbol{P}$ \\
\hline PSQ-VS & $\begin{array}{l}\text { Between } \\
\text { Groups } \\
\text { Within G } \\
\text { Total } \\
\end{array}$ & $\begin{array}{l}\text { Comb } \\
\text { Linear } \\
\text { Term } \\
\text { ps }\end{array}$ & $\begin{array}{l}\text { Unweighted } \\
\text { Weighted } \\
\text { Deviation } \\
\end{array}$ & $\begin{array}{r}48.644 \\
6.170 \\
5.830 \\
42.813 \\
4585.694 \\
4634.337 \\
\end{array}$ & $\begin{array}{r}2 \\
1 \\
1 \\
1 \\
264 \\
266 \\
\end{array}$ & $\begin{array}{r}24.322 \\
6.170 \\
5.830 \\
42.813 \\
17.370\end{array}$ & $\begin{array}{r}1.400 \\
.355 \\
.336 \\
2.465\end{array}$ & $\begin{array}{l}.248 \\
.552 \\
.563 \\
.118\end{array}$ \\
\hline PSQ-PS & $\begin{array}{l}\text { Y Between } \\
\text { Groups } \\
\text { Within G } \\
\text { Total } \\
\end{array}$ & $\begin{array}{l}\text { (Comb } \\
\text { Linear } \\
\text { Term } \\
\text { ps }\end{array}$ & $\begin{array}{l}\text { Unweighted } \\
\text { Weighted } \\
\text { Deviation }\end{array}$ & $\begin{array}{r}86.394 \\
82.830 \\
82.457 \\
3.937 \\
11906.820 \\
11993.213 \\
\end{array}$ & $\begin{array}{r}2 \\
1 \\
1 \\
1 \\
264 \\
266 \\
\end{array}$ & $\begin{array}{r}43.197 \\
82.830 \\
82.457 \\
3.937 \\
45.102\end{array}$ & $\begin{array}{r}.958 \\
1.837 \\
1.828 \\
.087\end{array}$ & $\begin{array}{l}.386 \\
.177 \\
.177 \\
.768\end{array}$ \\
\hline PSQ-IS & $\begin{array}{l}\text { Within G } \\
\text { Total }\end{array}$ & $\begin{array}{l}\text { (Combi } \\
\text { Linear } \\
\text { Term }\end{array}$ & $\begin{array}{l}\text { Unweighted } \\
\text { Weighted } \\
\text { Deviation }\end{array}$ & $\begin{array}{r}46.192 \\
9.707 \\
11.000 \\
35.191 \\
7125.541 \\
7171.732 \\
\end{array}$ & $\begin{array}{r}2 \\
1 \\
1 \\
1 \\
251 \\
253 \\
\end{array}$ & $\begin{array}{r}23.096 \\
9.707 \\
11.000 \\
35.191 \\
28.389\end{array}$ & $\begin{array}{r}.814 \\
.342 \\
.387 \\
1.240\end{array}$ & $\begin{array}{l}.444 \\
.559 \\
.534 \\
.267\end{array}$ \\
\hline PSQ-PH & $\begin{array}{l}\text { S Between } \\
\text { Groups } \\
\text { Within G } \\
\text { Total } \\
\end{array}$ & $\begin{array}{l}\text { (Comb } \\
\text { Linear } \\
\text { Term } \\
\text { ps }\end{array}$ & $\begin{array}{l}\text { Unweighted } \\
\text { Weighted } \\
\text { Deviation }\end{array}$ & $\begin{array}{r}48.425 \\
4.733 \\
5.092 \\
43.333 \\
12175.254 \\
12223.679\end{array}$ & \begin{tabular}{r|}
2 \\
1 \\
1 \\
1 \\
259 \\
261
\end{tabular} & $\begin{array}{r}24.213 \\
4.773 \\
5.092 \\
43.333 \\
47.009\end{array}$ & $\begin{array}{l}.515 \\
.102 \\
.108 \\
.922\end{array}$ & $\begin{array}{l}.598 \\
.750 \\
.742 \\
.338\end{array}$ \\
\hline PSQ-T & $\begin{array}{l}\text { Within G } \\
\text { Total }\end{array}$ & $\begin{array}{l}\text { (Combi } \\
\text { Linear } \\
\text { Term }\end{array}$ & $\begin{array}{l}\text { Unweighted } \\
\text { Weighted } \\
\text { Deviation }\end{array}$ & $\begin{array}{r}637.091 \\
336.375 \\
365.181 \\
271.910 \\
93382.571 \\
94019.663\end{array}$ & \begin{tabular}{r|}
2 \\
1 \\
1 \\
1 \\
249 \\
251
\end{tabular} & $\begin{array}{l}318.546 \\
336.375 \\
365.181 \\
271.910 \\
375.030\end{array}$ & $\begin{array}{l}.849 \\
.897 \\
.974 \\
.725\end{array}$ & $\begin{array}{l}.429 \\
.345 \\
.325 \\
.395\end{array}$ \\
\hline
\end{tabular}

VS= Vocational Strain; PSY= Psychological Strain; IS= Interpersonal Strain;

PHS= Physical Strain

* = Statistically significant result 
Table 37

Analysis of Variance (ANOVA) for Scope of Practice and

Occupational Stress Inventory-Personal Resources Questionnaire (PRQ)

\begin{tabular}{|c|c|c|c|c|c|c|c|c|}
\hline \multicolumn{4}{|c|}{ Source of Variance } & SS & $d f$ & $\boldsymbol{M S}$ & & $\boldsymbol{P}$ \\
\hline PRQ-RE & $\begin{array}{l}\text { Between } \\
\text { Groups } \\
\text { Within G } \\
\text { Total }\end{array}$ & $\begin{array}{l}\text { (Comb } \\
\text { Linear } \\
\text { Term } \\
\text { ps }\end{array}$ & $\begin{array}{l}\text { Unweighted } \\
\text { Weighted } \\
\text { Deviation }\end{array}$ & $\begin{array}{r}254.852 \\
55.592 \\
55.592 \\
199.260 \\
13725.041 \\
13979.893\end{array}$ & $\begin{array}{r}2 \\
1 \\
1 \\
1 \\
258 \\
260 \\
\end{array}$ & $\begin{array}{r}127.426 \\
55.592 \\
55.592 \\
199.260 \\
53.198\end{array}$ & $\begin{array}{l}2.395 \\
1.045 \\
1.045 \\
3.746\end{array}$ & $\begin{array}{l}.093 \\
.308 \\
.308 \\
.054\end{array}$ \\
\hline PRQ-SC & $\begin{array}{l}\text { Between } \\
\text { Groups } \\
\text { Within G } \\
\text { Total }\end{array}$ & $\begin{array}{l}\text { (Combi } \\
\text { Linear } \\
\text { Term } \\
\text { ps }\end{array}$ & $\begin{array}{l}\text { Unweighted } \\
\text { Weighted } \\
\text { Deviation }\end{array}$ & $\begin{array}{r}131.643 \\
39.385 \\
40.707 \\
90.936 \\
10694.296 \\
10825.939 \\
\end{array}$ & $\begin{array}{r}2 \\
1 \\
1 \\
1 \\
259 \\
261 \\
\end{array}$ & $\begin{array}{l}65.822 \\
39.385 \\
40.707 \\
90.936 \\
41.291\end{array}$ & $\begin{array}{r}1.594 \\
.954 \\
.986 \\
2.202\end{array}$ & $\begin{array}{l}.205 \\
.330 \\
.322 \\
.139\end{array}$ \\
\hline PRQ-SS & $\begin{array}{l}\text { Between } \\
\text { Groups } \\
\text { Within G } \\
\text { Total } \\
\end{array}$ & $\begin{array}{l}\text { (Combi } \\
\text { Linear } \\
\text { Term } \\
\text { ps }\end{array}$ & $\begin{array}{l}\text { Unweighted } \\
\text { Weighted } \\
\text { Deviation }\end{array}$ & $\begin{array}{r}174.675 \\
142.631 \\
139.579 \\
35.096 \\
13451.310 \\
13625.985 \\
\end{array}$ & $\begin{array}{r}2 \\
1 \\
1 \\
1 \\
259 \\
261 \\
\end{array}$ & $\begin{array}{r}87.337 \\
142.631 \\
139.579 \\
35.096 \\
51.936\end{array}$ & $\begin{array}{r}1.682 \\
2.746 \\
2.688 \\
.676\end{array}$ & $\begin{array}{l}.188 \\
.099 \\
.102 \\
.412\end{array}$ \\
\hline PRQ-RC & $\begin{array}{l}\text { Between } \\
\text { Groups } \\
\text { Within G } \\
\text { Total }\end{array}$ & $\begin{array}{l}\text { (Combi } \\
\text { Linear } \\
\text { Term } \\
\text { ips }\end{array}$ & $\begin{array}{l}\text { Unweighted } \\
\text { Weighted } \\
\text { Deviation }\end{array}$ & $\begin{array}{r}30.634 \\
1.136 \\
.804 \\
29.830 \\
8382.668 \\
8413.302 \\
\end{array}$ & $\begin{array}{r}2 \\
1 \\
1 \\
1 \\
259 \\
261 \\
\end{array}$ & $\begin{array}{r}15.317 \\
1.036 \\
.804 \\
29.830 \\
32.366\end{array}$ & $\begin{array}{l}.473 \\
.032 \\
.025 \\
.922\end{array}$ & $\begin{array}{l}.624 \\
.858 \\
.875 \\
.338\end{array}$ \\
\hline PRQ-T & $\begin{array}{l}\text { Between } \\
\text { Groups } \\
\text { Within G } \\
\text { Total }\end{array}$ & $\begin{array}{l}\text { (Combir } \\
\text { Linear } \\
\text { Term }\end{array}$ & $\begin{array}{l}\text { Unweighted } \\
\text { Weighted } \\
\text { Deviation }\end{array}$ & $\begin{array}{r}1044.240 \\
46.992 \\
63.192 \\
981.048 \\
99827.379 \\
100871.62\end{array}$ & $\begin{array}{r}2 \\
1 \\
1 \\
1 \\
254 \\
256\end{array}$ & $\begin{array}{r}522.120 \\
46.992 \\
63.192 \\
981.048 \\
393.021\end{array}$ & $\begin{array}{r}1.828 \\
.120 \\
.161 \\
-2.496\end{array}$ & $\begin{array}{l}.267 \\
.730 \\
.689 \\
.115\end{array}$ \\
\hline
\end{tabular}

$\mathrm{RE}=$ Recreation; $\mathrm{SC}=$ Self-Care; $\mathrm{SS}=$ Social Support; $\mathrm{RC}=$ Rational/Cognitive

$*=$ Statistically significant result 
Table 38

Tukey HSD Multiple Comparisons for Scope of Practice and Occupational Stress Inventory-

ORQ: Role Overload (ORQ-RO) and Responsibility (ORQ-R)

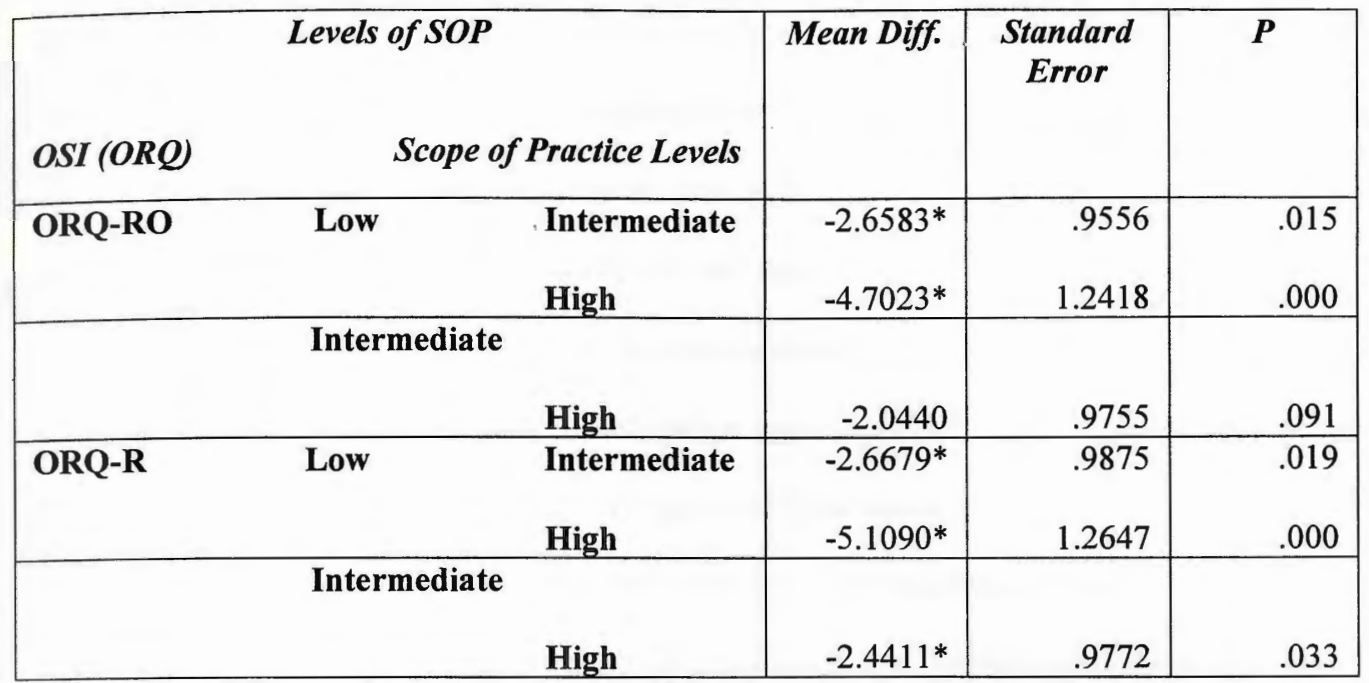

* The mean difference is significant at the .05 level

the higher the stress related to responsibility. Stress related to responsibility is defined by Osipow (1998) as measuring the extent to which the individual has, or feels, a great deal of responsibility

for the performance and welfare of others on the job. Therefore, the findings may suggest that with higher scores on SOP respondents identified with higher occupational stress scores relating to role responsibility. In addition, ORQ-PE (physical environment) showed positive correlations with all of the SOP measures: SOP-A $(r=.203)$, SOP-B $(r=.143)$, and SOP-T $(r=.188)$. Based on

Osipow's (1998) definition of ORQ-PE, respondents were exposed to high levels of environmental toxins or extreme physical conditions. There was a positive correlation between SOP-A $(r=.147)$ and the overall occupational stress indicated in

ORQ-T. Therefore, with higher scores in the ORQ-T, there were higher scores in SOP-A.

Relationship Between Collaboration and Occupational Stress. Table 40 provides an overview of the significant positive relationships that were identified with ORQ-RO subscale with CPS-A $(r=.171)$ and CPS-T $(r=.127)$. These finding indicated that with higher scores on the assertiveness dimension and total CPS scores, there were higher stress related to role overload. Significant negative correlations were seen with ORQ-RI (role insufficiency) with CPS-C (cooperativeness, $r=-.197$ ), indicating that with higher levels of cooperation, CRNAs experience 
less role insufficiency. In addition, further negative correlations were identified with role ambiguity (ORQ-RA) and CPS-C $(r=-.225)$ and CPS-T $r=-.183)$, suggesting that with higher scores on copperativeness and total collaboration, yields lower role ambiguity. There were further positive correlations seen between ORQ-R (responsibility) and CPS-A scores ( $r=.185$ ), indicating higher assertiveness scores and higher responsibility related stress. Finally, there was a negative correlation between the overall occupational stress (ORQ-T) and the CPS-C ( $r=-.128)$. Therefore suggesting that higher overall stress scores reveals lower levels of cooperativeness (CPS-C).

There were very few significant findings in terms of the PSQ subscale of the OSI and the CPS-C scores. Negatively correlated relationships were identified between CPS-C and PSQ-VS (vocational strain $r=-.125$ ), with PSQ-PSY (psychological strain, $r=-.127$ ), and with PSQ-Total $(r=-.138)$. These findings suggest that most of the personal strain subscales are inversely related to CPS-C. CPS-C (cooperativeness) primarily reflects the degree in which the CRNA clarifies with the anesthesiologist mutual expectations regarding the nature of shared responsibilities in patient care. It seems that based on this analysis, CRNAs struggle with attempting to satisfy this characteristic of collaboration. More effort and personal strain may be utilized by the CRNA in these situations, lowering the scores on the CPS-C dimension. There were positive correlations with higher scores reported on the PRQ-SC (self-care) and CPS-C ( $r=. .152)$ and CPS-T $(r=.121)$. All of the remaining subscales (PRQ-SS, PRQ-RC, and PRQ-Total) also indicated positive correlations with all CPS scales (CPS-A, CPS-C, and CPS-Total). Higher scores on the PRQ-T scale and the CPS-T indicates highly developed coping resources, along with strong collaborative approaches to practice.

Relationship Between Collaboration and Occupational Stress According to Different

Levels of Scope of Practice. Two separate sets of Pearson correlations were conducted, one addressing total scores on all three variables (Table 41), another for the high and the low SOP groups on the CPS and OSI scales (Table 42). Table 42 provides data which only views CRNA respondents who fell into the reported higher (broader) scope of practice group $(n=39)$ on CPS and OSI measures. The significant correlations for this group were in the following: there was an inverse relationship with lower ORQ-RA and higher CPS-C ( $r=-.411)$, and CPS-T $(r=-.346)$, but 
positive correlations between PSQ-PHS and CPS-A ( $r=.385)$. It seems that with this group, the higher perceived levels of collaboration in terms of the CPS-T

Table 39

Pearson Correlations Based on Scope of Practice (A, B, \& T) and Occupational Stress (All Sub-Scales)

\begin{tabular}{|c|c|c|c|c|c|c|c|}
\hline $\begin{array}{l}\text { ORQ } \\
\text { Sub-Scales }\end{array}$ & SOP-A & SOP-B & SOP-T & $\begin{array}{l}\text { PSQ/PRQ } \\
\text { Sub-Scales }\end{array}$ & SOP-A & SOP-B & SOP-T \\
\hline $\begin{array}{l}\text { ORQ-RO } \\
\text { Pearson Corr. } \\
\text { Sig. (2-tailed) } \\
\mathrm{N} \\
\end{array}$ & $\begin{array}{r}.196 * * \\
.001 \\
275 \\
\end{array}$ & $\begin{array}{r}.133^{*} \\
.023 \\
292 \\
\end{array}$ & $\begin{array}{r}.196 * * \\
.001 \\
271 \\
\end{array}$ & $\begin{array}{l}\text { PSQ-VS } \\
\text { Pearson Corr. } \\
\text { Sig. (2-tailed) } \\
\mathrm{N}\end{array}$ & $\begin{array}{r}-.046 \\
.448 \\
271 \\
\end{array}$ & $\begin{array}{r}-.069 \\
.245 \\
288 \\
\end{array}$ & $\begin{array}{r}-.057 \\
.352 \\
267 \\
\end{array}$ \\
\hline $\begin{array}{l}\text { ORQ-RI } \\
\text { Pearson Corr. } \\
\text { Sig. (2-tailed) } \\
\text { N }\end{array}$ & $\begin{array}{r}-.079 \\
.188 \\
276 \\
\end{array}$ & $\begin{array}{r}.153 * * \\
.009 \\
293 \\
\end{array}$ & $\begin{array}{r}-.139 * \\
.021 \\
272 \\
\end{array}$ & $\begin{array}{l}\text { PSQ-PSY } \\
\text { Pearson Corr. } \\
\text { Sig. (2-tailed) } \\
\text { N }\end{array}$ & $\begin{array}{r}-.044 \\
.471 \\
271 \\
\end{array}$ & $\begin{array}{r}-.096 \\
.102 \\
288\end{array}$ & $\begin{array}{r}-.070 \\
.252 \\
267 \\
\end{array}$ \\
\hline $\begin{array}{l}\text { ORQ-RA } \\
\text { Pearson Corr. } \\
\text { Sig. (2-tailed) } \\
\mathrm{N}\end{array}$ & $\begin{array}{r}-.085 \\
.162 \\
275 \\
\end{array}$ & $\begin{array}{r}-.101 \\
.085 \\
292 \\
\end{array}$ & $\begin{array}{r}-.102 \\
.095 \\
271 \\
\end{array}$ & $\begin{array}{l}\text { PSQ-IS } \\
\text { Pearson Corr. } \\
\text { Sig. (2-tailed) } \\
\mathrm{N} \\
\end{array}$ & $\begin{array}{l}.023 \\
.717 \\
257 \\
\end{array}$ & $\begin{array}{r}-.042 \\
.485 \\
274 \\
\end{array}$ & $\begin{array}{r}-.001 \\
.985 \\
254 \\
\end{array}$ \\
\hline $\begin{array}{l}\text { ORQ-RB } \\
\text { Pearson Corr. } \\
\text { Sig. (2-tailed) } \\
\mathrm{N} \\
\end{array}$ & $\begin{array}{l}.094 \\
.121 \\
273 \\
\end{array}$ & $\begin{array}{l}.004 \\
.948 \\
290 \\
\end{array}$ & $\begin{array}{l}.082 \\
.181 \\
269 \\
\end{array}$ & $\begin{array}{l}\text { PSQ-PHS } \\
\text { Pearson Corr. } \\
\text { Sig. (2-tailed) } \\
\mathrm{N}\end{array}$ & $\begin{array}{r}-.013 \\
.827 \\
266 \\
\end{array}$ & $\begin{array}{r}-.072 \\
.225 \\
283 \\
\end{array}$ & $\begin{array}{r}-.029 \\
.635 \\
262 \\
\end{array}$ \\
\hline $\begin{array}{l}\text { ORQ-R } \\
\text { Pearson Corr. } \\
\text { Sig. (2-tailed) } \\
\mathrm{N}\end{array}$ & $\begin{array}{r}.253 * * \\
.000 \\
274 \\
\end{array}$ & $\begin{array}{r}.175^{* *} \\
.003 \\
290 \\
\end{array}$ & $\begin{array}{r}.265^{* *} \\
.000 \\
270 \\
\end{array}$ & $\begin{array}{l}\text { PSQ-Total } \\
\text { Pearson Corr. } \\
\text { Sig. (2-tailed) } \\
\text { N }\end{array}$ & $\begin{array}{r}-.026 \\
.681 \\
255 \\
\end{array}$ & $\begin{array}{r}-.081 \\
.185 \\
272 \\
\end{array}$ & $\begin{array}{r}-.050 \\
.425 \\
252 \\
\end{array}$ \\
\hline $\begin{array}{l}\text { ORQ-PE } \\
\text { Pearson Corr. } \\
\text { Sig. (2-tailed) } \\
\text { N }\end{array}$ & $\begin{array}{r}.203^{* *} \\
.001 \\
272\end{array}$ & $\begin{array}{r}.143^{*} \\
.015 \\
289\end{array}$ & $\begin{array}{r}.188^{* *} \\
.002 \\
268\end{array}$ & $\begin{array}{l}\text { PRQ- RE } \\
\text { Pearson Corr. } \\
\text { Sig. (2-tailed) } \\
\text { N }\end{array}$ & $\begin{array}{r}-.024 \\
.699 \\
265 \\
\end{array}$ & $\begin{array}{r}-.014 \\
.815 \\
282 \\
\end{array}$ & $\begin{array}{r}-.013 \\
.830 \\
261 \\
\end{array}$ \\
\hline $\begin{array}{l}\text { ORQ-Total } \\
\text { Pearson Corr. } \\
\text { Sig. (2-tailed) } \\
\text { N }\end{array}$ & $\begin{array}{r}.147^{*} \\
.016 \\
266 \\
\end{array}$ & $\begin{array}{l}.050 \\
.402 \\
282 \\
\end{array}$ & $\begin{array}{l}.120 \\
.053 \\
262 \\
\end{array}$ & $\begin{array}{l}\text { PRQ-SC } \\
\text { Pearson Corr. } \\
\text { Sig. (2-tailed) } \\
\mathrm{N} \\
\end{array}$ & $\begin{array}{l}.007 \\
.911 \\
266 \\
\end{array}$ & $\begin{array}{r}-.081 \\
.176 \\
283 \\
\end{array}$ & $\begin{array}{r}-.050 \\
.416 \\
262 \\
\end{array}$ \\
\hline & & & & $\begin{array}{l}\text { PRQ-SS } \\
\text { Pearson Corr. } \\
\text { Sig. (2-tailed) } \\
\text { N }\end{array}$ & $\begin{array}{l}.102 \\
.096 \\
266\end{array}$ & $\begin{array}{l}.094 \\
.114 \\
282\end{array}$ & $\begin{array}{r}.124^{*} \\
.045 \\
262\end{array}$ \\
\hline & & & & $\begin{array}{l}\text { PRQ-RC } \\
\text { Pearson Corr. } \\
\text { Sig. (2-tailed) } \\
\text { N }\end{array}$ & $\begin{array}{l}.040 \\
.515 \\
266 \\
\end{array}$ & $\begin{array}{l}.050 \\
.403 \\
283 \\
\end{array}$ & $\begin{array}{l}.030 \\
.633 \\
262 \\
\end{array}$ \\
\hline & & & & $\begin{array}{l}\text { PRQ-Total } \\
\text { Pearson Corr. } \\
\text { Sig. (2-tailed) } \\
\text { N }\end{array}$ & $\begin{array}{l}.020 \\
.745 \\
261 \\
\end{array}$ & $\begin{array}{l}.002 \\
.978 \\
277 \\
\end{array}$ & $\begin{array}{l}.009 \\
.890 \\
257\end{array}$ \\
\hline
\end{tabular}

** Correlation is significant at the 0.01 level (2-tailed)

* Correlation is significant at the 0.05 level (2-tailed) 
Table 40

Pearson Correlations Based on Collaboration (A, C, \& T)

and Occupational Stress (All Sub-Scales)

\begin{tabular}{|c|c|c|c|c|c|c|c|}
\hline $\begin{array}{l}\text { ORQ } \\
\text { Sub-Scales }\end{array}$ & CPS-A & CPS-C & CPS-T & $\begin{array}{l}\text { PSQ/PRQ } \\
\text { Sub-Scales }\end{array}$ & CPS-A & CPS-C & CPS-T \\
\hline $\begin{array}{l}\text { ORQ-RO } \\
\text { Pearson Corr. } \\
\text { Sig. (2-tailed) } \\
\mathrm{N}\end{array}$ & $\begin{array}{r}.171^{* *} \\
.003 \\
295 \\
\end{array}$ & $\begin{array}{l}.059 \\
.313 \\
294 \\
\end{array}$ & $\begin{array}{r}.127^{*} \\
.030 \\
292 \\
\end{array}$ & $\begin{array}{l}\text { PSQ-VS } \\
\text { Pearson Corr. } \\
\text { Sig. (2-tailed) } \\
\mathrm{N}\end{array}$ & $\begin{array}{l}.007 \\
.904 \\
290 \\
\end{array}$ & $\begin{array}{r}-.125^{*} \\
.034 \\
289 \\
\end{array}$ & $\begin{array}{r}-.067 \\
.258 \\
287 \\
\end{array}$ \\
\hline $\begin{array}{l}\text { ORQ-RI } \\
\text { Pearson Corr. } \\
\text { Sig. (2-tailed) } \\
\mathrm{N} \\
\end{array}$ & $\begin{array}{r}. .004 \\
.948 \\
296 \\
\end{array}$ & $\begin{array}{r}-.197 * * \\
.001 \\
295 \\
\end{array}$ & $\begin{array}{r}-.114 \\
.051 \\
293 \\
\end{array}$ & $\begin{array}{l}\text { PSQ-PSY } \\
\text { Pearson Corr. } \\
\text { Sig. (2-tailed) } \\
\mathrm{N}\end{array}$ & $\begin{array}{l}.044 \\
.456 \\
290 \\
\end{array}$ & $\begin{array}{r}-.127 * \\
.030 \\
289 \\
\end{array}$ & $\begin{array}{r}-.048 \\
.420 \\
287 \\
\end{array}$ \\
\hline $\begin{array}{l}\text { ORQ-RA } \\
\text { Pearson Corr. } \\
\text { Sig. (2-tailed) } \\
\mathrm{N}\end{array}$ & $\begin{array}{r}-.097 \\
.097 \\
295 \\
\end{array}$ & $\begin{array}{r}-.225 * * \\
.000 \\
294 \\
\end{array}$ & $\begin{array}{r}-.183^{* *} \\
.002 \\
292 \\
\end{array}$ & $\begin{array}{l}\text { PSQ-IS } \\
\text { Pearson Corr. } \\
\text { Sig. (2-tailed) } \\
\mathrm{N}\end{array}$ & $\begin{array}{l}.070 \\
.249 \\
275 \\
\end{array}$ & $\begin{array}{r}-.073 \\
.228 \\
274 \\
\end{array}$ & $\begin{array}{r}-.006 \\
.923 \\
272 \\
\end{array}$ \\
\hline $\begin{array}{l}\text { ORQ-RB } \\
\text { Pearson Corr. } \\
\text { Sig. (2-tailed) } \\
\mathrm{N} \\
\end{array}$ & $\begin{array}{l}.089 \\
.127 \\
293 \\
\end{array}$ & $\begin{array}{r}-.100 \\
.087 \\
292 \\
\end{array}$ & $\begin{array}{r}-.009 \\
.877 \\
290 \\
\end{array}$ & $\begin{array}{l}\text { PSQ-PHS } \\
\text { Pearson Corr. } \\
\text { Sig. (2-tailed) } \\
\mathrm{N}\end{array}$ & $\begin{array}{l}.112 \\
.059 \\
285 \\
\end{array}$ & $\begin{array}{r}-.085 \\
.152 \\
284 \\
\end{array}$ & $\begin{array}{r}.013 \\
.827 \\
282 \\
\end{array}$ \\
\hline $\begin{array}{l}\text { ORQ-R } \\
\text { Pearson Corr. } \\
\text { Sig. (2-tailed) } \\
\mathrm{N} \\
\end{array}$ & $\begin{array}{r}.185 * * \\
.001 \\
293 \\
\end{array}$ & $\begin{array}{l}.022 \\
.710 \\
292 \\
\end{array}$ & $\begin{array}{r}.111 \\
.058 \\
290 \\
\end{array}$ & $\begin{array}{l}\text { PSQ-Total } \\
\text { Pearson Corr. } \\
\text { Sig. (2-tailed) } \\
\mathrm{N} \\
\end{array}$ & $\begin{array}{l}.050 \\
.411 \\
273 \\
\end{array}$ & $\begin{array}{r}-.138 * \\
.023 \\
272 \\
\end{array}$ & $\begin{array}{r}-.052 \\
.397 \\
270 \\
\end{array}$ \\
\hline $\begin{array}{l}\text { ORQ-PE } \\
\text { Pearson Corr. } \\
\text { Sig. (2-tailed) } \\
\mathrm{N} \\
\end{array}$ & $\begin{array}{r}.081 \\
.168 \\
292 \\
\end{array}$ & $\begin{array}{l}.012 \\
.843 \\
291 \\
\end{array}$ & $\begin{array}{l}.050 \\
.396 \\
289 \\
\end{array}$ & $\begin{array}{l}\text { PRQ- RE } \\
\text { Pearson Corr. } \\
\text { Sig. (2-tailed) } \\
\text { N }\end{array}$ & $\begin{array}{l}.038 \\
.522 \\
284 \\
\end{array}$ & $\begin{array}{l}.105 \\
.079 \\
283 \\
\end{array}$ & $\begin{array}{r}.082 \\
.172 \\
281 \\
\end{array}$ \\
\hline $\begin{array}{l}\text { ORQ-Total } \\
\text { Pearson Corr. } \\
\text { Sig. (2-tailed) } \\
\mathrm{N}\end{array}$ & $\begin{array}{l}.098 \\
.097 \\
290 \\
\end{array}$ & $\begin{array}{r}-.128 * \\
.031 \\
284 \\
\end{array}$ & $\begin{array}{r}-.020 \\
.732 \\
. \quad 282 \\
\end{array}$ & $\begin{array}{l}\text { PRQ-SC } \\
\text { Pearson Corr. } \\
\text { Sig. (2-tailed) } \\
\mathrm{N}\end{array}$ & $\begin{array}{l}.066 \\
.264 \\
285 \\
\end{array}$ & $\begin{array}{r}.152^{*} \\
.010 \\
284 \\
\end{array}$ & $\begin{array}{r}.121^{*} \\
.042 \\
282 \\
\end{array}$ \\
\hline & & & & $\begin{array}{l}\text { PRQ-SS } \\
\text { Pearson Corr. } \\
\text { Sig. (2-tailed) } \\
\text { N }\end{array}$ & $\begin{array}{r}.145^{*} \\
.014 \\
284 \\
\end{array}$ & $\begin{array}{r}.127^{*} \\
.033 \\
283 \\
\end{array}$ & $\begin{array}{r}.154 * * \\
.010 \\
281 \\
\end{array}$ \\
\hline & & & & $\begin{array}{l}\text { PRQ-RC } \\
\text { Pearson Corr. } \\
\text { Sig. (2-tailed) } \\
\text { N }\end{array}$ & $\begin{array}{r}.158 * * \\
.008 \\
285 \\
\end{array}$ & $\begin{array}{r}.197 * * \\
.001 \\
284 \\
\end{array}$ & $\begin{array}{r}.198 * * \\
.001 \\
282 \\
\end{array}$ \\
\hline & & & & $\begin{array}{l}\text { PRQ-Total } \\
\text { Pearson Corr. } \\
\text { Sig. (2-tailed) } \\
\text { N }\end{array}$ & $\begin{array}{r}.141^{*} \\
.018 \\
279\end{array}$ & $\begin{array}{r}.199 * * \\
.001 \\
278\end{array}$ & $\begin{array}{r}.192^{* *} \\
.001 \\
276\end{array}$ \\
\hline
\end{tabular}

** Correlation is significant at the 0.01 level (2-tailed)

* Correlation is significant at the 0.05 level (2-tailed) 
Table 41

Pearson Correlations Based on Total Scores on

Scope of Practice, Collaboration, and Occupational Stress

\begin{tabular}{|ll|r|r|r|r|}
\hline & SOP-T & \multicolumn{1}{c|}{ CPS-T } & \multicolumn{1}{|l|}{ ORQ-T } & \multicolumn{1}{|l|}{ PSQ-T } \\
\hline SOP-T & Pearson Correlation & & & & \\
& Sig. (2-tailed) & & & & \\
& $\mathrm{N}$ & $.277^{* *}$ & & & \\
\hline CPS-T & Pearson Correlation & .000 & & & \\
& Sig. (2-tailed) & 279 & & & \\
& $\mathrm{~N}$ & .120 & -.020 & & \\
\hline ORQ-T & Pearson Correlation & .051 & .732 & & \\
& Sig. (2-tailed) & 262 & 282 & & \\
& $\mathrm{~N}$ & -.050 & -.052 & $.623^{* *}$ & \\
\hline PSQ-T & Pearson Correlation & .425 & .397 & .000 & \\
& Sig. (2-tailed) & 252 & 270 & 296 & \\
& $\mathrm{~N}$ & .009 & $.192^{* *}$ & $-.337^{* *}$ & $-.524^{* *}$ \\
& .890 & .001 & .000 & .000 \\
PRQ-T & Pearson Correlation & 257 & 276 & 300 & 300 \\
& Sig. (2-tailed) & & & \\
& $\mathrm{N}$ & & & \\
\end{tabular}

** Correlation is significant at the 0.01 level (2-tailed)

scale, the lower the stress related to role ambiguity. On the other hand, the higher the assertiveness on the CPS-A scale, the higher the psychological strain related to physical strain (PSQ-PHS). There were no other significant correlations identified in the higher SOP group for the subscales of the OSI and the CPS scales.

Table 43 presents the findings in relation to groups who fell into the lower (more restricted) SOP group $(n=40)$. There were significant correlations between ORQ-RO (role overload) and collaboration in the CPS-A $(r=.504)$, CPS-C $(r=.415)$, and CPS-T $(r=.490)$. This would seem to indicate that for the group with lower SOP scores, those with a higher level of collaboration on all three scales are less likely to be stressed in relation to role overload. In addition, the following significant correlations were found in the lower SOP group: ORQ-R and CPS-A $(r=.447)$, ORQ-T and CPS-A ( $r=$ .334). This finding indicates that the higher the assertiveness the lower the stress related to responsibility, and that the lower overall occupational stress is likely to be in CRNAs who perceive higher levels of assertiveness. A significant correlation between PSQ-PSY and CPS-A $(r=.360)$ suggests that CRNAs who are experiencing psychological strain and/or emotional problems, tend to have higher assertiveness scores. Finally there was a relationship among PRQ-SC and CPS-C ( $r=$ .342), revealing that in lower SOP groups, there were higher use of personal resources from the 
subscale of self-care in relation to higher CPS-C scores. The findings revealed in these two tables indicated that the CRNAs seem to experience collaboration occupational stress differently according to their scope of practice. Only in the following sequence were all variables correlated among one another: PRQ-SS (social support) along with SOP-T( $r=.124)$, CPS-A $(r=.145)$, CPS-C $(r=.127)$, and CPS-T $(r=.154)$ all resulted in positive correlations. This would indicate that when PRQ-SS (social support) is higher, which means that CRNAs feel support and help from those around him/her (Osipow, 1998), there are reported higher overall broader scope of practice, and higher levels of collaboration, on all three CPS scales.

\section{Other Findings}

In addition to the results reported earlier regarding the characteristics of the ACT in terms of SOP in Table 22, other results were also found in terms of the CPS and OSI: ACT employment arrangement (physician group practice versus all others), gender, age (above and below 50 years), and credentials (above and below master's degree). Means, standard deviations, and t-Testing was conducted. Tables $44,45,46$, and 47 provide an overview of the results. There were no significant differences in whether CRNA respondents were employed and practiced in an physician-based group or not, on all total scales of the CPS and all total subscales of the OSI (Table 44). As pointed out earlier, there were no differences in terms of age, educational credentials, and gender on SOP-T scores, except that male respondents had slightly higher SOP-T scores (refer to Table 22). In the analyses of gender (Table 45), age (Table 46), and educational credentials (Table 47) on CPS and OSI, there were no significant difference reported, as well. 
Table 42

Pearson Correlations Based on High (Broader) Scope of Practice,

Collaboration, and Occupational Stress

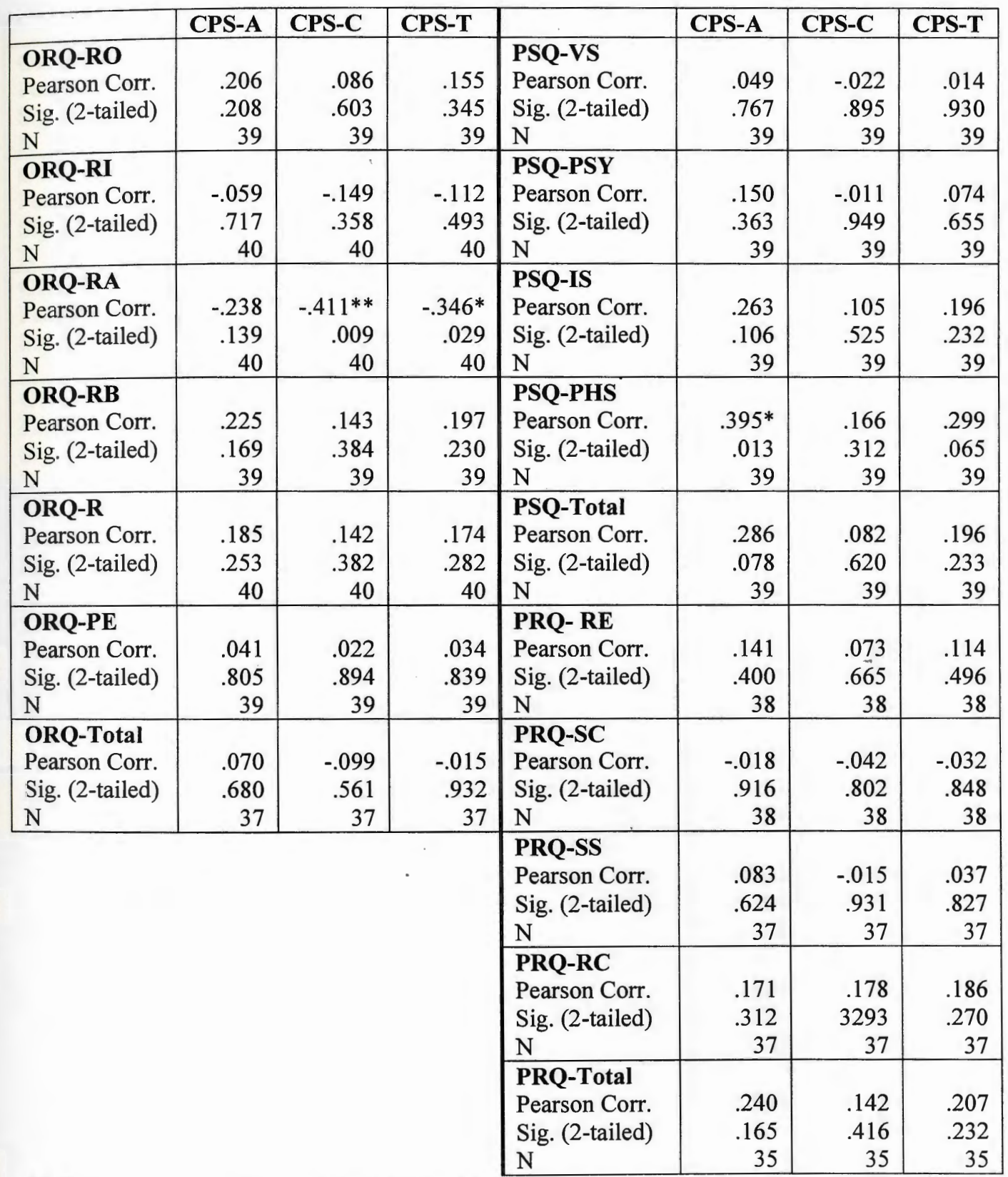

** Correlation is significant at the 0.01 level (2-tailed)

* Correlation is significant at the 0.05 level (2-tailed) 
Table 43

Pearson Correlations Based on Low (Restricted) Scope of Practice,

Collaboration, and Occupational Stress

\begin{tabular}{|c|c|c|c|c|c|c|c|}
\hline & CPS-A & CPS-C & CPS-T & & CPS-A & CPS-C & CPS-T \\
\hline $\begin{array}{l}\text { ORQ-RO } \\
\text { Pearson Corr. } \\
\text { Sig. (2-tailed) } \\
\mathrm{N}\end{array}$ & $\begin{array}{r}.504^{* *} \\
.001 \\
40 \\
\end{array}$ & $\begin{array}{r}.415^{* *} \\
.008 \\
40 \\
\end{array}$ & $\begin{array}{r}.490 * * \\
.001 \\
40 \\
\end{array}$ & $\begin{array}{l}\text { PSQ-VS } \\
\text { Pearson Corr. } \\
\text { Sig. (2-tailed) } \\
\mathrm{N}\end{array}$ & $\begin{array}{r}.243 \\
.137 \\
39 \\
\end{array}$ & $\begin{array}{r}.108 \\
.515 \\
39 \\
\end{array}$ & $\begin{array}{r}.181 \\
.269 \\
39 \\
\end{array}$ \\
\hline $\begin{array}{l}\text { ORQ-RI } \\
\text { Pearson Corr. } \\
\text { Sig. (2-tailed) } \\
\mathrm{N}\end{array}$ & $\begin{array}{r}.189 \\
.242 \\
40 \\
\end{array}$ & $\begin{array}{r}.098 \\
.546 \\
40 \\
\end{array}$ & $\begin{array}{r}.150 \\
.355 \\
40 \\
\end{array}$ & $\begin{array}{l}\text { PSQ-PSY } \\
\text { Pearson Corr. } \\
\text { Sig. (2-tailed) } \\
\mathrm{N}\end{array}$ & $\begin{array}{r}.366^{*} \\
.022 \\
39 \\
\end{array}$ & $\begin{array}{r}.130 \\
.432 \\
39 \\
\end{array}$ & $\begin{array}{r}.255 \\
.117 \\
39 \\
\end{array}$ \\
\hline $\begin{array}{l}\text { ORQ-RA } \\
\text { Pearson Corr. } \\
\text { Sig. (2-tailed) } \\
\mathrm{N}\end{array}$ & $\begin{array}{r}.047 \\
.773 \\
40 \\
\end{array}$ & $\begin{array}{r}-.034 \\
.833 \\
40 \\
\end{array}$ & $\begin{array}{r}.003 \\
.986 \\
40 \\
\end{array}$ & $\begin{array}{l}\text { PSQ-IS } \\
\text { Pearson Corr. } \\
\text { Sig. (2-tailed) } \\
\mathrm{N}\end{array}$ & $\begin{array}{r}.213 \\
.219 \\
35 \\
\end{array}$ & $\begin{array}{r}-.040 \\
.818 \\
35 \\
\end{array}$ & $\begin{array}{r}.082 \\
.641 \\
35 \\
\end{array}$ \\
\hline $\begin{array}{l}\text { ORQ-RB } \\
\text { Pearson Corr. } \\
\text { Sig. (2-tailed) } \\
\mathrm{N}\end{array}$ & $\begin{array}{r}.264 \\
.109 \\
38 \\
\end{array}$ & $\begin{array}{r}-.065 \\
.698 \\
38 \\
\end{array}$ & $\begin{array}{r}.091 \\
.588 \\
38 \\
\end{array}$ & $\begin{array}{l}\text { PSQ-PHS } \\
\text { Pearson Corr. } \\
\text { Sig. (2-tailed) } \\
\mathrm{N}\end{array}$ & $\begin{array}{r}.246 \\
.143 \\
37 \\
\end{array}$ & $\begin{array}{r}-.127 \\
.453 \\
37 \\
\end{array}$ & $\begin{array}{r}.046 \\
.788 \\
37 \\
\end{array}$ \\
\hline $\begin{array}{l}\text { ORQ-R } \\
\text { Pearson Corr. } \\
\text { Sig. (2-tailed) } \\
\mathrm{N}\end{array}$ & $\begin{array}{r}.447 * * \\
.005 \\
38 \\
\end{array}$ & $\begin{array}{r}.112 \\
.505 \\
38 \\
\end{array}$ & $\begin{array}{r}.286 \\
.082 \\
38 \\
\end{array}$ & $\begin{array}{l}\text { PSQ-Total } \\
\text { Pearson Corr. } \\
\text { Sig. (2-tailed) } \\
\mathrm{N}\end{array}$ & $\begin{array}{r}.289 \\
.097 \\
34 \\
\end{array}$ & $\begin{array}{r}-.015 \\
.935 \\
34 \\
\end{array}$ & $\begin{array}{r}.134 \\
.449 \\
34 \\
\end{array}$ \\
\hline $\begin{array}{l}\text { ORQ-PE } \\
\text { Pearson Corr. } \\
\text { Sig. (2-tailed) } \\
\mathrm{N}\end{array}$ & $\begin{array}{r}.011 \\
.947 \\
39\end{array}$ & $\begin{array}{r}-.211 \\
.197 \\
39 \\
\end{array}$ & $\begin{array}{r}-.119 \\
.471 \\
39 \\
\end{array}$ & $\begin{array}{l}\text { PRQ- RE } \\
\text { Pearson Corr. } \\
\text { Sig. (2-tailed) } \\
\mathrm{N}\end{array}$ & $\begin{array}{r}-.044 \\
.794 \\
37 \\
\end{array}$ & $\begin{array}{r}-.023 \\
.891 \\
37 \\
\end{array}$ & $\begin{array}{r}-.035 \\
.835 \\
37 \\
\end{array}$ \\
\hline $\begin{array}{l}\text { ORQ-Total } \\
\text { Pearson Corr. } \\
\text { Sig. (2-tailed) } \\
\text { N }\end{array}$ & $\begin{array}{r}.334 * \\
.047 \\
36\end{array}$ & $\begin{array}{r}.034 \\
.844 \\
36\end{array}$ & $\begin{array}{r}.184 \\
.283 \\
36\end{array}$ & $\begin{array}{l}\text { PRQ-SC } \\
\text { Pearson Corr. } \\
\text { Sig. (2-tailed) } \\
\mathrm{N}\end{array}$ & $\begin{array}{r}.216 \\
.193 \\
38\end{array}$ & $\begin{array}{r}.342 * \\
.035 \\
38\end{array}$ & $\begin{array}{r}.307 \\
.061 \\
38\end{array}$ \\
\hline & & & . & $\begin{array}{l}\text { PRQ-SS } \\
\text { Pearson Corr. } \\
\text { Sig. (2-tailed) } \\
\mathrm{N}\end{array}$ & $\begin{array}{r}-.202 \\
.224 \\
38 \\
\end{array}$ & $\begin{array}{r}-.032 \\
.851 \\
38 \\
\end{array}$ & $\begin{array}{r}-.008 \\
.482 \\
38 \\
\end{array}$ \\
\hline & & & & $\begin{array}{l}\text { PRQ-RC } \\
\text { Pearson Corr. } \\
\text { Sig. (2-tailed) } \\
\mathrm{N}\end{array}$ & $\begin{array}{r}.104 \\
.536 \\
38 \\
\end{array}$ & $\begin{array}{r}.282 \\
.113 \\
38 \\
\end{array}$ & $\begin{array}{r}.205 \\
.218 \\
38 \\
\end{array}$ \\
\hline & & & & $\begin{array}{l}\text { PRQ-Total } \\
\text { Pearson Corr. } \\
\text { Sig. (2-tailed) } \\
\mathrm{N}\end{array}$ & $\begin{array}{r}-.008 \\
.961 \\
37\end{array}$ & $\begin{array}{r}.057 \\
.353 \\
37\end{array}$ & $\begin{array}{r}.089 \\
.601 \\
37\end{array}$ \\
\hline
\end{tabular}

** Correlation is significant at the 0.01 level (2-tailed)

* Correlation is significant at the 0.05 level (2-tailed) 
Table 44

Means, Standard Deviation, and t-Test Comparing

Employment Arrangement with CPS-T, ORQ-T, PSQ-T, and PRQ-T

\begin{tabular}{|c|c|c|c|c|c|}
\hline \multirow{3}{*}{$\begin{array}{c}\text { Factor on } \\
\text { Employment } \\
\text { Arrangement: }\end{array}$} & \multirow[t]{3}{*}{$\mathbf{N}$} & \multirow[t]{3}{*}{ Mean } & \multirow{3}{*}{$\begin{array}{l}\text { Standard } \\
\text { Deviation }\end{array}$} & \multicolumn{2}{|c|}{ t-Test } \\
\hline & & & & \multicolumn{2}{|c|}{ - } \\
\hline & & & & F Value & (Sig.) \\
\hline CPS-T & & & & & \\
\hline Physician Group & 203 & 54.22 & 13.04 & & \\
\hline All Others & 103 & 52.99 & 14.01 & .734 & .392 \\
\hline \multicolumn{6}{|l|}{ ORQ-T } \\
\hline Physician Group & 194 & 131.74 & 23.90 & & \\
\hline All Others & 125 & 132.66 & 27.36 & 4.28 & .039 \\
\hline \multicolumn{6}{|l|}{ PSQ-T } \\
\hline Physician Group & 191 & 71.69 & 18.19 & & \\
\hline All Others & 118 & 73.04 & 21.59 & 2.88 & .091 \\
\hline \multicolumn{6}{|l|}{ PRQ-T } \\
\hline Physician Group & 195 & 139.85 & 19.20 & & \\
\hline All Others & 119 & 138.83 & 20.61 & .028 & .868 \\
\hline
\end{tabular}


Table 45

Means, Standard Deviation, and T-test Comparing

Gender with CPS-T, ORQ-T, PSQ-T, and PRQ-T

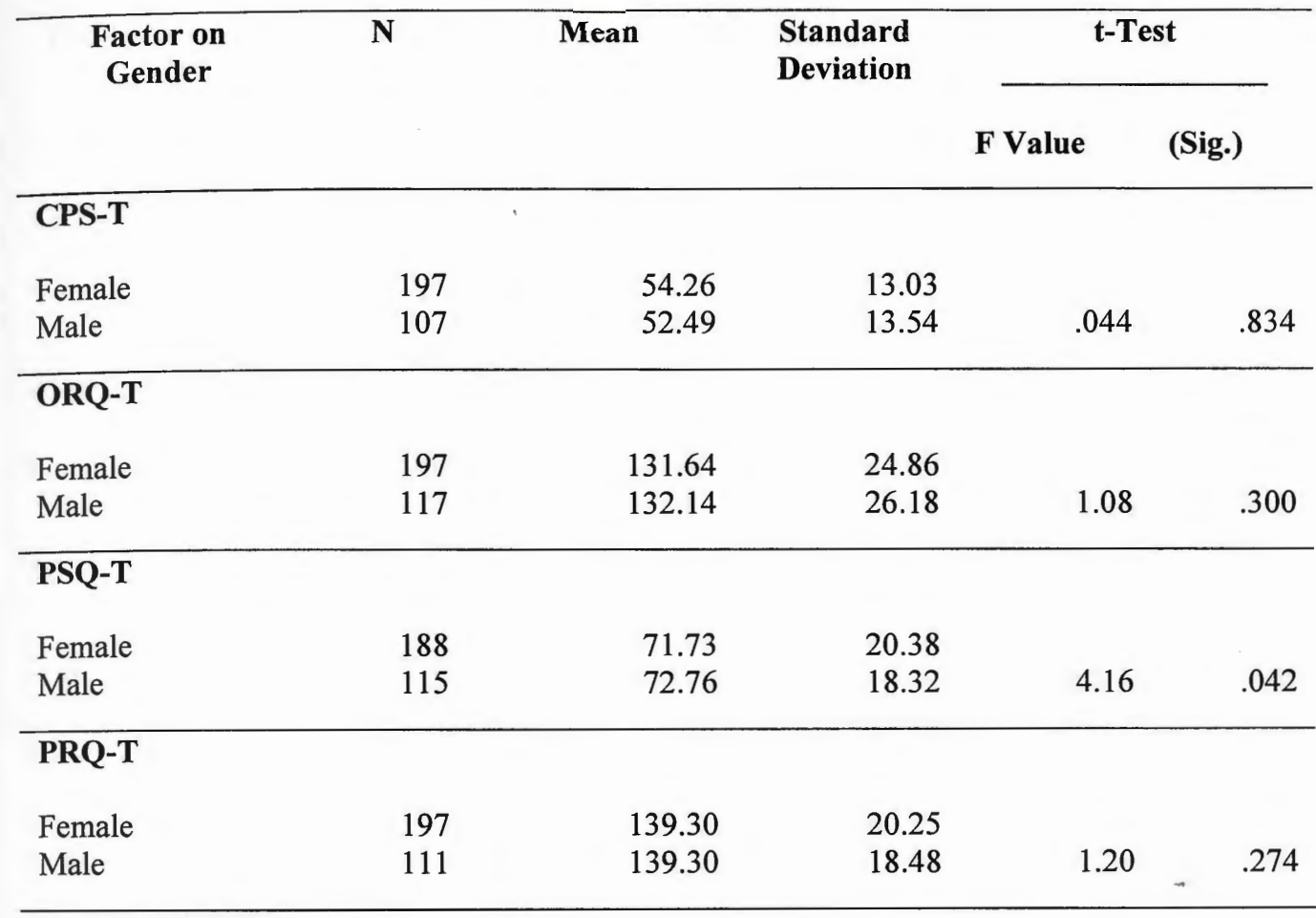


Table 46

Means, Standard Deviation, and T-test Comparing

Age with CPS-T, ORQ-T, PSQ-T, and PRQ-T

\begin{tabular}{|c|c|c|c|c|c|}
\hline \multirow[t]{2}{*}{ Factor on Age } & \multirow[t]{2}{*}{$\mathbf{N}$} & \multirow[t]{2}{*}{ Mean } & \multirow{2}{*}{$\begin{array}{l}\text { Standard } \\
\text { Deviation }\end{array}$} & \multicolumn{2}{|c|}{ t-Test } \\
\hline & & & & F Value & (Sig.) \\
\hline CPS-T & & . & & & \\
\hline Older $(>=50)$ & 111 & 54.55 & 13.28 & & \\
\hline Younger $(<50)$ & 193 & 53.11 & 13.19 & .026 & .873 \\
\hline \multicolumn{6}{|l|}{ ORQ-T } \\
\hline Older $(>=50)$ & 115 & 126.13 & 24.00 & & \\
\hline Younger $(<50)$ & 199 & 135.12 & 25.53 & 1.70 & .193 \\
\hline \multicolumn{6}{|l|}{ PSQ-T } \\
\hline Older $(>=50)$ & 113 & 69.42 & 18.83 & & \\
\hline Younger $(<50)$ & 190 & 73073 & 19.92 & 1.99 & .159 \\
\hline \multicolumn{6}{|l|}{ PRQ-T } \\
\hline Older $(>=50)$ & 114 & 142.46 & 17.70 & & \\
\hline Younger $(<50)$ & 194 & 137.49 & 20.46 & 1.75 & .187 \\
\hline
\end{tabular}


Table 47

Means, Standard Deviation, and T-test Comparing

Educational Level with CPS-T, ORQ-T, PSQ-T, and PRQ-T

\begin{tabular}{|c|c|c|c|c|c|}
\hline \multirow{2}{*}{$\begin{array}{l}\text { Factor on } \\
\text { Credential }\end{array}$} & \multirow[t]{2}{*}{$\mathbf{N}$} & \multirow[t]{2}{*}{ Mean } & \multirow{2}{*}{$\begin{array}{l}\text { Standard } \\
\text { Deviation }\end{array}$} & \multicolumn{2}{|c|}{ t-Test } \\
\hline & & & & F Value & (Sig.) \\
\hline CPS-T & & & & & \\
\hline Master or Higher & 159 & 52.87 & 13.28 & & \\
\hline Less than Masters & 145 & 54.65 & 13.20 & .385 & .536 \\
\hline \multicolumn{6}{|l|}{ ORQ-T } \\
\hline Master or Higher & 160 & 137.76 & 25.12 & & \\
\hline Less than Masters & 154 & 125.66 & 23.99 & .538 & .464 \\
\hline \multicolumn{6}{|l|}{ PSQ-T } \\
\hline Master or Higher & 153 & 73039 & 20.65 & & \\
\hline Less than Masters & 150 & 70.67 & 18.25 & 1.36 & .245 \\
\hline \multicolumn{6}{|l|}{ PRQ-T } \\
\hline Master or Higher & 155 & 138.99 & 19.56 & & \\
\hline Less than Masters & 153 & 139.77 & 19.64 & .117 & .732 \\
\hline
\end{tabular}




\section{CHAPTER V}

\section{CONCLUSIONS, IMPLICATIONS, AND RECOMMENDATIONS}

\section{Introduction}

The purpose of this study was to examine specific characteristics of CRNA scope of practice in anesthesia care team settings in relation to collaboration and occupational stress. The philosophical underpinnings in this study stem from a critical philosophy viewpoint, as a broad perspective in understanding the depiction of domination and conflict between nurse anesthetists and anesthesiologists in anesthesia care team environments. The theoretical framework in this study specifically focuses on the interrelated concepts of care and therapy in nursing practice, driving toward quality practice, as Kim (1998a) has conceptualized. The following section provides an overview of the quality of practice framework in relation to the study.

The organization of Kim's (1998a) quality of practice framework is based on the four components of goals of patient care, the process of care, quality of care, and patient outcomes. The primary focus in this study is directed toward the process component in the framework. The process component refers to the activities, performances, management, and instrumentation that occur in patient care. Thus, Kim (1994, 1998a) views nursing practice as involving a complex process, which includes both the individual nurse's perspective, and a interdisciplinary coordinated process in addressing both the philosophies of care and therapy. Anesthesia care team practice is uniquely positioned in carrying out these two processes with CRNAs and anesthesiologists sharing in the anesthesia patient care activities. Conflicts may arise when boundaries between both professionals are not clearly delineated. The success of any "care-team" focus, as in the ACT setting, is related to an effective coordination of care activities, and will influence the quality of anesthesia care provided. In an effort to capture the essences of the individual and coordinated practice processes in the ACT, measures of collaboration were utilized as a modifying variable in understanding the relationship between CRNA scope of practice and occupational stress.

The first section of the survey utilized in the study provided preliminary demographic information that set the stage for the descriptive component of the CRNA respondents. Gleaned from the demographic descriptions of the sample, were the characteristics of the respondents in terms of employment arrangement, practice setting, the quantity of CRNAs and anesthesiologists within the setting, age, gender, 
academic credential, and years of experiences. These characteristics were than examined in relation to the context of their reported scope of practice.

The primary goal in the development of the scope of practice tool was to provide an organized mapping of the anesthesia activities found in ACT settings, from pre-anesthesia to post-anesthesia care. The SOP tool hence, is utilized as a way of understanding both the philosophies of care and therapeutics involved in individual practice in ACT settings. The items on the SOP tool reflected many aspects of anesthesia care both from a physical "hands-on" therapeutic sense, and from an interactive (CRNA-patient) caring perspective. The collaborative practice scale (CPS) was utilized simply as a way of gauging the strength of the individual CRNA's practice process, with that of the anesthesiologist's role in coordinating the anesthesia care activities. Finally, the occupational stress inventory (OSI) was used as an indication of individual CRNA's role related stress measure.

\section{Summary of Findings and Conclusions}

The research was guided by several research questions as outlined. The first research question was "what are the characteristics of the anesthesia care team environment based on aspects of individual CRNA scope of practice?" In summary, this study found that in terms of ACT characteristics, there were significant differences in the SOP scale according to the level of education of the CRNA respondents. CRNAs with masters degree or higher were more likely to have higher SOP scores. This means that more highly educated CRNAs are more likely to be engaged in a broad spectrum of practice in anesthesia care teams. This may be the result of self-selection on the part of the CRNAs, or higher level expectations by co-working anesthesiologists.

In relation to employment arrangement, CRNAs employed by hospitals reported higher SOP scores than those employed by anesthesiology groups. This suggests that there may be institutionallyoriented structures in hospital-based practices that allow CRNAs to engage in a broader spectrum of anesthesia care, in contrast to what exist in CRNA practice in anesthesiologists owned groups. In terms of the availability of specialty anesthesia services, and whether CRNA respondents actually performed these anesthetics, there were significant differences reported. These findings indicated that CRNAs who have access to most of the specialty anesthesia services were more apt to be personally involved in these cases. 
These findings indicated that CRNA's scope of practice is likely to be determined by the contextual expectations and arrangements that exist in the ACT setting, rather than by their individual characteristics.

The second research question was "what are individual CRNAs reported perceptions of collaboration between CRNAs and anesthesiologists, based on the collaborative practice scale?" Based on the results outlined related to the CPS, very few CRNAs practicing in ACTs perceive their practice as collaborating with anesthesiologists. The overall levels of perceived assertiveness and cooperativeness by this group fell at the middle point within the ranges, indicating that in general, CRNAs tended to feel somewhat constrained and limited in their collaborative practice with anesthesiologists. Of the five mode preferences on the CPS, the compromising mode was most frequently reported by the respondents in the sample, with the avoidance mode as the next most frequent type. This finding indicated that in most situations, CRNAs are more apt to utilize a compromising or an avoiding approach to conflict resolution, as opposed to collaborating, or competition. It seems that CRNA respondents prefer to avoid escalating the conflict by striving to neutralize interpersonal differences, further reducing their ability to satisfy their own individual concerns regarding patient care situations. This may mean that either the CRNAs themselves feel constrained and dominated to assert their authority and rights, or the CRNAs are institutionally and organizationally constrained and dominated. Therefore, they feel powerless, thus resorting to accommodation and compromise. This is in line with the arguments offered by critical philosophy, which suggest that people in social relations may be systematically constrained to assert themselves through power-domination. There certainly are both institutional and professional power differences between CRNAs and anesthesiologists

The third research question was "is there a significant relationship between CRNAs reported individual scope of practice in ACT settings and collaboration?" Based on the SOP scale in relation to CPS scores, higher mean scores on the CPS were reported in groups with a broader (less restricted) SOP in the ACT setting, and lower mean scores on the CPS were reported in groups with more restricted SOP environments. These results indicated that the low SOP group in general perceived lower levels of both assertiveness and cooperativeness in their practices, than those who viewed their practice as having higher scope. These findings, therefore, support the research questions in that there was a significant relationship between the SOP and perceived level of collaboration in ACT settings. The theoretical meaning behind 
these findings suggest that having a broader scope of practice indicates increased responsibilities, increased degree of independence, and increased degree of active engagement in complex anesthesia care. In these situations in practice, CRNAs may be viewed as emotionally and professionally more self-assured. In addition, CRNAs may be viewed by anesthesiologists as colleagues, which would allow more intrinsic power for CRNAs to practice in an environment with increased autonomy and independence.

The fourth research question was; "is there a relationship among CRNAs reported scope of practice, perception of collaboration, and occupational stress?" In terms of the relationships among scope of practice and occupational stress, there were significant differences associated with two subscales of the OSI and SOP. On the two OSI subscales of role overload (RO) and responsibility (R), the higher SOP groups had higher occupational stress scores than the lower SOP groups. This may mean that those with broader (less restricted) scope of practice are experiencing increased stress in terms of role overload and responsibility. There were no significant correlations between SOP and the OSI dimensions of role stress and psychological strain. In relation to CRNA use of coping resources, there was a significant relationship between SOP with coping resources and social support. This suggest that although CRNAs with a broader (less restricted) scope of practice experience some role overload and increased responsibility, they are capable of using appropriate coping resources when dealing with occupational stress. Finally, as reported earlier, higher scores on role insufficiency with SOP-B and SOP-T, suggests that CRNAs who score lower in the personal performance of many of the skills and procedures have higher role insufficiency in ACT settings. In addition, these same CRNA respondents had higher scores on role ambiguity, and had lower scores on the CPS-C and CPS-T scales. These findings indicated that CRNAs seem to experience collaboration and occupational stress differently based on their reported level of scope of practice in the anesthesia care team environment.

A revised model for the relationship among scope of practice, collaboration, and occupational stress are presented in Figure 6. The model suggest that there are multiple factors that contribute and influence CRNA scope of practice in anesthesia care teams. The most significant factors, as identified in the analysis were the structural component (based on employment arrangements), and personal factors (specifically, educational level). These two factors have a significant relationship to levels of scope of 
practice (weather broader or restricted). In terms of collaboration, CRNAs with a broader scope of practice tend to have higher perceived collaboration. But, as noted earlier, CRNAs with a lower scope of practice tend to fall within the categories of compromise and avoidance. Although there was limited significance in terms of CRNA occupational role stress, when role-overload and increased responsibility are identified, CRNAs tend to utilize appropriate coping resources to overcome these role stressors.

\section{$\underline{\text { Limitations }}$}

Although the sample under investigation was statistically adequate to meet the requirements for effect size and power, and relatively homogenous with respect to regional and national demographics, a larger response rate might have provided even greater significance to address the research questions. Future studies examining collaboration and occupational stress may include a broader sample size including all seven regions of the United States, based on AANA membership distribution. In addition, the accuracy and honesty of the respondents may have influenced by the attitude of the respondent in relation to the occurrences of the particular day in which the survey was completed. Another issue that may have impacted the overall response rate was related to the amount of time necessary to complete the survey and the survey's length. This was evident by six respondents who wrote in the margins of the survey that the questionnaire was very long and took more than 45 minutes to complete. This "survey-burden" that was experienced by these particular respondents may have contributed to the lower return rate. Finally, a major concern in this study was how the large number of non-respondents $(69 \%)$ could have influenced the final analysis. Therefore, although the sample size met the minimum requirements for power, other factors may have motivate the respondents to fill-out the questionnaires. These factors include attitudes about employer-employee relationships, beliefs about filling out questionnaires in general, and overall feelings toward research studies and contributing to knowledge development. One way to curtail the low response rate would be to implement a second phase of data collection for non-respondents.

\section{Implications and Recommendations}

Widespread variations in the manner in which CRNA's practice in anesthesia care teams (ACTs) has created an urgency to better understand the salient features of CRNA scope of practice (SOP). Variations to the structural nature of CRNA scope of practice in anesthesia care teams has many possible connotations for improving both the efficiency and quality of anesthesia care services. Although this study 
does not directly indicate how the context of the ACT structure influences patient care outcomes, ensuring quality anesthesia care services must include a clearer understanding of each partners role (both CRNAs and anesthesiologists) in the situation. This study begins to unfold the many characteristics and relationships among how CRNAs practice in ACTs, their therapeutic and caring measures for patients, and their interactions and collaborative approaches with anesthesiologists. In the following section, implications and recommendations for this study are presented both from a quality of anesthesia care perspective and its influence on patient care outcomes.

Although this study's primary focus is related to elaborating on the process of anesthesia care team practice addressing the individual and coordinated practice processes in Kim's (1998a) framework, any research study from a nursing science perspective must include how client care is influenced. In the case of the present study, patient care outcomes studies are recommended, in terms of measuring the success or failure of the ACT environment. Because morbidity and mortality in relation to anesthesia care has been significantly reduced over the past twenty years, primarily based on improved technology and new and improved anesthesia agents, it would be impossible to link these measures to quality of ACT care. In addition, patient satisfaction data has always provided favorable patient experiences (usually greater than 90\% satisfaction). Many current patient satisfaction tools measure the patient's entire peri-operative experience, and do not separate out the anesthesia component. Usually, patients are unable to identify their anesthesia care provider on post-operative rounds. Many times patients are evaluated by an anesthesiologist several days before surgery, and anesthesia is provided by someone else (CRNA and/or anesthesiologist). Based on the results in this study, CRNAs are less apt to perform both pre-anesthetic and post-anesthetic evaluations, therefore eliminating a major nursing component of interacting with patients.

This in itself creates an environment where CRNAs may approach anesthesia care from merely the technical-cognitive approach, further removing them from a meaningful nursing perspective, incorporating the philosophies of care and therapy. Are CRNAs practicing in ACTs primarily "intra-operative" anesthesia technicians? Why is it that most patients do not understand the role of the CRNA? What are the dynamics between anesthesiologists and CRNAs that may have contributed to the role of CRNAs? Have anesthesiologists dominated CRNA practice? 
An indication that CRNAs scope of practice tends to be broader within hospital-based employment compared to anesthesiologists-owned groups, suggest that one way for CRNAs to improve independence and autonomy may be through creating a "new form" of employment arrangement. One way to examine this finding and provide recommendations to address patient care outcomes in relation to ACT practice, is to identify examplar practice environments, where CRNAs are afforded less restrictions to practice, perceive higher collaboration with anesthesiologists, and have less role stress. Another method to investigate practice patterns and CRNA independence and autonomy would be in a comparison study between hospital-employed CRNAs and anesthesiology-owned groups. This could be accomplished utilizing a qualitative approach. In this case, it is desirable that both the CRNAs and anesthesiologists be included in the study, possibly utilizing a critical method such as reflective inquiry. Critical reflective inquiry is a method of inquiry that involves critical examination of 'what is actually going on in situations of practice' through a systematic self-reflection, reflective discourse, and critically oriented change. Kim (1998b) points out that while critical reflective inquiry as a method is not oriented to verification or refutation of theories and hypotheses, its goals are to (a) understand the nature and meaning of practice to practitioners, (b) correct and improve the practice through self-reflection and criticism, and (c) generate models of "good" practice and theories of application through reflection and critique of actual occurrences.

From this approach both CRNAs and anesthesiologists in the practice environment may develop consistent standards or models that best utilizes both providers. Hence, possibly reducing cost for services, improving job satisfaction, reducing job turnover, reducing stress, and improving overall quality of care. All of these outcome characteristics can be measured and may be useful for re-designing organizational structures within ACTs, thus eliminating the duplication of services, reducing operating room turnover time, and ultimately improving the efficiency and quality of services to patients.

In reference to the scope of practice tool utilized in this study, an on-going instrument re-design has been instituted to refine the items in the scale in an effort to accurately describe all features of SOP. The first phase of instrument refinement begins with demonstrating the clarity of each item in to tool. This will be accomplished by distributing the tool to experts in the specialty of nurse anesthesia. These experts will then provide feedback and suggestions to improve the quality of each item in the tool. In the second phase, utilizing a Delphi technique, items in the tool will be categorized by the experts into either the 
philosophies of therapy or care, based on Kim's (1998a) framework. The over-riding operational definition is: CRNA scope of practice in ACTs is based on the philosophies of therapy and care. Those categorized as philosophy of therapy orient the CRNA to address patient's problems with therapeutic interventions and strategies. Those categorized as philosophy of care lead to the actions of the CRNA in relation to patients as human beings in need of support, care, understanding, and connection.

This research has attempted to illustrate the characteristics of anesthesia care team practices from a CRNA perspective, how collaboration influences the process, and the relationship with role stress. Although this study merely scratches the surface in terms of better understanding of anesthesia care team settings, it begins to illuminate the many possibilities that are available to improve the practice environment, and ultimately improving the quality of practice. It has long been said that both CRNAs and anesthesiologists must continue to value their individual worth to anesthesia care delivery. The challenge ahead is to create an atmosphere that encourages a structure that includes incentives and opportunities for both providers to work in a collaborative fashion. This focus can virtually eliminate disparities, and both providers can pool their energies and creativity (both from a advanced nursing and medical care perspective) toward a common goal of quality anesthesia care. 
Figure 6

A Revised Model of Relationships Among Scope of Practice, Collaboration, and Occupational Stress

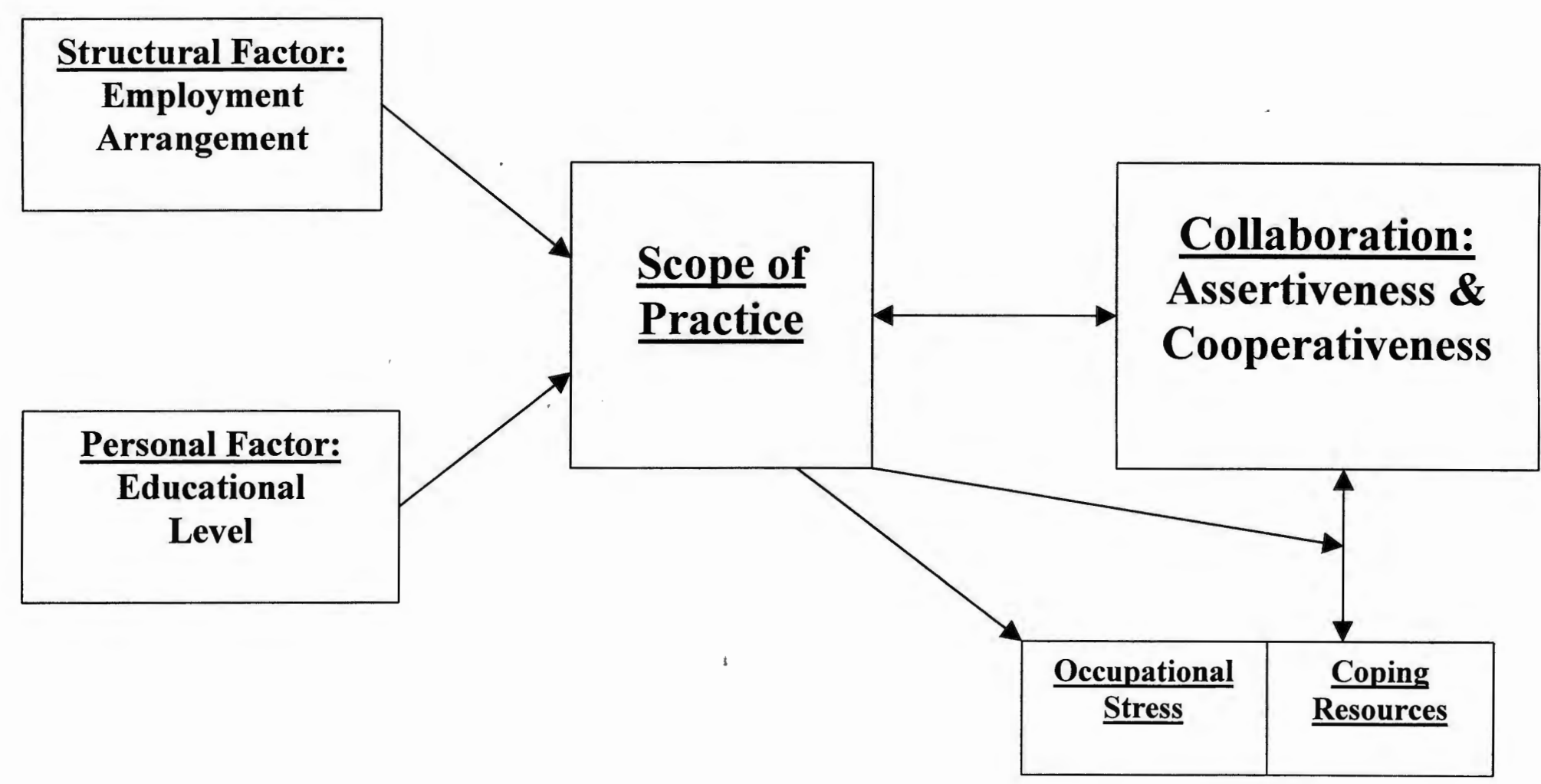




\section{APPENDIX A: CRNA DEMOGRAPHICS}

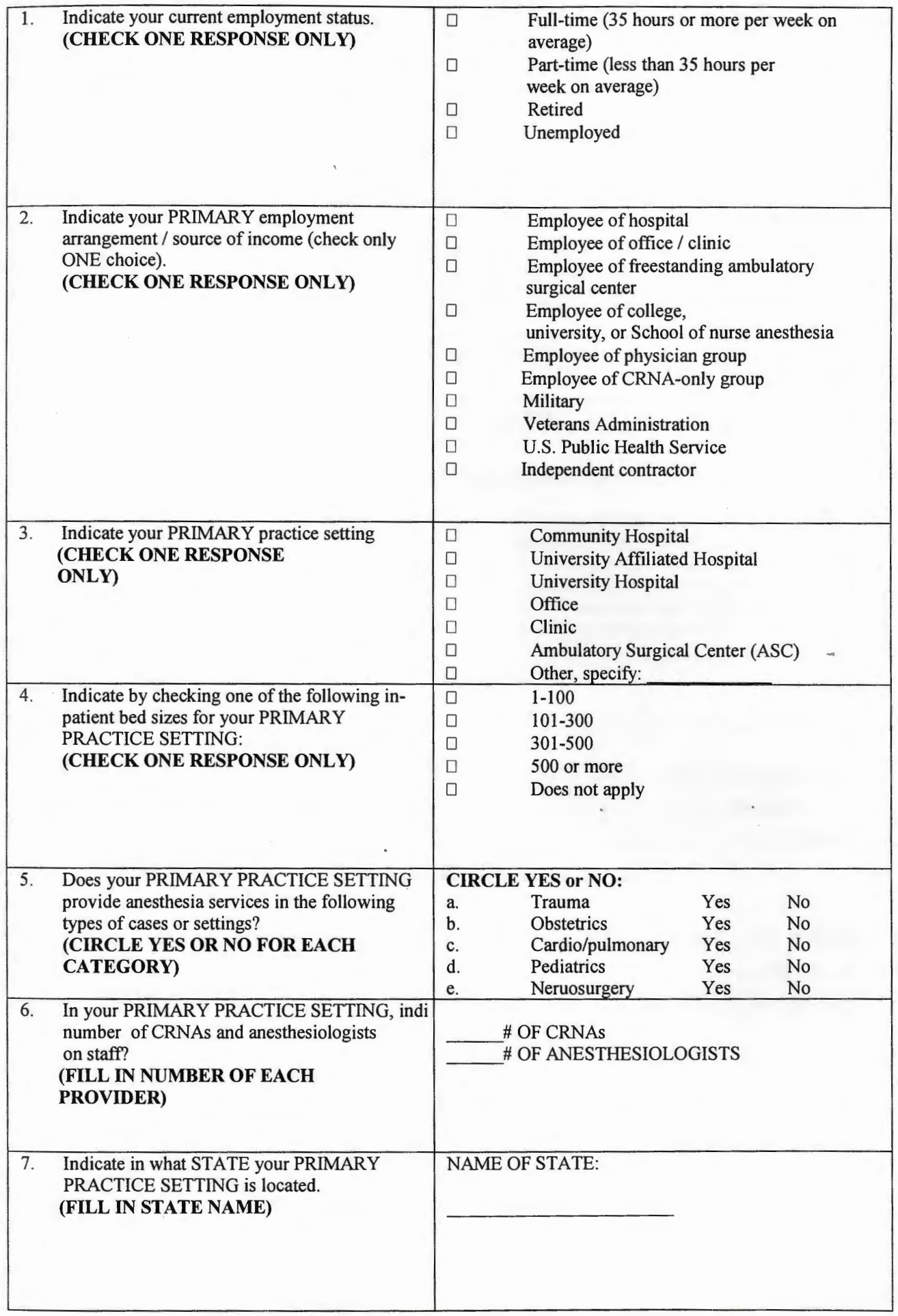




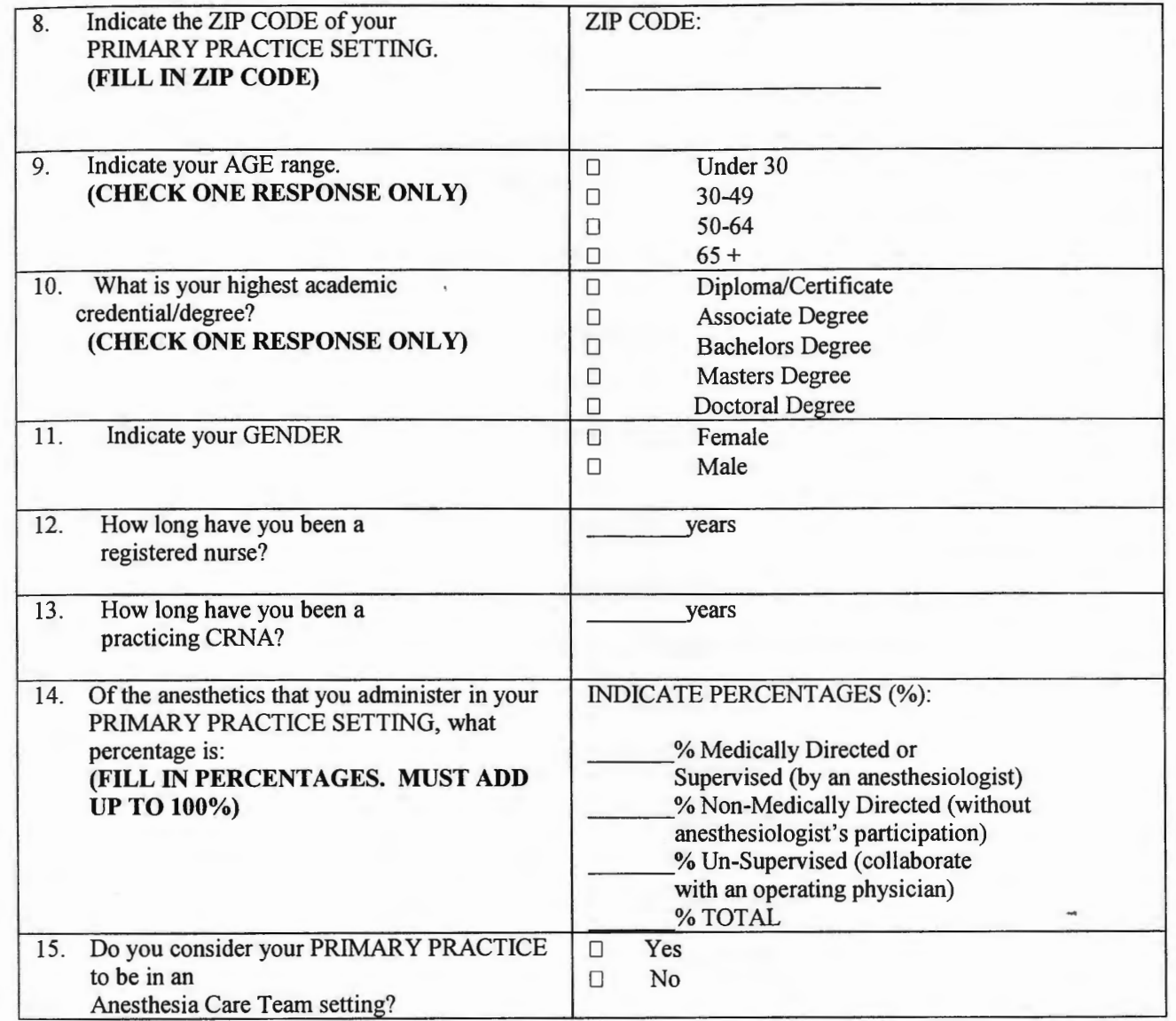

IF YOUR PRIMARY PRACTICE DOES NOT INCLUDE MEDICAL DIRECTION OR SUPERVISION BY AN ANESTHESIOLOGIST (from Question \# 14 a, above), PLEASE SKIP TO THE OSI-R, AND ONLY COMPLETE THE OSI-R BOOKLET.

\section{IF YOUR PRIMARY PRACTICE DOES INCLUDE MEDICAL DIRECTION OR SUPERVISION BY AN ANESTHESIOLOGIST (from Question \# 14 a, above),PLEASE CONTINUE AND COMPLETE ALL THREE REMAINING INSTRUMENTS.}




\section{APPENDIX B}

\section{SCOPE OF PRACTICE TOOL (SOP)}

\section{Of the anesthetics that you administer in the context of the anesthesia care team practice setting, how often do you personally perform the following anesthesia care activities:}

\section{CIRCLE YOUR RESPONSES:}

\begin{tabular}{|c|c|c|c|c|c|c|}
\hline $\begin{array}{l}\text { 1. Perform pre-anesthetic assessment } \\
\text { and evaluation. }\end{array}$ & $\begin{array}{l}\mathbf{5} \\
\text { Always } \\
\end{array}$ & $\begin{array}{c}4 \\
\text { Most of the time }\end{array}$ & $\begin{array}{c}3 \\
\text { Half of the time }\end{array}$ & $\begin{array}{c}2 \\
\text { Occasionally }\end{array}$ & Never & 1 \\
\hline $\begin{array}{l}\text { 2. Document the pre-anesthetic } \\
\text { assessment and evaluation. }\end{array}$ & $\begin{array}{l}\mathbf{5} \\
\text { Always } \\
\end{array}$ & $\begin{array}{c}4 \\
\text { Most of the time }\end{array}$ & $\begin{array}{c}3 \\
\text { Half of the time }\end{array}$ & $\begin{array}{c}\mathbf{2} \\
\text { Occasionally }\end{array}$ & Never & 1 \\
\hline $\begin{array}{l}\text { 3. Discuss the purpose, risks, and } \\
\text { benefits of the anesthetic with the } \\
\text { patient. }\end{array}$ & $\begin{array}{l}5 \\
\text { Always }\end{array}$ & $\begin{array}{c}4 \\
\text { Most of the time }\end{array}$ & $\begin{array}{c}3 \\
\text { Half of the time }\end{array}$ & $\begin{array}{c}\mathbf{2} \\
\text { Occasionally }\end{array}$ & Never & 1 \\
\hline $\begin{array}{l}\text { 4. Obtain informed consent from the } \\
\text { patient and/or designated person. }\end{array}$ & $\begin{array}{l}\mathbf{5} \\
\text { Always } \\
\end{array}$ & $\begin{array}{c}4 \\
\text { Most of the time }\end{array}$ & $\begin{array}{c}3 \\
\text { Half of the time }\end{array}$ & $\begin{array}{c}\mathbf{2} \\
\text { Occasionally }\end{array}$ & Never & 1 \\
\hline 5. Order pre-anesthetic medications. & $\begin{array}{l}\mathbf{5} \\
\text { Always } \\
\end{array}$ & $\begin{array}{c}4 \\
\text { Most of the time }\end{array}$ & $\begin{array}{c}3 \\
\text { Half of the time }\end{array}$ & $\begin{array}{c}\mathbf{2} \\
\text { Occasionally }\end{array}$ & Never & 1 \\
\hline $\begin{array}{l}\text { 6. Administer pre-anesthetic } \\
\text { medications. }\end{array}$ & $\begin{array}{l}\mathbf{5} \\
\text { Always } \\
\end{array}$ & $\begin{array}{c}4 \\
\text { Most of the time }\end{array}$ & $\begin{array}{c}3 \\
\text { Half of the time }\end{array}$ & $\begin{array}{c}\mathbf{2} \\
\text { Occasionally } \\
\end{array}$ & Never & 1 \\
\hline 7. Request consultations. & $\begin{array}{l}\mathbf{5} \\
\text { Always } \\
\end{array}$ & $\begin{array}{c}4 \\
\text { Most of the time }\end{array}$ & $\begin{array}{c}3 \\
\text { Half of the time }\end{array}$ & $\begin{array}{c}\mathbf{2} \\
\text { Occasionally }\end{array}$ & Never & 1 \\
\hline 8. Request diagnostic tests/studies. & $\begin{array}{l}\mathbf{5} \\
\text { Always } \\
\end{array}$ & $\begin{array}{c}4 \\
\text { Most of the time }\end{array}$ & $\begin{array}{c}3 \\
\text { Half of the time }\end{array}$ & $\begin{array}{c}\mathbf{2} \\
\text { Occasionally } \\
\end{array}$ & Never & 1 \\
\hline $\begin{array}{l}\text { 9. Develop and implement the } \\
\text { anesthesia plan. }\end{array}$ & $\begin{array}{l}\mathbf{5} \\
\text { Always } \\
\end{array}$ & $\begin{array}{c}4 \\
\text { Most of the time }\end{array}$ & $\begin{array}{c}3 \\
\text { Half of the time }\end{array}$ & $\begin{array}{c}\mathbf{2} \\
\text { Occasionaily }\end{array}$ & Never & 1 \\
\hline $\begin{array}{l}\text { 10. Initiate the planned anesthetic } \\
\text { technique, including; general, } \\
\text { regional, local anesthesia, or sedation. }\end{array}$ & $\begin{array}{l}\mathbf{5} \\
\text { Always } \\
\end{array}$ & $\begin{array}{l}4 \\
\text { Most of the time }\end{array}$ & $\begin{array}{l}3 \\
\text { Half of the time }\end{array}$ & $\begin{array}{c}2 \\
\text { Occasionally }\end{array}$ & Never & 1 \\
\hline $\begin{array}{l}\text { 11. Discuss the process of induction } \\
\text { of general anesthesia with the patient. }\end{array}$ & $\begin{array}{l}\mathbf{5} \\
\text { Always }\end{array}$ & $\begin{array}{c}4 \\
\text { Most of the time }\end{array}$ & $\begin{array}{c}3 \\
\text { Half of the time }\end{array}$ & $\begin{array}{c}\mathbf{2} \\
\text { Occasionally }\end{array}$ & Never & 1 \\
\hline $\begin{array}{l}\text { 12. Mange the induction of anesthesia } \\
\text { without anesthesiologist presence. }\end{array}$ & $\begin{array}{l}\mathbf{5} \\
\text { Always } \\
\end{array}$ & $\begin{array}{c}4 \\
\text { Most of the time }\end{array}$ & $\begin{array}{c}3 \\
\text { Half of the time }\end{array}$ & $\begin{array}{c}\mathbf{2} \\
\text { Occasionally } \\
\end{array}$ & Never & 1 \\
\hline $\begin{array}{l}\text { 13. Administer anesthetics and adjunct } \\
\text { drugs. }\end{array}$ & $\begin{array}{l}\mathbf{5} \\
\text { Always }\end{array}$ & $\begin{array}{c}4 \\
\text { Most of the time }\end{array}$ & $\begin{array}{c}3 \\
\text { Half of the time }\end{array}$ & $\begin{array}{c}\mathbf{2} \\
\text { Occasionally }\end{array}$ & Never & 1 \\
\hline $\begin{array}{l}\text { 14. Monitor the patient's response to } \\
\text { surgery and anesthesia. }\end{array}$ & $\begin{array}{l}\mathbf{5} \\
\text { Always } \\
\end{array}$ & $\begin{array}{c}4 \\
\text { Most of the time }\end{array}$ & $\begin{array}{c}3 \\
\text { Half of the time }\end{array}$ & $\begin{array}{c}\mathbf{2} \\
\text { Occasionally } \\
\end{array}$ & Never & 1 \\
\hline $\begin{array}{l}\text { 15. Select and apply appropriate non- } \\
\text { invasive monitoring modalities. }\end{array}$ & $\begin{array}{l}5 \\
\text { Always }\end{array}$ & $\begin{array}{c}4 \\
\text { Most of the time }\end{array}$ & $\begin{array}{c}3 \\
\text { Half of the time }\end{array}$ & $\begin{array}{c}2 \\
\text { Occasionally }\end{array}$ & Never & 1 \\
\hline $\begin{array}{l}\text { 16. Select and insert appropriate } \\
\text { invasive monitoring modalities. }\end{array}$ & $\begin{array}{l}\mathbf{5} \\
\text { Always } \\
\end{array}$ & $\begin{array}{c}4 \\
\text { Most of the time }\end{array}$ & $\begin{array}{c}3 \\
\text { Half of the time }\end{array}$ & $\begin{array}{c}\mathbf{2} \\
\text { Occasionally }\end{array}$ & Never & 1 \\
\hline $\begin{array}{l}\text { 17. Manage the patient's airway and } \\
\text { pulmonary status. }\end{array}$ & $\begin{array}{l}\mathbf{5} \\
\text { Always } \\
\end{array}$ & $\begin{array}{c}4 \\
\text { Most of the time }\end{array}$ & $\begin{array}{c}3 \\
\text { Half of the time }\end{array}$ & $\begin{array}{c}\mathbf{2} \\
\text { Occasionally } \\
\end{array}$ & Never & 1 \\
\hline $\begin{array}{l}\text { 18. Manage emergence and recovery } \\
\text { from anesthesia without } \\
\text { anesthesiologist presence. }\end{array}$ & $\begin{array}{l}\mathbf{5} \\
\text { Always }\end{array}$ & $\begin{array}{c}4 \\
\text { Most of the time }\end{array}$ & $\begin{array}{c}3 \\
\text { Half of the time }\end{array}$ & $\begin{array}{c}\mathbf{2} \\
\text { Occasionally }\end{array}$ & Never & 1 \\
\hline $\begin{array}{l}\text { 19. Provide post-anesthesia follow-up } \\
\text { evaluation and care. }\end{array}$ & $\begin{array}{l}\mathbf{5} \\
\text { Always } \\
\end{array}$ & $\begin{array}{c}4 \\
\text { Most of the time }\end{array}$ & $\begin{array}{c}3 \\
\text { Half of the time }\end{array}$ & $\begin{array}{c}\mathbf{2} \\
\text { Occasionally } \\
\end{array}$ & Never & 1 \\
\hline $\begin{array}{l}\text { 20. Communicate with the patient } \\
\text { during the post-anesthesia course. }\end{array}$ & $\begin{array}{l}\mathbf{5} \\
\text { Always } \\
\end{array}$ & $\begin{array}{c}4 \\
\text { Most of the time }\end{array}$ & $\begin{array}{c}3 \\
\text { Half of the time }\end{array}$ & $\begin{array}{c}2 \\
\text { Occasionally }\end{array}$ & Never & 1 \\
\hline $\begin{array}{l}\text { 21. Discharge patients from the post- } \\
\text { anesthesia care area. }\end{array}$ & $\begin{array}{l}\mathbf{5} \\
\text { Always }\end{array}$ & $\begin{array}{c}4 \\
\text { Most of the time }\end{array}$ & $\begin{array}{c}3 \\
\text { Half of the time }\end{array}$ & $\begin{array}{c}\mathbf{2} \\
\text { Occasionally }\end{array}$ & Never & 1 \\
\hline $\begin{array}{l}\text { 22. Initiate and modify pain relief } \\
\text { therapy. }\end{array}$ & $\begin{array}{l}\mathbf{5} \\
\text { Always }\end{array}$ & $\begin{array}{c}4 \\
\text { Most of the time }\end{array}$ & $\begin{array}{c}3 \\
\text { Half of the time }\end{array}$ & $\begin{array}{c}\mathbf{2} \\
\text { Occasionally } \\
\end{array}$ & Never & 1 \\
\hline $\begin{array}{l}\text { 23. Discuss the pain management plan } \\
\text { with the patient. }\end{array}$ & $\begin{array}{l}\mathbf{5} \\
\text { Always }\end{array}$ & $\begin{array}{c}4 \\
\text { Most of the time }\end{array}$ & $\begin{array}{c}3 \\
\text { Half of the time }\end{array}$ & $\begin{array}{c}\mathbf{2} \\
\text { Occasionally }\end{array}$ & Never & 1 \\
\hline $\begin{array}{l}\text { 24. Respond to emergencies and } \\
\text { provide airway management, fluid \& } \\
\text { drugs, and ACLS. }\end{array}$ & $\begin{array}{l}\mathbf{5} \\
\text { Always }\end{array}$ & $\begin{array}{c}4 \\
\text { Most of the time }\end{array}$ & $\begin{array}{c}3 \\
\text { Half of the time }\end{array}$ & $\begin{array}{c}\mathbf{2} \\
\text { Occasionally }\end{array}$ & Never & 1 \\
\hline
\end{tabular}




\section{Of the anesthetics that you administer in the context of the anesthesia care team practice setting, how often do you personally perform the following anesthesia techniques and types of cases. CIRCLE YOUR RESPONSES:}

\begin{tabular}{|c|c|c|c|c|c|}
\hline 25. Administer General anesthesia. & $\begin{array}{l}\mathbf{5} \\
\text { Always }\end{array}$ & $\begin{array}{c}4 \\
\text { Most of the time }\end{array}$ & $\begin{array}{l}3 \\
\text { Half of the time }\end{array}$ & $\begin{array}{c}\mathbf{2} \\
\text { Occasionally }\end{array}$ & $\begin{array}{c}1 \\
\text { Never }\end{array}$ \\
\hline 26. Administer Subarachnoid Block. & $\begin{array}{l}\mathbf{5} \\
\text { Always }\end{array}$ & $\begin{array}{c}4 \\
\text { Most of the time }\end{array}$ & $\begin{array}{l}3 \\
\text { Half of the time }\end{array}$ & $\begin{array}{c}\mathbf{2} \\
\text { Occasionally }\end{array}$ & $\begin{array}{c}1 \\
\text { Never }\end{array}$ \\
\hline 27. Administer Epidural Anesthesia. & $\begin{array}{l}\mathbf{5} \\
\text { Always }\end{array}$ & $\begin{array}{c}\mathbf{4} \\
\text { Most of the time }\end{array}$ & $\begin{array}{l}3 \\
\text { Half of the time }\end{array}$ & $\begin{array}{c}\mathbf{2} \\
\text { Occasionally }\end{array}$ & $\begin{array}{c}1 \\
\text { Never }\end{array}$ \\
\hline 28. Administer Brachial Plexus Block. & $\begin{array}{l}\mathbf{5} \\
\text { Always } \\
\end{array}$ & $\begin{array}{c}4 \\
\text { Most of the time }\end{array}$ & $\begin{array}{l}3 \\
\text { Half of the time }\end{array}$ & $\begin{array}{c}\mathbf{2} \\
\text { Occasionally }\end{array}$ & $\begin{array}{c}1 \\
\text { Never }\end{array}$ \\
\hline 29. Administer Bier Block. & $\begin{array}{l}\mathbf{5} \\
\text { Always } \\
\end{array}$ & $\begin{array}{c}4 \\
\text { Most of the time }\end{array}$ & $\begin{array}{c}3 \\
\text { Half of the time }\end{array}$ & $\begin{array}{c}2 \\
\text { Occasionally }\end{array}$ & $\begin{array}{c}1 \\
\text { Never }\end{array}$ \\
\hline 30. Administer Ophthalmologic Block. & $\begin{array}{l}\mathbf{5} \\
\text { Always } \\
\end{array}$ & $\begin{array}{c}4 \\
\text { Most of the time }\end{array}$ & $\begin{array}{l}3 \\
\text { Half of the time }\end{array}$ & $\begin{array}{c}\mathbf{2} \\
\text { Occasionally }\end{array}$ & $\begin{array}{c}1 \\
\text { Never }\end{array}$ \\
\hline $\begin{array}{l}\text { 31. Manage Monitored Anesthesia Care } \\
\text { (MAC). }\end{array}$ & $\begin{array}{l}\mathbf{5} \\
\text { Always }\end{array}$ & $\begin{array}{c}4 \\
\text { Most of the time }\end{array}$ & $\begin{array}{l}3 \\
\text { Half of the time }\end{array}$ & $\begin{array}{c}\mathbf{2} \\
\text { Occasionally }\end{array}$ & $\begin{array}{c}1 \\
\text { Never } \\
\end{array}$ \\
\hline 32. Manage Acute Pain. & $\begin{array}{l}\mathbf{5} \\
\text { Always }\end{array}$ & $\begin{array}{c}4 \\
\text { Most of the time }\end{array}$ & $\begin{array}{l}3 \\
\text { Half of the time }\end{array}$ & $\begin{array}{c}\mathbf{2} \\
\text { Occasionally }\end{array}$ & $\begin{array}{c}1 \\
\text { Never }\end{array}$ \\
\hline 33. Manage Chronic pain. & $\begin{array}{l}\mathbf{5} \\
\text { Always } \\
\end{array}$ & $\begin{array}{c}4 \\
\text { Most of the time }\end{array}$ & $\begin{array}{l}3 \\
\text { Half of the time }\end{array}$ & $\begin{array}{c}\mathbf{2} \\
\text { Occasionally }\end{array}$ & $\begin{array}{c}1 \\
\text { Never }\end{array}$ \\
\hline 34. Insert Arterial Catheters. & $\begin{array}{l}\mathbf{5} \\
\text { Always }\end{array}$ & $\begin{array}{c}4 \\
\text { Most of the time }\end{array}$ & $\begin{array}{l}3 \\
\text { Half of the time }\end{array}$ & $\begin{array}{c}\mathbf{2} \\
\text { Occasionally }\end{array}$ & $\begin{array}{c}1 \\
\text { Never }\end{array}$ \\
\hline 35. Insert Pulmonary Artery Catheters. & $\begin{array}{l}\mathbf{5} \\
\text { Always } \\
\end{array}$ & $\begin{array}{c}4 \\
\text { Most of the time }\end{array}$ & $\begin{array}{c}3 \\
\text { Half of the time }\end{array}$ & $\begin{array}{c}\mathbf{2} \\
\text { Occasionally }\end{array}$ & $\begin{array}{c}1 \\
\text { Never }\end{array}$ \\
\hline $\begin{array}{l}\text { 36. Insert Central Venous Pressure } \\
\text { Catheters. }\end{array}$ & $\begin{array}{l}\mathbf{5} \\
\text { Always }\end{array}$ & $\begin{array}{c}4 \\
\text { Most of the time }\end{array}$ & $\begin{array}{l}3 \\
\text { Half of the time }\end{array}$ & $\begin{array}{c}\mathbf{2} \\
\text { Occasionally }\end{array}$ & $\begin{array}{c}1 \\
\text { Never }\end{array}$ \\
\hline $\begin{array}{l}\text { 37. Manage Cardio-pulmonary Bypass } \\
\text { Anesthesia. }\end{array}$ & $\begin{array}{l}\mathbf{5} \\
\text { Always }\end{array}$ & $\begin{array}{c}4 \\
\text { Most of the time }\end{array}$ & $\begin{array}{l}3 \\
\text { Half of the time }\end{array}$ & $\begin{array}{c}\mathbf{2} \\
\text { Occasionally }\end{array}$ & $\begin{array}{c}1 \\
\text { Never }\end{array}$ \\
\hline 38. Manage Obstetric Anesthesia. & $\begin{array}{l}\mathbf{5} \\
\text { Always }\end{array}$ & $\begin{array}{c}4 \\
\text { Most of the time }\end{array}$ & $\begin{array}{l}3 \\
\text { Half of the time }\end{array}$ & $\begin{array}{c}\mathbf{2} \\
\text { Occasionally }\end{array}$ & $\begin{array}{c}1 \\
\text { Never }\end{array}$ \\
\hline 39. Manage Pediatric Anesthesia. & $\begin{array}{l}\mathbf{5} \\
\text { Always } \\
\end{array}$ & $\begin{array}{c}4 \\
\text { Most of the time }\end{array}$ & $\begin{array}{c}3 \\
\text { Half of the time }\end{array}$ & $\begin{array}{c}\mathbf{2} \\
\text { Occasionally } \\
\end{array}$ & $\begin{array}{c}1 \\
\text { Never }\end{array}$ \\
\hline 40. Manage Intra-cranial Anesthesia. & $\begin{array}{l}\mathbf{5} \\
\text { Always }\end{array}$ & $\begin{array}{c}4 \\
\text { Most of the time }\end{array}$ & $\begin{array}{l}3 \\
\text { Half of the time }\end{array}$ & $\begin{array}{c}2 \\
\text { Occasionally }\end{array}$ & $\begin{array}{c}1 \\
\text { Never }\end{array}$ \\
\hline 41. Manage Trauma Anesthesia. & $\begin{array}{l}\mathbf{5} \\
\text { Always }\end{array}$ & $\begin{array}{c}4 \\
\text { Most of the time }\end{array}$ & $\begin{array}{l}3 \\
\text { Half of the time }\end{array}$ & $\begin{array}{c}\mathbf{2} \\
\text { Occasionally }\end{array}$ & $\begin{array}{c}1 \\
\text { Never }\end{array}$ \\
\hline
\end{tabular}




\section{APPENDIX C}

\section{COLLABORATIVE PRACTICE SCALE (CPS)}

DIRECTIONS: The following items represent statements about your anesthesia care-team practice situation. Please respond to each item by circling the number for the response that best describes your behavior. There are no right or wrong answers. The researcher is looking for your actual behavior in these situations, rather than your desirable and/or expected behavior. If you choose lower numbers from the right, you indicate that you never or seldom behave in the manner described. If you choose higher numbers to the left, you indicate that you frequently or always behave in the manner described. Please do not skip any items. All of your responses are anonymous.

\section{CIRCLE YOUR RESPONSES:}

\begin{tabular}{|c|c|c|c|c|}
\hline $\begin{array}{l}\text { 1. I ask anesthesiologists about their } \\
\text { expectations regarding the degree of my } \\
\text { involvement in anesthesia care decisions. }\end{array}$ & $\begin{array}{l}\mathbf{5} \\
\text { Always } \\
\end{array}$ & $\begin{array}{c}4^{3} \\
\text { Most of the time Half of the time }\end{array}$ & $\begin{array}{c}2 \\
\text { Occasionally } \\
\end{array}$ & $\begin{array}{c}1 \\
\text { Never } \\
\end{array}$ \\
\hline $\begin{array}{l}\text { 2. I negotiate with the anesthesiologist to } \\
\text { establish our responsibilities for discussing } \\
\text { different kinds of information with patients } \\
\text { and families. }\end{array}$ & $\begin{array}{l}\mathbf{5} \\
\text { Always }\end{array}$ & $\stackrel{4}{\text { Most of the time Half of the time }}$ & $\stackrel{2}{2}$ Occasionally & $\begin{array}{l}1 \\
\text { Never }\end{array}$ \\
\hline $\begin{array}{l}\text { 3. I clarify the scope of my professional } \\
\text { expertise when it is greater than the } \\
\text { anesthesiologist thinks it is. }\end{array}$ & $\begin{array}{l}\mathbf{5} \\
\text { Always } \\
\end{array}$ & $\begin{array}{c}4 \\
\text { Most of the time Half of the time }\end{array}$ & $\begin{array}{c}2 \\
\text { Occasionally }\end{array}$ & $\begin{array}{l}1 \\
\text { Never } \\
\end{array}$ \\
\hline $\begin{array}{l}\text { 4. I discuss with the anesthesiologist the } \\
\text { degree to which I want to be involved in } \\
\text { planning aspects of patient care. }\end{array}$ & $\begin{array}{l}\mathbf{5} \\
\text { Always }\end{array}$ & $\begin{array}{cc}4 & 3 \\
\text { Most of the time Half of the time }\end{array}$ & $\begin{array}{c}\mathbf{2} \\
\text { Occasionally }\end{array}$ & $\begin{array}{c}1 \\
\text { Never }\end{array}$ \\
\hline $\begin{array}{l}\text { 5. I suggest to the anesthesiologist patient } \\
\text { care approaches that I think would be } \\
\text { useful. }\end{array}$ & $\begin{array}{l}\mathbf{5} \\
\text { Always }\end{array}$ & $\begin{array}{cc}4 & 3 \\
\text { Most of the time Half of the time }\end{array}$ & $\begin{array}{c}\mathbf{2} \\
\text { Occasionally }\end{array}$ & $\begin{array}{c}1 \\
\text { Never }\end{array}$ \\
\hline $\begin{array}{l}\text { 6. I discuss with the anesthesiologist areas } \\
\text { of practice that reside more within the } \\
\text { realm of nursing than medicine. }\end{array}$ & $\begin{array}{l}\mathbf{5} \\
\text { Always }\end{array}$ & $\begin{array}{cc}4 & 3 \\
\text { Most of the time Half of the time }\end{array}$ & $\begin{array}{c}\mathbf{2} \\
\text { Occasionally }\end{array}$ & $\begin{array}{c}1 \\
\text { Never }\end{array}$ \\
\hline $\begin{array}{l}\text { 7. I tell the anesthesiologist when, in my } \\
\text { judgement, his/her anesthesia care orders } \\
\text { seem inappropriate. }\end{array}$ & $\begin{array}{l}\mathbf{5} \\
\text { Always }\end{array}$ & $\begin{array}{c}4 \\
\text { Most of the time Half of the time }\end{array}$ & $\begin{array}{c}\mathbf{2} \\
\text { Occasionally }\end{array}$ & $\begin{array}{c}1 \\
\text { Never }\end{array}$ \\
\hline $\begin{array}{l}\text { 8. I tell the anesthesiologist of any } \\
\text { difficulties I foresee in the patient's ability } \\
\text { to deal with anesthesia care options and } \\
\text { their consequences. }\end{array}$ & $\begin{array}{l}\mathbf{5} \\
\text { Always }\end{array}$ & $\begin{array}{c}4 \\
\text { Most of the time Half of the time }\end{array}$ & $\begin{array}{c}\mathbf{2} \\
\text { Occasionally }\end{array}$ & $\begin{array}{c}1 \\
\text { Never }\end{array}$ \\
\hline $\begin{array}{l}\text { 9. I inform the anesthesiologist about } \\
\text { areas of practice that are unique to nurse } \\
\text { anesthesia. }\end{array}$ & $\begin{array}{l}\mathbf{5} \\
\text { Always }\end{array}$ & $\begin{array}{cc}4 & 3 \\
\text { Most of the time Half of the time }\end{array}$ & $\begin{array}{c}\mathbf{2} \\
\text { Occasionally }\end{array}$ & $\begin{array}{l}\mathbf{1} \\
\text { Never }\end{array}$ \\
\hline
\end{tabular}




\section{CIRCLE YOUR RESPONSES:}

\begin{tabular}{|c|c|c|c|c|}
\hline $\begin{array}{l}\text { 10. I reinforce the value of medical care by } \\
\text { the anesthesiologist when talking to the } \\
\text { patient. }\end{array}$ & $\begin{array}{l}\mathbf{5} \\
\text { Always }\end{array}$ & $\begin{array}{c}4 \\
\text { Most of the time Half of the time }\end{array}$ & $\begin{array}{c}2 \\
\text { Occasionally }\end{array}$ & $\begin{array}{l}\mathbf{1} \\
\text { Never }\end{array}$ \\
\hline $\begin{array}{l}\text { 11. I ask the anesthesiologist's assessment } \\
\text { of what may be needed to strengthen the } \\
\text { patient's response to anesthesia. }\end{array}$ & $\begin{array}{l}\mathbf{5} \\
\text { Always }\end{array}$ & $\begin{array}{cc}4 \\
\text { Most of the time Half of the time }\end{array}$ & $\begin{array}{c}\mathbf{2} \\
\text { Occasionally }\end{array}$ & $\begin{array}{l}1 \\
\text { Never }\end{array}$ \\
\hline $\begin{array}{l}\text { 12. I discuss with the anesthesiologist the } \\
\text { similarities and differences in nursing and } \\
\text { medical approaches to patient care. }\end{array}$ & $\begin{array}{l}\mathbf{5} \\
\text { Always }\end{array}$ & $\begin{array}{c}4 \\
\text { Most of the time Half of the time }\end{array}$ & $\begin{array}{c}\mathbf{2} \\
\text { Occasionally }\end{array}$ & $\begin{array}{l}\mathbf{1} \\
\text { Never }\end{array}$ \\
\hline $\begin{array}{l}\text { 13. I consider the anesthesiologist's } \\
\text { opinion when developing an anesthesia } \\
\text { care plan. }\end{array}$ & $\begin{array}{l}\mathbf{5} \\
\text { Always }\end{array}$ & $\begin{array}{cc}4 & 3 \\
\text { Most of the time Half of the time }\end{array}$ & $\begin{array}{c}\mathbf{2} \\
\text { Occasionally }\end{array}$ & $\begin{array}{l}1 \\
\text { Never }\end{array}$ \\
\hline $\begin{array}{l}\text { 14. I discuss areas of agreement and } \\
\text { disagreement with the anesthesiologist in } \\
\text { an effort to develop mutually agreeable } \\
\text { anesthesia care goals. }\end{array}$ & $\begin{array}{l}\mathbf{5} \\
\text { Always }\end{array}$ & $\begin{array}{cc}4 \\
\text { Most of the time Half of the time }\end{array}$ & $\begin{array}{c}\mathbf{2} \\
\text { Occasionally }\end{array}$ & $\begin{array}{c}1 \\
\text { Never }\end{array}$ \\
\hline $\begin{array}{l}\text { 15. I discuss with the anesthesiologist the } \\
\text { degree to which I think he/she should be } \\
\text { involved in planning and implementing } \\
\text { aspects of anesthesia care. }\end{array}$ & $\begin{array}{l}\mathbf{5} \\
\text { Always }\end{array}$ & $\begin{array}{cc}4 & 3 \\
\text { Most of the time Half of the time }\end{array}$ & $\begin{array}{c}\mathbf{2} \\
\text { Occasionally }\end{array}$ & $\begin{array}{c}1 \\
\text { Never }\end{array}$ \\
\hline $\begin{array}{l}\text { 16. I work toward consensus with the } \\
\text { anesthesiologist regarding the best } \\
\text { approach in caring for the patient. }\end{array}$ & $\begin{array}{l}\mathbf{5} \\
\text { Always }\end{array}$ & $\begin{array}{c}4 \\
\text { Most of the time Half of the time }\end{array}$ & $\begin{array}{c}\mathbf{2} \\
\text { Occasionally }\end{array}$ & $\begin{array}{l}1 \\
\text { Never }\end{array}$ \\
\hline $\begin{array}{l}\text { 17. I discuss with the anesthesiologist } \\
\text { his/her expectations regarding the degree } \\
\text { of their involvement in the anesthesia care } \\
\text { decision-making process. }\end{array}$ & $\begin{array}{l}\mathbf{5} \\
\text { Always }\end{array}$ & $\begin{array}{c}4 \\
\text { Most of the time Half of the time }\end{array}$ & $\begin{array}{c}\mathbf{2} \\
\text { Occasionally }\end{array}$ & $\begin{array}{l}1 \\
\text { Never }\end{array}$ \\
\hline $\begin{array}{l}\text { 18. I acknowledge to the anesthesiologist } \\
\text { those aspects of anesthesia care where } \\
\text { he/she has more expertise than I do. }\end{array}$ & $\begin{array}{l}\mathbf{5} \\
\text { Always }\end{array}$ & $\begin{array}{c}4 \\
\text { Most of the time Half of the time }\end{array}$ & $\begin{array}{c}\mathbf{2} \\
\text { Occasionally }\end{array}$ & $\begin{array}{c}1 \\
\text { Never }\end{array}$ \\
\hline $\begin{array}{l}\text { 19. I clarify whether the anesthesiologist } \\
\text { or I will have the responsibility for } \\
\text { discussing different kinds of information } \\
\text { with patients and/or families. }\end{array}$ & $\begin{array}{l}\mathbf{5} \\
\text { Always }\end{array}$ & $\begin{array}{cc} & 3 \\
\text { Most of the time Half of the time }\end{array}$ & $\begin{array}{c}\mathbf{2} \\
\text { Occasionally }\end{array}$ & 1 \\
\hline
\end{tabular}




\title{
APPENDIX D
}

Electronic Mail Letter from Dr. Sandra Weiss: "Permission to use CPS."

\author{
Subj: Re:CPS TOOL \\ Date: $9 / 25 / 00$ 7:03:43 PM Eastem Daylight Time \\ From: Sandra.Weiss@nursing.ucsf.edu \\ To: Vapor2@aol.com \\ File: cps 1.doc ( 28160 bytes) \\ DL Time (45333 bps): $<1$ minute

\section{Dear Professor Alves,}

Your study sounds very interesting and significant to nursing practice. You definitely have my permission to modify the Collaborative Practice Scales in the manner you have proposed in order to enhance the relevance of the scales to anesthesiology. Good luck to you as you move forward in your program of research.

Sincerely,

Sandra Weiss

Sandra Weiss, PhD, DNSc, FAAN

Professor, department of Community Health Systems

University of California, San Francisco-School of Nursing (415) 476-3105 


\section{APPENDIX E \\ OCCUPATIONL STRESS INVENTORY-REVISED (OSI-R)}

\section{Sample Questions}

Occupational Role Questionnaire (ORQ)

1. At work I am expected to do too many different tasks in too little time.

2. I have to take work home with me.

3. I am bored with my job.

4. I have to perform tasks that are beneath my ability.

\section{Psychological Strain Questionnaire (PSQ)}

1. The quality of my work is good.

2. Lately, I am easily irritated.

3. Lately, I have been tired.

\section{Personal Resources Questionnaire (PRQ)}

1. I spend enough time in recreational activities to satisfy my needs.

2. I get the sleep I need.

3. When faced with a problem I use a systematic approach.

"Reproduced by special permission of the Publisher, Psychological Assessment Resources, Inc., 16204 North Florida Avenue, Lutz, Florida 33549, from the Occupational Stress Inventory - Revised by Samuel Osipow and Arnold Spokane, Copyright, 1981, 1987, 1998 by Psychological Assessment Resources, Inc. Further reproduction is prohibited without permission from PAR, Inc.” 


\title{
APPENDIX F
}

\section{Expedited IRB Approval from: University of Rhode Island, Office of Research Compliance}

\author{
The University of Rhode Islatd \\ INSTITUTUONAL. REVIEW BOARD OA WUAN SUERECTS (IRB) \\ IRB ACTION REPORT
}

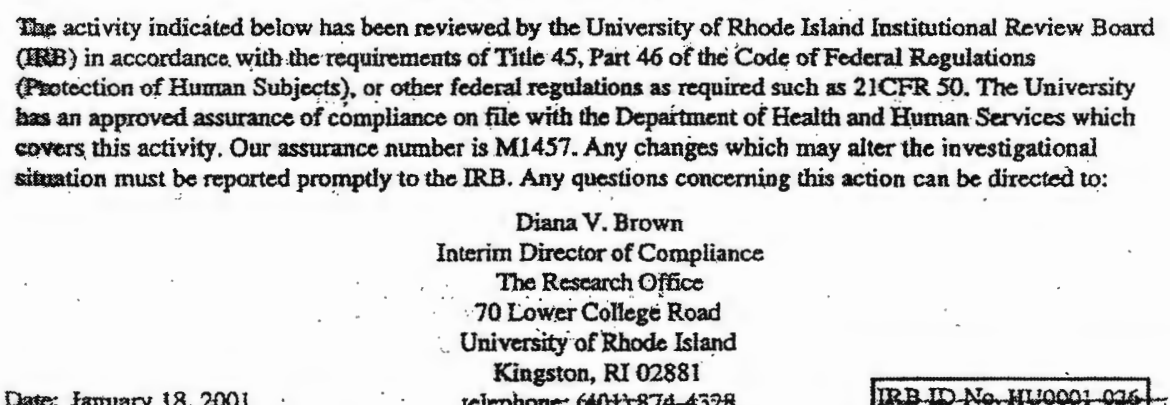

Daste: Jaxiuary 18,2001

telephone: $(401) 874-4528$

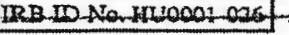

\begin{abstract}
"Examining Collaborative Practice in Anesthesia Care Team Settings, and Occupational Stress in Nurse Anesthetists."
\end{abstract}

\begin{tabular}{l|l}
\hline Eagify Investizator or Sponsor: & Studen Investivator or Co-Pl: \\
Hesook Suzie Kim, RN, PhD & Steve L. Alves, CRNA, \\
White Hall & 273 Ash Street \\
Brockton, MA 02301
\end{tabular}

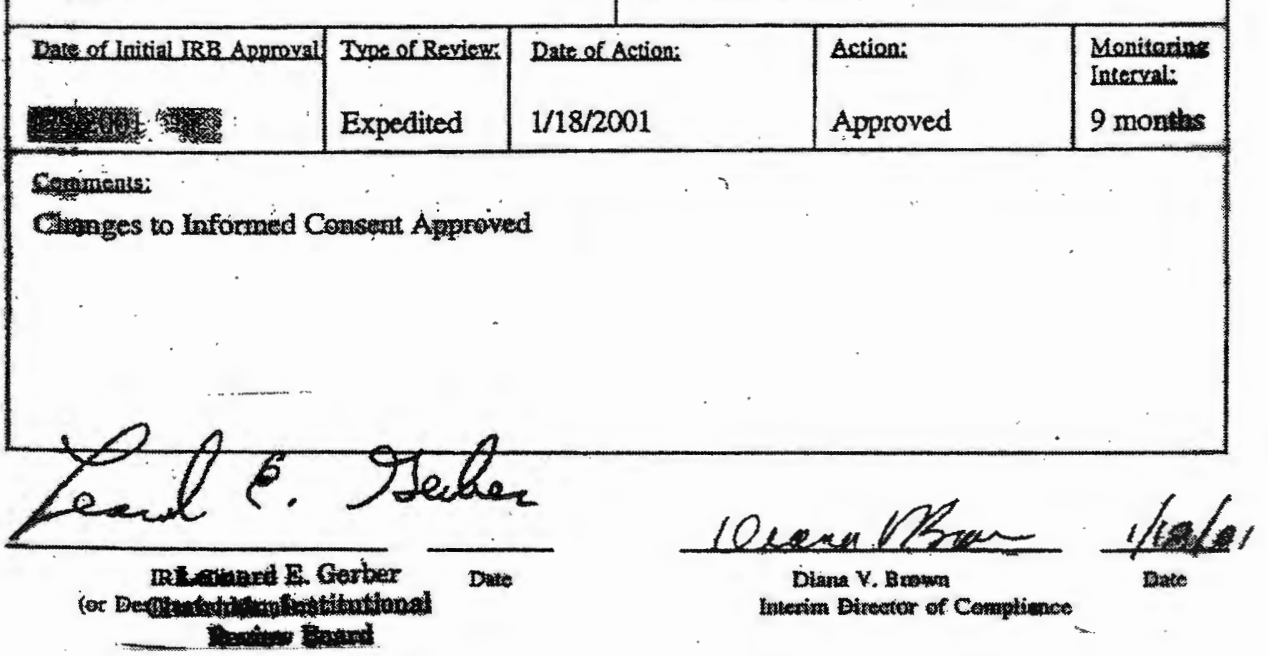




\section{APPENDIX G}

\section{Explanatory Letter/Consent}

\section{February 20, 2001}

\section{Dear CRNA Colleague:}

Enclosed are a series of questionnaires being utilized in a study to examine collaborative practice in anesthesia care team settings, to be completed by you. Each questionnaire focuses on different aspects of the research project; demographic information, questions about CRNA scope of practice, collaboration scale, and the occupational stress inventory.

It is estimated that $89 \%$ of CRNAs from the 6 New England states practice in anesthesia care teams (ACTs). Therefore, we are obligated to create practice environments that attempt to overcome barriers and restrictions to CRNA scope of practice, and improve overall quality patient care. The aim of this study is to develop a better understanding of individual CRNA scope of practice in ACTs, the nature of collaborative practice, and their influence on occupational stress in CRNAs. Because we are all interested and concerned about the future of our profession, I ask you to help provide this information to improve CRNA practice in anesthesia care team (ACT) settings.

Thank you for your assistance.

Sincerely,

Steve L. Alves, CRNA, MSNA

Doctoral Student 


\section{APPENDIX H}

Reminder Post Card

April 3, 2001

Dear CRNA:

This card is sent to you as a reminder to complete the questionnaires that you received for the Alves study on anesthesia care team practice. If you have misplaced or lost the questionnaires, please feel free to contact Claire Collins for replacements at:

(781)961-9217 (or email at ccoll10505@aol.com). If you have already returned the series of questionnaires, THANKS FOR YOUR PARTICIPATION!

Sincerely,

Claire Collins

Research Assistant

701 Irving Road

Randolph, MA 02368 


\section{Appendix I}

Scope of Practice (SOP) Tool Item Intercorrelational Matrix

\begin{tabular}{|c|c|c|c|c|c|c|c|c|c|c|c|c|c|c|c|c|c|}
\hline $\begin{array}{l}\text { SOP } \\
\text { Items }\end{array}$ & SOP1 & SOP2 & SOP3 & SOP4 & SOP5 & SOP6 & SOP7 & SOP8 & SOP9 & SOP10 & SOP11 & SOP12 & SOP13 & SOP14 & SOP15 & SOP16 & SOP17 \\
\hline SOP2 & .53 & & & & & & & & & & & & & & & & \\
\hline SOP3 & .57 & .49 & & & & & & & & & & & & & & & \\
\hline SOP4 & .50 & .47 & .66 & & & & & & & & & & & & & & \\
\hline SOP5 & .32 & .26 & .40 & .34 & & & & & & & & & & & & & \\
\hline SOP6 & .19 & .19 & .17 & .16 & .37 & & & & & & & & & & & & \\
\hline SOP7 & .30 & .35 & .42 & .48 & .43 & .22 & & & & & & & & & & & \\
\hline SOP8 & .33 & .34 & .38 & .42 & .40 & .18 & .72 & & & & & & & & & & \\
\hline SOP9 & .32 & .22 & .39 & .32 & .26 & .16 & .33 & .34 & & & & & & & . & & \\
\hline SOP10 & .10 & .14 & .21 & .22 & .07 & .10 & .19 & .19 & .26 & & & & & & . & & \\
\hline SOP11 & .17 & .11 & .31 & .19 & .13 & .07 & .24 & .20 & .19 & .28 & & & & & & & \\
\hline SOP12 & .14 & .10 & .27 & .21 & .21 & -.04 & .35 & .28 & .20 & .22 & .17 & & & & & & \\
\hline SOP13 & -.06 & -.05 & -.01 & -.07 & .01 & .13 & -.04 & .03 & .13 & .20 & .10 & -.06 & & & & & \\
\hline SOP14 & .03 & .01 & .02 & -.00 & -.06 & .11 & .01 & .02 & -.01 & .15 & .11 & .02 & .25 & & & & \\
\hline SOP15 &. .04 & .07 & .14 & .05 & -.02 & -.01 & .02 & -.07 & .11 & .21 & .09 & .01 & .25 & .23 & & & \\
\hline SOP16 & .20 & .17 & .27 & .20 & .18 & .11 & .22 & .17 & .31 & .31 & .19 & .30 & .13 & .06 & .20 & & \\
\hline SOP17 & -.06 & -.02 & -.01 & -.05 & .05 & .10 & .01 & .06 & -.01 & .13 & .11 & .00 & .45 & .35 & .23 & .04 & \\
\hline SOP18 & -.01 & -.02 & .11 & .11 & .08 & -.01 & .09 & .08 & .01 & .12 & .17 & .25 & .05 & .13 & .09 & .09 & .13 \\
\hline SOP19 & .19 & .26 & .34 & .27 & .20 & .04 & .42 & .35 & .18 & .24 & .19 & .25 & .00 & .05 & .15 & .29 & -.02 \\
\hline SOP20 & .20 & .15 & .25 & .30 & .18 & .10 & .31 & .33 & .18 & .18 & .18 & .18 & -.05 & .09 & .17 & .21 & -.01 \\
\hline SOP21 & .28 & .25 & .32 & .37 & .23 & -.00 & .32 & .31 & .13 & .17 & .09 & .38 & -.10 & -.00 & .09 & .27 & -.08 \\
\hline SOP22 & .13 & .15 & .21 & .24 & .23 & .02 & .26 & .28 & .19 & .21 & .19 & .11 & .11 & .09 & .14 & .20 & .17 \\
\hline SOP23 & .23 & .17 & .34 & .35 & .22 & .16 & .34 & .33 & .25 & .23 & .30 & .16 & .10 & .09 & .13 & .22 & -.00 \\
\hline SOP24 & .12 & .18 & .15 & .16 & .04 & -.00 & .19 & .18 & .08 & .08 & .06 & .20 & .04 & .07 & .06 & .21 & .00 \\
\hline
\end{tabular}




\section{APPENDIX I (Continued)}

Scope of Practice (SOP) Tool Item Intercorrelational Matrix

\begin{tabular}{|c|c|c|c|c|c|c|c|c|c|c|c|c|c|c|c|}
\hline $\begin{array}{l}\text { SOP } \\
\text { Items }\end{array}$ & $\begin{array}{l}\text { SOP } \\
18\end{array}$ & $\begin{array}{l}\text { SOP } \\
19\end{array}$ & $\begin{array}{l}\text { SOP } \\
20\end{array}$ & $\begin{array}{l}\text { SOP } \\
21\end{array}$ & $\begin{array}{l}\text { SOP } \\
22\end{array}$ & $\begin{array}{l}\text { SOP } \\
23\end{array}$ & $\begin{array}{l}\text { SOP } \\
25\end{array}$ & $\begin{array}{l}\text { SOP } \\
26\end{array}$ & $\begin{array}{l}\text { SOP } \\
27\end{array}$ & $\begin{array}{l}\text { SOP } \\
28\end{array}$ & $\begin{array}{l}\text { SOP } \\
29\end{array}$ & $\begin{array}{l}\text { SOP } \\
\mathbf{3 0}\end{array}$ & $\begin{array}{l}\text { SOP } \\
31 \\
\end{array}$ & $\begin{array}{l}\text { SOP } \\
32 \\
\end{array}$ & $\begin{array}{l}\text { SOP } \\
33 \\
\end{array}$ \\
\hline SOP1 & & & & & & & -.10 & .13 & .21 & .25 & -.04 & .16 & -.11 & .05 & .14 \\
\hline SOP2 & & & & & & & -.10 & .15 & .23 & .22 & .08 & .17 & -.05 & .04 & .08 \\
\hline SOP3 & & & & & & & -.06 & .19 & .31 & .30 & -.00 & .17 & -.02 & .13 & .16 \\
\hline SOP4 & & & & & & & -.04 & .31 & .37 & .35 & .11 & .17 & -.02 & .11 & .15 \\
\hline SOP5 & & & & & & & -.04 & .20 & .21 & .12 & .02 & .13 & -.08 & .19 & .16 \\
\hline SOP6 & & & & & · & & .04 & .14 & .15 & .05 & .06 & .03 & .06 & .03 & .08 \\
\hline SOP7 & & & & & & & .03 & .26 & .29 & .24 & .15 & .21 & -.04 & .18 & .11 \\
\hline SOP8 & & & & & & & .04 & .22 & .28 & .22 & .15 & .20 & -.07 & .23 & .12 \\
\hline SOP9 & & & & & & & .03 & .14 & .15 & .17 & .01 & .12 & -.01 & .13 & .11 \\
\hline SOP10 & & & & & & & .14 & .39 & .23 & .22 & .17 & .11 & .02 & .17 & .04 \\
\hline SOP11 & & & & & & & .07 & .15 & .15 & .10 & .09 & .02 & -.04 & .11 & .07 \\
\hline SOP12 & & & & & & & -.03 & .21 & .23 & .26 & .14 & .21 & -.18 & .07 & .20 \\
\hline SOP13 & & & & & & & .34 & .11 & .08 & .04 & .20 & .02 & .24 & .09 & -.15 \\
\hline SOP14 & & & & & & & .22 & .01 & .03 & .03 & -.01 & .04 & .14 & .04 & .07 \\
\hline SOP15 & & & & & & & .07 & .07 & .08 & .08 & .04 & .05 & .09 & .14 & .05 \\
\hline SOP16 & & & & & & & .06 & .36 & .40 & .32 & .12 & .19 & -.04 & .18 & .17 \\
\hline SOP17 & & & & & & & .35 & .02 & .10 & .07 & .09 & .07 & .24 & .06 & -.10 \\
\hline SOP18 & & & & & & & .08 & .09 & .10 & .03 & .06 & .04 & .00 & .03 & .08 \\
\hline SOP19 & .24 & & & & & & -.02 & .18 & .23 & .22 & .15 & .21 & -.06 & .19 & .19 \\
\hline SOP20 & .10 & .57 & & & & & .16 & .13 & .23 & .14 & .05 & .10 & -.09 & .16 & .20 \\
\hline SOP21 & .09 & .37 & .31 & & & & .14 & .26 & .33 & .49 & .09 & .36 & -.27 & .18 & .31 \\
\hline SOP22 & .21 & .39 & .30 & .33 & & & .11 & $.26_{\mathrm{s}}$ & .30 & .25 & .15 & .14 & .03 & .30 & .17 \\
\hline SOP23 & .19 & .37 & .43 & .32 & .56 & & -.01 & .25 & .31 & .28 & .10 & .22 & -.11 & .24 & .27 \\
\hline SOP24 & .07 & .25 & .20 & .26 & .23 & .22 & .12 & .15 & .26 & .15 & .09 & .08 & .01 & .21 & .17 \\
\hline
\end{tabular}




\section{APPENDIX I (Continued)}

Scope of Practice (SOP) Tool Item Intercorrelational Matrix

\begin{tabular}{lllllllll}
\hline $\begin{array}{l}\text { SOP } \\
\text { Items }\end{array}$ & SOP34 & SOP35 & SOP36 & SOP37 & SOP38 & SOP39 & SOP40. SOP41 \\
\hline SOP1 & .08 & .17 & .14 & .13 & .03 & -.07 & -.07 & .02 \\
SOP2 & .08 & .22 & .15 & .14 & .17 & -.04 & -.02 & -.00 \\
SOP3 & .16 & .24 & .23 & .16 & .07 & -.03 & -.04 & .08 \\
SOP4 & .12 & .30 & .27 & .18 & .04 & .03 & -.06 & .01 \\
SOP5 & .17 & .25 & .18 & .02 & .02 & .04 & .09 & -.02 \\
SOP6 & .20 & .13 & .06 & -.09 & -.07 & -.03 & .08 & -.01 \\
SOP7 & .16 & .16 & .14 & .05 & .05 & -.03 & -.03 & .01 \\
SOP8 & .13 & .12 & .11 & .09 & .12 & .06 & .02 & .11 \\
SOP9 & .17 & .19 & .23 & .10 & .04 & .05 & .06 & .09 \\
SOP10 & .22 & .15 & .22 & .02 & .05 & .11 & .01 & .09 \\
SOP11 & .16 & .10 & .13 & -.03 & -.02 & .01 & .11 & .09 \\
SOP12 & .13 & .06 & .14 & -.02 & .16 & .03 & -.07 & .12 \\
SOP13 & .22 & .08 & .12 & -.02 & .08 & .17 & .15 & .12 \\
SOP14 & .09 & .07 & .10 & .02 & -.00 & .04 & .08 & .03 \\
SOP15 & .12 & .05 & .07 & .09 & .08 & .19 & .13 & .12 \\
SOP16 & .56 & .43 & .50 & .26 & .09 & .05 & .20 & .22 \\
SOP17 & .13 & .05 & .09 & .02 & .09 & .16 & .13 & .06 \\
SOP18 & .08 & .07 & .11 & -.10 & -.08 & .08 & .03 & .02 \\
SOP19 & .13 & .19 & .20 & .10 & .05 & .06 & -.08 & .03 \\
SOP20 & .03 & .11 & .11 & .01 & .02 & .02 & -.06 & -.10 \\
SOP21 & .07 & .18 & .18 & .11 & .12 & .02 & -.10 & .02 \\
SOP22 & .14 & .27 & .27 & .11 & .04 & .13 & .14 & .08 \\
SOP23 & .10 & .23 & .21 & .07 & -.04 & .00 & .02 & .00 \\
SOP24 & .17 & .15 & .18 & .19 & .31 & .17 & .18 & .23 \\
\hline
\end{tabular}




\section{Appendix I (Continued)}

Scope of Practice (SOP) Tool Item Intercorrelational Matrix

\begin{tabular}{|c|c|c|c|c|c|c|c|c|c|c|c|c|c|c|c|c|}
\hline $\begin{array}{l}\text { SOP } \\
\text { Items }\end{array}$ & $\begin{array}{l}\text { SOP } \\
25\end{array}$ & $\begin{array}{l}\text { SOP } \\
26\end{array}$ & $\begin{array}{l}\text { SOP } \\
27\end{array}$ & $\begin{array}{l}\text { SOP } \\
28 \\
\end{array}$ & $\begin{array}{l}\text { SOP } \\
29\end{array}$ & $\begin{array}{l}\text { SOP } \\
30\end{array}$ & $\begin{array}{l}\text { SOP } \\
31\end{array}$ & $\begin{array}{l}\text { SOP } \\
32\end{array}$ & $\begin{array}{l}\text { SOP } \\
33\end{array}$ & $\begin{array}{l}\text { SOP } \\
34\end{array}$ & $\begin{array}{l}\text { SOP } \\
35 \\
\end{array}$ & $\begin{array}{l}\text { SOP } \\
36\end{array}$ & $\begin{array}{l}\text { SOP } \\
\mathbf{3 7}\end{array}$ & $\begin{array}{l}\text { SOP } \\
\mathbf{3 8}\end{array}$ & $\begin{array}{l}\text { SOP } \\
39\end{array}$ & $\begin{array}{l}\text { SOP } \\
40 \\
\end{array}$ \\
\hline SOP26 & .16 & & & & & & & & & & & & & & & \\
\hline SOP27 & .11 & .61 & & & & & & & & & & & & & & \\
\hline SOP28 & .03 & .36 & .56 & & & & & & & & & & & & & \\
\hline SOP29 & .30 & .41 & .29 & .10 & & & & & & & & & & & & \\
\hline SOP30 & -.11 & .10 & .16 & .45 & .02 & & & & & & & & & & & \\
\hline SOP31 & .59 & .11 & .06 & -.13 & .26 & -.38 & & & & & & & & & & \\
\hline SOP32 & .10 & .24 & .22 & .05 & .21 & .01 & .16 & & & & & & & & & \\
\hline SOP33 & -.06 & .14 & .13 & .13 & .08 & .36 & -.18 & .26 & & & & & & & & \\
\hline SOP34 & .32 & .43 & .37 & .14 & .38 & -.11 & .28 & .20 & -.02 & & & & & & & \\
\hline SOP35 & .05 & .39 & .55 & .35 & .09 & .14 & .04 & .16 & .09 & .41 & & & & & & \\
\hline SOP36 & .13 & .46 & .59 & .36 & .19 & .09 & .12 & .13 & .02 & .50 & .85 & & & & & \\
\hline SOP37 & .05 & .11 & .19 & .11 & -.03 & .12 & -.02 & .09 & .00 & .24 & .39 & .34 & & & & \\
\hline SOP38 & .19 & .26 & .29 & .13 & .13 & -.01 & .17 & .15 & . 11 & .10 & -.01 & .06 & .01 & & & \\
\hline SOP39 & .34 & .25 & .15 & .01 & .23 & -.08 & .28 & .15 & .03 & .18 & .05 & .08 & -.02 & .38 & & \\
\hline SOP40 & .20 & .13 & .09 & -.08 & .02 & -.06 & .17 & .19 & .09 & .33 & .20 & .14 & .22 & .19 & .36 & \\
\hline SOP41 & .23 & .19 & .11 & .05 & .07 & -.04 & .15 & .10 & .09 & .25 & .05 & .06 & .15 & .41 & .42 & .60 \\
\hline
\end{tabular}


Appendix J

Collaborative Practice Scale Item Intercorrelational Matrix

\begin{tabular}{|c|c|c|c|c|c|c|c|c|c|c|c|c|c|c|c|c|c|c|}
\hline $\begin{array}{l}\text { CPS } \\
\text { Items }\end{array}$ & $\begin{array}{l}\text { CP } \\
\text { S1 }\end{array}$ & $\begin{array}{l}\text { CPS } \\
2\end{array}$ & $\begin{array}{l}\text { CPS } \\
3\end{array}$ & $\begin{array}{l}\text { CPS } \\
4\end{array}$ & $\begin{array}{l}\text { CPS } \\
5\end{array}$ & $\begin{array}{l}\text { CPS } \\
6 \\
\end{array}$ & $\begin{array}{l}\text { CPS } \\
7 \\
\end{array}$ & $\begin{array}{l}\text { CPS } \\
8 \\
\end{array}$ & $\begin{array}{l}\text { CPS } \\
9 \\
\end{array}$ & $\begin{array}{l}\text { CPS } \\
10 \\
\end{array}$ & $\begin{array}{l}\text { CPS } \\
11 \\
\end{array}$ & $\begin{array}{l}\text { CPS } \\
12 \\
\end{array}$ & $\begin{array}{l}\text { CPS } \\
13\end{array}$ & $\begin{array}{l}\text { CPS } \\
14\end{array}$ & $\begin{array}{l}\text { CP } \\
\text { S15 }\end{array}$ & $\begin{array}{l}\text { CP } \\
\text { S16 }\end{array}$ & CPS17 & $\begin{array}{l}\text { CPS } \\
\mathbf{1 8}\end{array}$ \\
\hline CPS2 & .48 & & & & & & & & & & & & & & & & & \\
\hline CPS3 & .10 & .28 & & & & & & & & & & & & & & & & \\
\hline CPS4 & .34 & .44 & .50 & & & & & & & & & & & & & & & \\
\hline CPS5 & .13 & .19 & .42 & .49 & & & & & & & & & & & & & & \\
\hline CPS6 & .31 & .31 & .31 & .35 & .33 & & & & & & & & & & & & & \\
\hline CPS7 & .06 & .08 & .45 & .30 & .55 & .29 & & & & & & & & & & & & \\
\hline CPS8 & .16 & .16 & .40 & .43 & .58 & .28 & .64 & & & & & & & . & & & & \\
\hline CPS9 & .19 & .29 & .27 & .33 & $.30^{\circ}$ & .64 & .32 & .28 & & & & & & & & & & \\
\hline CPS10 & .24 & .23 & .03 & .21 & .12 & .29 & .09 & .20 & .28 & & & & & & & & & \\
\hline CPS11 & .32 & .27 & .15 & .30 & .24 & .28 & .14 & .29 & .24 & .42 & & & & & & & & \\
\hline CPS12 & .24 & .27 & .23 & .31 & .24 & .53 & .19 & .17 & .54 & .27 & .34 & & & & & & & \\
\hline CPS13 & .09 & .09 & .11 & .13 & .26 & .10 & .16 & .25 & .01 & .30 & .32 & .06 & & & & & & \\
\hline CPS14 & .07 & .17 & .32 & .39 & .49 & .26 & .42 & .53 & .22 & .21 & .29 & .22 & .48 & & & & & \\
\hline CPS15 & .30 & .35 & .19 & .47 & .34 & .31 & .27 & .33 & .35 & .27 & .29 & .34 & .16 & .49 & & & & \\
\hline CPS16 & .08 & .07 & .10 & .16 & .30 & .19 & .19 & .31 & .12 & .22 & .20 & .06 & .53 & .46 & .23 & & & \\
\hline CPS17 & .42 & .36 & .22 & .49 & .23 & .40 & .18 & .29 & .28 & .32 & .31 & .37 & .17 & .37 & .63 & .27 & & \\
\hline CPS18 & .08 & .09 & .17 & .19 & .27 & .20 & .31 & .41 & .19 & .37 & .28 & .11 & .49 & .46 & .30 & .48 & .32 & \\
\hline CPS19 & .32 & .39 & .27 & .40 & .22 & .28 & .18 & .29 & .26 & .28 & .21 & .21 & .07 & .33 & .45 & .22 & .43 & .27 \\
\hline
\end{tabular}




\section{BIBLIOGRAPHY}

Alexander, D.E., Monk, J.S., \& Jones, P. (1985). Occupational stress, personal strain, and coping among residents and family members. Journal of Medical Education, $60_{2} 830-839$.

American Association of Nurse Anesthetists (1990). Human factors inventory survey, AANA Executive Summary, August, 1990,2-3. Park Ridge, IL: AANA

American Association of Nurse Anesthetists (1996). Nurse anesthetists and anesthesiologists practicing together. In: AANA professional practice manual for the certified registered nurse anesthetist, Position Statement No. 1.9. Park Ridge, IL: AANA

American Association of Nurse Anesthetists (1999). 1999 active reported membership. AANA News Bulletin, 53, (10), 6-7.

American Association of Nurse Anesthetists (2000). 2000 active reported membership. AANA News Bulletin, 54, (10), 9-10.

American Association of Nurse Anesthetists (2001). 2001 active reported membership in the six New England states. AANA Membership Department, Written Report.

American Nurses Association (1980). A social policy statement. Washington DC: ANA.

Babbie, E (1990). Survey research methods $\left(2^{\text {nd }}\right.$ ed.). Belmont, CA: Wadsworth Continuum Publishing.

Bacharach, S.B., Bainberger, P., \& Mitchell, S. (199.0). Work design, role conflict, and role ambiguity: the case of elementary and secondary schools. Educ. Evaluation Policy Anal., 12, 415-432.

Baggs, J. G. \& Ryan, S. A. (1990). ICU nurse-physician collaboration and nursing satisfaction. Nursing Economics, 8, 386-392.

Baggs, J.G. \& Schmidt, M.H. (1988). Collaboration between nurses and physicians. Image: Journal of Nursing Scholarship, 20, 145-149.

Bailey, J.T., Steffen, S.M., \& Grout, J.W. (1980). The stress audit: identifying the stressors of ICU nursing. Journal of Nursing Education, 6, 15-25.

Beehr, T.A., \& Drexler, J.A. (1986). Social support, autonomy, and hierarchial level as moderators of the role characteristics-outcome relationship. Journal of Occupational Behavior, 7, 207214. 
Burke, R.J., \& Richardsen, A.M. (1996). Stress burnout and health. In C.R. Cooper (Ed.). Handbook of stress medicine and health. New York: CRC Press.

Cavagnaro, M.A. (1983). A comparison of stress factors as they affect CRNAs. AANA Journal,3, 290-294.

Cherniss, C. (1980b). Staff burnout: job stress in the human services. Beverly Hills, CA: Sage.

Cohen, J. (1977). Statistical power analysis for the behavioral sciences. New York: Academic Press.

Creswell, J.W. (1994). Research design: Qualitative and quantitative approaches Thousand Oaks, CA: Sage.

Cromwell, J. (1996). Health professions substitution: A case study of anesthesia. In: The U.S. Health Workforce: Power, Politics, and Policy (p. 219-228). Washington, DC: Association of academic Health centers.

Devereux, P. M. (1981). Essential elements of nurse-physician collaboration. Journal of Nursing Administration, 1(5), 19-23.

Dick, K. (1998). An examination in how nurses' assess, recognize, and identify the care of acutely confused hospitalized elderly patients. A PhD Dissertation. University of Rhode Island, Kingston, RI.

Dillman, D.A. (1978). Mail and telephone surveys: The total design method. New York, NY: John Wiley.

Esposito, M.B. (1998). An exploration of the nature of nursing practice in patient-focused care. A PhD Dissertation. University of Rhode Island, Kingston, RI.

Eubanks, P. (1991). Quality improvement: key to changing nurse MD relations. Hospitals, 4 , 26-30.

Evans, S.A., \& Carlson, R. (1992). Nurse/physician collaboration: Solving the nursing shortage crisis. American Journal of Critical Care, 1,1, 25-32.

Fain, J. A. (1999). Reading, understanding, and applying nursing research. Philadelphia, PA: F.A. Davis. 
Farber, B.A. (1983). Introduction: a critical perspective on burnout. In B.A. Farber (Ed.), Stress and burnout in the human service professions. (pp. 1-22). New York: Pergamon.

Fassett, S. \& Calmes, S.H. (1995). Perceptions by an anesthesia care team on the need for medical direction. AANA Journal, 63,2, 117-123.

Fink, A. (1995). The survey handbook. Thousand Oaks, CA: Sage Publications.

Foster, S.D. (1999). The evolution of the role of the certified registered nurse anesthetist. In: W.R. Waugaman, S.D. Foster, \& B. M. Rigor (Eds.) ( $3^{\text {rd }}$ ed.). Principles and practice of nurse anesthesia (p. 17-25). Stamford, CT: Appleton \& Lange.

Freudenberger, H.J., \& Richelson, G. (1980). Burnout: the high cost of high achievement. New York: Anchor Press.

Friesen, D., \& Sarros, J. (1986). Sources of burnout among educators. Journal of Organizational Behavior, 10, 179-188.

Gallagher, A.M. (1983). Relationship of perceived occupational stress to reported physical symptoms. Unpublished master's thesis, University of Maryland, College Park

Grando, V.T. (1998). Articulating nursing for advanced practice nursing. In T.J. Sullivan (ed.) p. 499-514. Collaboration: a health care imperative. New York: McGraw-Hill.

Habermas, J. (1971). Knowledge and human interests. Boston, MA: Beacon.

Habermas, J. (1984). The theory of communicative action: Volume 1. Boston, MA: Beacon.

Hahn, R.H. (1995). Sickness and healing: an anthropological perspective. New Haven, CT: Yale University Press.

Harris, R.B. (1989). Reviewing nursing stress according to a proposed coping-adaptation framework. Advances in Nursing Science, 11, 12-28.

Jackson, S.E. (1983). Participation in decision making as a strategy for reducing job-related strain. Journal of applied Psychology, 68, 3-19.

Jackson, S.E., Schwab, R.L., \& Schuler, R.S. (1986). Toward an understanding of the burnout phenomenon. Journal of Applied Psychology, 71, 630-640.

Jennings, B. M. \& Staggers, N. (1998). The language of outcomes. Advances in Nursing Science, $20,72-80$. 
Johns, G. (1996). Organizational behavior: Understanding and managing life at work. ( $4^{\text {th }}$ ed.). New York, NY: Harper-Collins College Publishers.

Kelly, J. W. (1991). A study to develop a model of anesthesia care provided by a team of physicians and nurses. Ann Arbor, MI..U.M.I. Dissertation Services.

Kendrick, P. (2000). Comparing the effects of stress and relationship style on student and practicing nurse anesthetists. AANA Journal, 68,2, 115-122.

Kennedy, H. P. (1999). Linking nurse midwifery practice to outcomes. A PhD Dissertation. University of Rhode Island, Kingston, RI.

Kennedy, A.H. (1986). Environment for collaborative practice and professionalism. In D.A. England, (ed.) p. 29-53, Collaboration in nursing. Maryland: Aspens Systems Corp.

Kerlinger, F. N. (1986). Foundations of behavioral research. $\left(3^{\text {rd }}\right.$. ed). Forth Worth: Harcourt Brace College Publishers.

Kilman, R. and Thomas, K. (1977). Developing a force-choice measure of conflict handling behavior: The mode instrument. Educational Psychology Measures, 37, 309-325.

Kim, H. S. (1983). The nature of theoretical thinking in nursing. New York: Springer.

Kim, H.S. (1987). Structuring the nursing knowledge system: a typology of four domains. Scholarly Inquiry for Nursing Practice: An International Journal, 1, 99-110.

Kim, H.S. (1994). Practice theories in nursing and a science of nursing practice. Scholarly Inquiry for Nursing Practice, 8, 145-158.

Kim, H. S. (1998a). Conceptualizing outcomes of nursing practice: Problems and prospects. A paper presented as the $40^{\text {th }}$ Annual Clare Dennison Memorial Lecturer. University of Rochester School of Nursing. October 9, 1998. Rochester, NY.

Kim, H. S. (1998b). Critical reflective inquiry for knowledge development in nursing practice. Unpublished paper presented at University of Rhode Island College of Nursing November 12, 1998. Kingston, RI.

Kim, H.S. (2000). The nature of theoretical thinking in nursing $\left(2^{\text {nd }}\right.$ ed.) New York: Springer. 
Kim, H. S. \& Holter, I. M. (1995). Critical theory for science of nursing practice. In A.

Omery, C. E. Kasper, \& G. G. Page (eds.) p. 205-219. In search of nursing science. Thousand Oaks, CA: Sage Publications.

Klein, J. D. (1997). When will managed care come to anesthesia? Journal of Health Care Finance, 23(3), 62-86.

Kolb, D.M. \& Bartunek, J.M. (1992). Hidden conflict in organizations: Uncovering behindthe-scenes disputes. (Eds.). Newbury Park, CA: Sage.

Lachman, V.D. (1983). Stress management: A manual for nurses. New York: Grune \& Stratton.

Landsbergis, P. (1988). Occupational stress among health care workers: a test of the job demands control model. Journal of Applied Behavioral Science, 25, 131-144.

Leiter, M.P. (1988b). Commitment as a function of stress reactions among nurses: a model of psychological evaluations of work settings. Canadian Journal of Community Mental Health, 7, 115132.

Leiter, M.P. (1991a). Coping patterns as predictors of burnout: the function of control and escapist coping. Journal of Occupational Behavior, 12,123-144.

Leiter, M.P. (1991b). The dream denied: professional burnout and the constraints of human service organizations. Canadian Psychology, 32, 547-555.

Loeffler, A.S. (1993). Job satisfaction and turnover of nurse anesthetists. Ann Arbor, MI:.U.M.I. Dissertation Services.

Maslach, C., \& Jackson, S.E. (1986). Maslach Burnout Inventory. (2nd. Ed.). Palo alto, CA: Consulting Psychologists Press.

McLain, B. R. (1988). Collaborative practice: A critical theory perspective. Research in Nursing and Health, 11, 391-398.

McLean, A. (1974). Occupational stress. Springfield, IL: Charles C. Thomas.

Mechanic, H.F. (1988). Redefining the expanded role. Nursing Outlook, 36, 280-284.

Mitchell, J.T. (1984). Critical incident stress debriefing process. Ambulance World, Fall, 31 -

34. 
Mitchell, J.T., \& Bray, G. (1990). Emergency services stress. New Jersey: Brady Books.

National Joint Practice Commission (1977). Statement on joint practice in primary care:

Definitions and guidelines. Chicago: The Commission.

Newman, J.E., \& Beehr, T.A. (1979). Personal organization strategies for handling job stress: a review of research and opinion. Personnel Psychology, 32, 1-44.

Osipow, S.H. (1998). Occupational Stress Inventory-Revised Edition (OSI-R). Odessa, FL: Psychological Assessment Resources.

Osipow, S.H. \& Spokane, A.R. (1981). Manual for Measures of Occupational Stress, Strain, and Coping (Form E-1). Columbus, OH: Marathon Consulting \& Press.

Osipow, S.H. \& Spokane, A.R. (1983). Manual for Measures of Occupational Stress, Strain, and Coping (Form E-2). Columbus, OH: Marathon Consulting \& Press.

Osipow, S.H. \& Spokane, A.R. (1984). Measuring occupational stress, strain, and coping. In S. Oskamp (Ed.), Applied Social Psychology Annual Review,5, 67-87.

Osipow, S.H. \& Spokane, A.R. (1987). Manual for the Occupational Stress InventoryResearch Version. Odessa, FL: Psychological Assessment Resources.

Pines, A., Aronson, E., \& Kafry, D. (1981). Burnout: from tedium to personal growth. New York: The Free Press.

Posner, K.L. \& Freund, P.R. (1999). Trends in quality of anesthesia care associated with changing staffing patterns, productivity, and concurrency of case supervision in a teaching hospital. Anesthesiology, 91, 3, 839-847.

Prescott, P. A. \& Bowen, S. A. (1985). Physician-nurse relationships. Annuals of Internal Medicine, 103, 127-133.

Quick, J.C., Murphy, L.R., \& Hurrell, J.L., Jr. (1992). Stress and well-being at work: assessments and interventions for occupational mental health. Washington, DC: American Psychological Association.

Ray, E.B. \& Miller, K.I. (1994). Social support, home/work stress, and burnout: who can help? Journal of Applied Behavioral Science, 3, 357-373. 
Rosenbach, M.L. and Cromwell, J. (1988). A profile of anesthesia practice patterns. Health Affairs, 7, 4,118.

Ruble, T.L., \& Thomas, K.W. (1976). Support for a two-dimensional model of conflict behavior. Organizational Behavior and Human Performance, 16, 143-155.

Schirger, M. J. (1978). Introspection: a prerequisite for emancipation. Nursing Forum, 17,3, 317.

Shortridge, L.M., McLain, B.R., \& Gilliss, C.L. (1986). Graduate education for family primary care. In M.D. Mezey \& D.O. McGivern. (Eds.), Nurses, nurse practitioners. The evolution of primary care. (pp. 120-134). Boston, MA: Little, Brown.

Staum, B. \& Gould, H. (1980). A crisis in healthcare: the nurse shortage. Journal of Emergency Room Nursing,2,2, 82-95.

Sullivan, T. J. (1998). Collaboration: A health care imperative. New York, NY: McGrawHill.

TEFRA Medicare Regulations 405.552 (1982). Conditions for payment:

Anesthesiology services, 4, 7930. Chicago, IL: U.S. Commerce Clearinghouse.

Thompson, L.R. (1992). Relationship of job satisfaction to stress indicators and burnout among certified registered nurse anesthetists. Ann Arbor, MI..U.M.I. Dissertation Services.

Torgersen, K. A., \& Chamings, P.A. (1994). Examining collaborative relationships between anesthesiologists and certified registered nurse anesthetists in nurse anesthesia educational programs. AANA Journal, 62,2, 139-148.

Van Wagoner, S.L. (1985). Nonproductive behavior in occupational settings. Unpublished Master's thesis, University of Maryland, College Park.

Weiss, S.J. and Davis, H.P. (1985). Validity and reliability of the collaborative practice scales. Nursing Research, 34, 299-305. 